KEILA IAMAMOTO

Diagnóstico da raiva e das encefalites equinas do Leste e Oeste em equídeos pelo emprego da técnica de multiplex hemi-nested RT-PCR

São Paulo

2011 


\section{Diagnóstico da raiva e das encefalites equinas do Leste e Oeste em equídeos pelo emprego da técnica de multiplex hemi-nested RT-PCR}

Tese apresentada ao Programa de Pós-Graduação em Epidemiologia Experimental Aplicada às Zoonoses da Faculdade de Medicina Veterinária e Zootecnia da Universidade de São Paulo para obtenção do título de Doutor em Ciências

Departamento:

Medicina Veterinária Preventiva e Saúde Animal

Área de concentração:

Epidemiologia Experimental Aplicada às Zoonoses

Orientador:

Prof. Dr. Fumio Honma Ito

Co-orientador:

Prof ${ }^{a}$. Dr ${ }^{a}$. Juliana Galera Castilho

São Paulo 
Autorizo a reprodução parcial ou total desta obra, para fins acadêmicos, desde que citada a fonte.

DADOS INTERNACIONAIS DE CATALOGAÇÃO-NA-PUBLICAÇÃO

(Biblioteca Virginie Buff D’Ápice da Faculdade de Medicina Veterinária e Zootecnia da Universidade de São Paulo)

lamamoto, Keila

Diagnóstico da raiva e das encefalites equinas do Leste e Oeste em equídeos pelo emprego da técnica de multiplex hemi-nested RT-PCR / Keila lamamoto. -- 2011.

$107 \mathrm{f}$ : : il.

Tese (Doutorado) - Universidade de São Paulo. Faculdade de Medicina Veterinária e Zootecnia. Departamento de Medicina Veterinária Preventiva e Saúde Animal, São Paulo, 2011.

Programa de Pós-Graduação: Epidemiologia Experimental Aplicada às Zoonoses. Área de concentração: Epidemiologia Experimental Aplicada às Zoonoses.

Orientador: Prof. Dr. Fumio Honma Ito.

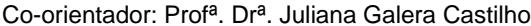

1. Multiplex hemi-nested RT-PCR (técnica). 2. Hemi-nested RT-PCR (técnica). 3. Raiva (diagnóstico). 4. Encefalite equina do Leste (diagnóstico). 5. Encefalite equina do Oeste (diagnóstico). I. Título. 


\section{CERTIFICADO}

Certificamos que o Projeto intitulado "Emprego da técnica de RT-PCR multiplex no diagnóstico das encefalites virais em eqüinos", protocolado sob o n¹271/2007, utilizando 2500 (dois mil e quinhentos) camundongos, sob a responsabilidade do Prof. Dr. Fumio Honma Ito, está de acordo com os princípios éticos de experimentação animal da Comissão de Bioética da Faculdade de Medicina Veterinária e Zootecnia da Universidade de São Paulo e foi aprovado na reunião do dia 23 de abril de 2008. Salientando que os animais serão sacrificados por dose excessiva de anestésico ou câmara $\mathrm{CO}_{2}$.

We certify that the Research "Use of RT-PCR multiplex technique for the diagnosis of viral encephalitis in equines", utilizing 2500 (two thousand, five hundred) mice, protocol number 1271/2007, under the responsibility Prof. Dr. Fumio Honma Ito, agree with Ethical Principles in Animal Research adopted by Bioethic Commission of the School of Veterinary Medicine and Animal Science of University of São Paulo was approved in the meeting of day 04/23/08.

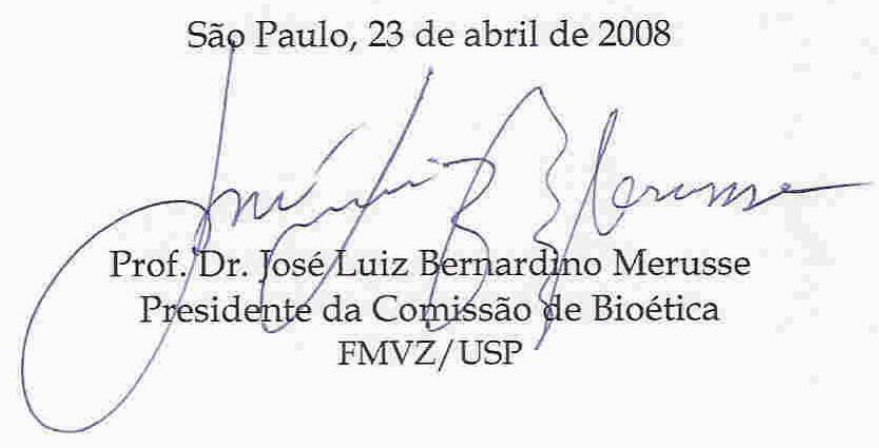




\section{FOLHA DE AVALIAÇÃO}

Nome: IAMAMOTO, Keila

Título: Diagnóstico da raiva e das encefalites equinas do Leste e Oeste em equídeos pelo emprego da técnica de multiplex hemi-nested RT-PCR

Tese apresentada ao Programa de Pós-Graduação em Epidemiologia Experimental Aplicada às Zoonoses da Faculdade de Medicina Veterinária e Zootecnia da Universidade de São Paulo para obtenção do título de Doutor em Ciências

Data:

\section{Banca Examinadora}

Prof. Dr.

Assinatura:

Instituição:

Julgamento:

Prof. Dr.

Instituição:

Assinatura:

Julgamento:

Prof. Dr.

Assinatura:

Instituição:

Julgamento:

Prof. Dr.

Instituição:

Assinatura:

Julgamento:

Prof. Dr.

Assinatura:

Instituição:

Julgamento: 
Ao meu marido, companheiro fiel e grande incentivador, Fábio Massaharu Nogi 
Ao meu estimado orientador, Fumio Honma Ito. 


\section{AGRADECIMENTOS}

Ao Prof. Dr. Fumio H. Ito, pela orientação, pelas longas conversas, pelos ensinamentos, por toda sua dedicação e contribuição à pesquisa sobre a raiva.

À Prof ${ }^{a}$. Dr ${ }^{a}$. Juliana G. Castilho, pesquisadora do Instituto Pasteur de São Paulo e co-orientadora nesse projeto, pela orientação, pelos ensinamentos, pela amizade e por estar sempre disposta a me ajudar.

Ao Instituto Pasteur, em nome da Sr ${ }^{a}$. Diretora, Dr ${ }^{\mathrm{a}}$. Neide Takaoka, por possibilitado a realização deste projeto.

À Dra ${ }^{a}$. Ivanete Kotait, supervisora do Laboratório de Diagnóstico de Raiva, pelo acolhimento e por todo suporte oferecido para a realização desse projeto.

À Drª . Maria Luiza Carrieri, chefe do Laboratório de Diagnóstico de Raiva, pelo apoio na execução do projeto.

Ao Dr. Pedro Fernando Vasconcelos, do Instituto Evandro Chagas, por sua solicitude e pelo fornecimento dos vírus padrão de encefalite equina do Leste e Oeste.

À minha amiga, Ekaterina D. Ono, pela amizade, pelos ensinamentos e pelo incentivo.

Ao pesquisador Dr. Pedro Carnieli Jr., pela amizade, pelos conselhos e ensinamentos.

Ao pesquisador Rafael de Novaes Oliveira, pela amizade e pelos ensinamentos.

À Adriana Rodrigues, pela amizade, pelo incentivo e por toda ajuda prestada.

Ao Willian, pela amizade, pelas risadas, pelos chás e lanchinhos e por toda ajuda. 
À Karin Corrêa Scheffer Ferreira, pela amizade e por compartilhar dos momentos difíceis.

Aos aprimorandos do programa FUNDAP, que me auxiliaram na colheita do material.

A todos os funcionários e amigos do Instituto Pasteur, pela amizade, pelo carinho e acolhimento, em especial Carla Isabel Macedo Levi da Silveira, Dra Zélia Pinheiro Peixoto, Graciane Maria Medeiros Caporale, Samira Maria Achkar, Andréa de Cássia Rodrigues da Silva, Luciana Botelho Chaves, Geralda Ribeiro Fraga Santos, Elpidio Ferreira, Rosangela Lopes, Silverlei Calvento da Silva, Maria Aparecida da Silva (Cida), Carmelinda A. Maia Andrade, Maria Souza Cavalcante (Fátima).

Aos colegas da pós-graduação, em especial à Karen Miyuki Asano e Enio Mori pelo auxílio, apoio e incentivo.

Aos meus colegas da SUVIS Itaim Paulista, em especial à Solange da Silva, Dr.Jair Hoshino e Dr. Luis José Altino, pela amizade, pelo apoio e incentivo.

À Maria Cícera de Oliveira Tavares, por sua fidelidade e por toda sua ajuda na manutenção de minha casa.

Aos meus irmãos, meus sogros, meus familiares e amigos, que sempre me acompanharam e me incentivaram.

Aos meus pais, Timóteo e Irene, pelo amor, pelo apoio e pelos inúmeros jantares.

Ao meu marido, Fábio Massaharu Nogi, pelo amor, carinho, incentivo e suporte. Obrigada pela paciência e pelo cuidado.

Ao CNPq, pela bolsa concedida (Processo №142816/2007-8). 
"Um mosaico consiste em milhares de pequenas pedras. Algumas são azuis, algumas verdes, algumas amarelas e outras douradas. Quando nos aproximamos do mosaico, podemos admirar a beleza de cada pedra. Mas, à medida que nos distanciamos, vemos que todas essas pequenas pedras nos revelam um belo quadro, narrando uma história que nenhuma delas sozinha pode contar.

Assim é a vida em comunidade. Cada um de nós é como uma pequena pedra, mas juntos revelamos a face de Deus ao mundo..."

Henri Nowen 


\section{RESUMO}

IAMAMOTO, K. Diagnóstico da raiva e das encefalites equinas do Leste e Oeste em equídeos pelo emprego da técnica de multiplex hemi-nested RT-PCR [Diagnosis of rabies and Eastern and Western Equine Viral Encephalitides in equids by multiplex hemi-nested RT-PCR technique]. 2011. $107 \mathrm{f}$. Tese de Doutorado em Ciências - Faculdade de Medicina Veterinária e Zootecnia, Universidade de São Paulo, São Paulo, 2011.

Várias zoonoses virais acometem equídeos causando quadros neurológicos, entre as quais a raiva e as encefalites equinas do Leste (EEE) e Oeste (WEE). O diagnóstico clínico geralmente não é conclusivo, o que torna imprescindível o diagnóstico laboratorial. Dados do Laboratório de Diagnóstico de Raiva do Instituto Pasteur de São Paulo, entre os anos 2000 e 2010, mostram que aproximadamente $75 \%$ das amostras enviadas foram negativas para raiva, ressaltando a relevância da realização de um diagnóstico diferencial para as encefalites equinas causadas por alfavírus. Os objetivos do estudo foram testar a adequação do uso de multiplex hemi-nested RT-PCR para o diagnóstico de raiva, EEE e WEE em amostras de sistema nervoso central de equídeos e realizar uma análise de custo das reações de cada técnica. Foram utilizados os primers 21G, 304 e 504 dirigidos ao gene $\mathrm{N}$ do vírus da raiva, e os primers cM3W, M2W, nEEE e nWEE dirigidos ao gene NSP1 dos vírus da EEE e WEE. Procedeu-se a um estudo preliminar dos primers e de seu uso em uma hemi-nested RT-PCR, avaliando a temperatura ótima de anelamento, a sensibilidade e especificidade analíticas e a reprodutibilidade da técnica em amostras de campo positivas para raiva e para EEE. A partir do protocolo estabelecido na reação de hemi-nested $\mathrm{RT}$-PCR, realizaram-se variações de concentração de reagentes no protocolo para a reação de multiplex hemi-nested RTPCR. Após o estabelecimento do protocolo para esta reação, os mesmos testes para verificação da sensibilidade e especificidade analíticas e da reprodutibilidade foram realizados, comparando-se os resultados com os obtidos pela hemi-nested RT-PCR. No teste de limiar de detecção, a sensibilidade analítica foi semelhante para as duas técnicas, obtendo-se $10^{-1,7}$ para os três vírus padrão CVS, EEEV e WEEV. No teste de limiar de detecção utilizando uma amostra com os três vírus verificou-se uma alta especificidade dos primers, sendo que na reação de multiplex 
hemi-nested RT-PCR foi possível detectar simultaneamente os três vírus padrão. Não houve diferença nas proporções de amostras detectadas como positivas para raiva obtidas pelas duas técnicas, analisando-se pelo teste exato de Fisher $(P=1,0000)$. No entando, para amostras de campo positivas para $E E E$, a proporção de amostras detectadas como positivas pela hemi-nested RT-PCR foi maior do que a proporção obtida pela multiplex hemi-nested RT-PCR $(P<0,0001)$. Apesar de não ter sido possível o uso de amostras de campo positivas para WEE nesse estudo, os resultados sugerem que seria possível a detecção pela multiplex hemi-nested RTPCR. Estes dados sugerem que a técnica de multiplex hemi-nested RT-PCR poderia ser aplicada para detecção de raiva e WEE, mas com limitações para a detecção de EEE. Pela análise de custo dos reagentes, o valor de uma reação de multiplex heminested RT-PCR é semelhante ao de uma hemi-nested RT-PCR, podendo representar uma economia de pelo menos $49,17 \%$.

Palavras-chave: Multiplex hemi-nested RT-PCR (técnica). Hemi-nested RT-PCR (técnica). Raiva (diagnóstico). Encefalite equina do Leste (diagnóstico). Encefalite equina do Oeste (diagnóstico). 


\begin{abstract}
IAMAMOTO, K. Diagnosis of rabies and Eastern and Western Equine Viral Encephalitides in equids by multiplex hemi-nested RT-PCR technique [Diagnóstico da raiva e das encefalites equinas do Leste e Oeste em equídeos pelo emprego da técnica de multiplex hemi-nested $R T-P C R]$. 2011. $107 \mathrm{f}$. Tese de Doutorado em Ciências - Faculdade de Medicina Veterinária e Zootecnia, Universidade de São Paulo, São Paulo, 2011.
\end{abstract}

Several viral zoonoses affect the equids causing neurological diseases, including rabies and Eastern and Western equine encephalitides (EEE and WEE). Clinical diagnosis is often not conclusive, in a way that laboratory diagnosis is essential. Data from the Laboratory of Rabies Diagnosis at the Pasteur Institute of São Paulo, between 2000 and 2010, demonstrate that approximately 75\% of submitted equid samples were negative for rabies, emphasizing the importance of achieving a differential diagnosis for equine encephalitis caused by alphaviruses. The aims of this study were to test the suitability of using multiplex hemi-nested RT-PCR for the diagnosis of rabies, EEE and WEE in equids central nervous system samples and to perform a cost analysis of the reactions of each technique. We used the primers $21 \mathrm{G}, 304$ and 504 directed to the $\mathrm{N}$ gene of rabies virus, and the primers cM3W, M2W, nEEE and nWEE directed the NSP1 gene of WEE and EEE viruses. A preliminary study of the primers was carried out, as well as their use in a hemi-nested RT-PCR, evaluating the optimal annealing temperature, the analytical sensitivity and specificity and the reproducibility of the technique in positive field samples for rabies and EEE. From the protocol established for the hemi-nested RT-PCR, variations in reagents concentrations for the multiplex hemi-nested RT-PCR protocol were perfomed. After establishing the protocol for this reaction, the same tests to verify the analytical sensitivity and specificity and reproducibility were performed and the results compared to those obtained by hemi-nested RT-PCR. In the detection threshold test, the analytical sensitivity was similar for both techniques, resulting in $10^{-1.7}$ for the three virus standard CVS, and EEEV WEEV. In the detection threshold test using a sample with the three viruses, a high specificity of the primers was verified and the multiplex hemi-nested RT-PCR was able to detect the three viruses simultaneously. There was no difference in the proportions of samples detected as 
positive for rabies obtained by both techniques, according to the Fisher exact test ( $P$ $=1.0000)$. However, for EEE positive field samples, the proportion of samples detected as positive by the hemi-nested RT-PCR was higher than the proportion obtained by multiplex hemi-nested RT-PCR $(P<0.0001)$. Although it was not possible to use WEE positive field samples in this study, the results suggest that its detection would be possible by multiplex hemi-nested RT-PCR. Thus, data suggest that the multiplex hemi-nested RT-PCR technique could be applied to detect rabies and WEE, but with limitations for the EEE detection. For the analysis of reagent costs, the cost of one multiplex hemi-nested RT-PCR is similar to one hemi-nested RT-PCR, and may represent a saving of $49,17 \%$ at least.

Key-words: Multiplex hemi-nested RT-PCR (tecnique). Hemi-nested RT-PCR (tecnique). Rabies (diagnosis). Eastern equine encephalitis (diagnosis). Western equine encephalitis (diagnosis). 


\section{LISTA DE QUADROS}

Quadro 1 - Índice de positividade para raiva das amostras de origem equina recebidas no Laboratório de Diagnóstico de Raiva do Instituto Pasteur de São Paulo - jan. - 2000 / dez. - 2010.

Quadro 2 - Amostras diagnosticadas como positivas para raiva pelas técnicas de imunofluorescência direta e isolamento viral em camundongos, no Laboratório de Diagnóstico de Raiva do Instituto Pasteur de São Paulo - jun. - 2008 / dez. - 2009

Quadro 3 - Amostras diagnosticadas como positivas para encefalite equina do Leste pelas técnicas de hemi-nested RT-PCR e isolamento viral em camundongos, no Laboratório de Diagnóstico de Raiva do Instituto Pasteur de São Paulo - jun. - 2008 / dez. - 2009.

Quadro 4 - Primers utilizados para a identificação do vírus da raiva direcionados à região do gene $\mathrm{N}$, segundo o sentido, a sequência, região de anelamento, temperatura de melting e porcentagem de ligações GC

Quadro 5 - Primers utilizados para a identificação do vírus da encefalite equina do Leste e Oeste direcionados à região do gene NSP1, segundo o sentido, a sequência, região de anelamento, temperatura de melting e porcentagem de ligações GC.

Quadro 6 - Combinação de primers senso e antissenso utilizados na técnica de hemi-nested RT-PCR de acordo com o vírus, tipo de reação e tamanho de fragmento esperado.

Quadro 7 - Protocolos testados pela técnica de multiplex RT-PCR, utilizando diferentes volumes de primers.

Quadro 8 - Protocolos testados pela técnica de multiplex hemi-nested RTPCR, utilizando diferentes combinações de reagentes

Quadro 9 - Intervalos de temperaturas utilizados para a escolha da temperatura ótima de anelamento segundo amostra de vírus padrão e reação (PCR e Hemi-nested). 


\section{LISTA DE FIGURAS}

Figura 1 - Eletroforese em gel de agarose a $2 \%$ corado com brometo de etídeo, referente ao teste de gradiente de temperatura em amostras de CVS, pela técnica de hemi-nested RT-PCR.

Figura 2 - Eletroforese em gel de agarose a $2 \%$ corado com brometo de etídeo, referente ao teste de gradiente de temperatura em amostras de EEEV, pela técnica de hemi-nested RT-PCR.

Figura 3 - Eletroforese em gel de agarose a $2 \%$ corado com brometo de etídeo, referente ao teste de gradiente de temperatura em amostras de WEEV, pela técnica de hemi-nested RT-PCR.

Figura 4 - Eletroforese em gel de agarose a $2 \%$ corado com brometo de etídeo, referente ao teste de limiar de detecção em amostras de CVS, pela técnica de hemi-nested RT-PCR.

Figura 5 - Eletroforese em gel de agarose a $2 \%$ corado com brometo de etídeo, referente ao teste de limiar de detecção em amostras de EEEV, pela técnica de hemi-nested RT-PCR.

Figura 6 - Eletroforese em gel de agarose a $2 \%$ corado com brometo de etídeo, referente ao teste de limiar de detecção em amostras de WEEV, pela técnica de hemi-nested RT-PCR

Figura 7 - Eletroforese em gel de agarose a $2 \%$ corado com brometo de etídeo, referente ao teste de limiar de detecção em amostras contendo os três RNAs virais, pela técnica de hemi-nested RTPCR, utilizando primers 504 e 304

Figura 8 - Eletroforese em gel de agarose a $2 \%$ corado com brometo de etídeo, referente ao teste de limiar de detecção em amostras contendo os três RNAs virais, pela técnica de hemi-nested RTPCR, utilizando primers $\mathrm{nEEE}$ e cM3W

Figura 9 - Eletroforese em gel de agarose a $2 \%$ corado com brometo de etídeo, referente ao teste de limiar de detecção em diluições contendo os três RNAs virais, pela técnica de hemi-nested RTPCR, utilizando primers nWEE e cM3W

Figura 10 - Eletroforese em gel de agarose a $2 \%$ corado com brometo de etídeo, referente à aplicação da ténica de RT-PCR em amostras de campo positivas para RABV (A) 
Figura 11 - Eletroforese em gel de agarose a $2 \%$ corado com brometo de etídeo, referente à aplicação da ténica de RT-PCR em amostras de campo positivas para RABV (B)

Figura 12 - Eletroforese em gel de agarose a $2 \%$ corado com brometo de etídeo, referente à aplicação da ténica de hemi-nested em amostras de campo positivas para RABV (A).

Figura 13 - Eletroforese em gel de agarose a $2 \%$ corado com brometo de etídeo, referente à aplicação da ténica de hemi-nested em amostras de campo positivas para RABV (B)

Figura 14 - Eletroforese em gel de agarose a $2 \%$ corado com brometo de etídeo, referente à aplicação da ténica de RT-PCR em amostras de campo positivas para EEEV

Figura 15 - Eletroforese em gel de agarose a $2 \%$ corado com brometo de etídeo, referente à aplicação da ténica de hemi-nested em amostras de campo positivas para EEEV $(A)$

Figura 16 - Eletroforese em gel de agarose a $2 \%$ corado com brometo de etídeo, referente à aplicação da ténica de hemi-nested em amostras de campo positivas para EEEV (B)

Figura 17 - Eletroforese em gel de agarose a $2 \%$ corado com brometo de etídeo, referente à aplicação da ténica de multiplex RT-PCR em amostras de campo e vírus padrão.

Figura 18 - Eletroforese em gel de agarose a $2 \%$ corado com brometo de etídeo, referente à aplicação da ténica de multiplex hemi-nested RT-PCR em amostras de campo e vírus padrão.

Figura 19 - Eletroforese em gel de agarose a 2\% corado com brometo de etídeo, referente ao teste de limiar de detecção para CVS, pela técnica de multiplex hemi-nested RT-PCR.

Figura 20 - Eletroforese em gel de agarose a 2\% corado com brometo de etídeo, referente ao teste de limiar de detecção para EEEV, pela técnica de multiplex hemi-nested RT-PCR

Figura 21 - Eletroforese em gel de agarose a $2 \%$ corado com brometo de etídeo, referente ao teste de limiar de detecção para WEEV, pela técnica de multiplex hemi-nested RT-PCR 
Figura 22 - Eletroforese em gel de agarose a 2\% corado com brometo de etídeo, referente ao teste de limiar de detecção em amostras contendo os três RNAs virais, pela técnica de multiplex heminested RT-PCR

Figura 23 - Eletroforese em gel de agarose a 2\% corado com brometo de etídeo, referente à aplicação da ténica de multiplex RT-PCR em amostras de campo positivas para raiva $(\mathrm{A})$

Figura 24 - Eletroforese em gel de agarose a 2\% corado com brometo de etídeo, referente à aplicação da ténica de multiplex RT-PCR em amostras de campo positivas para raiva (B)

Figura 25 - Eletroforese em gel de agarose a 2\% corado com brometo de etídeo, referente à aplicação da ténica de multiplex hemi-nested RT-PCR em amostras de campo positivas para raiva (A)

Figura 26 - Eletroforese em gel de agarose a 2\% corado com brometo de etídeo, referente à aplicação da ténica de multiplex hemi-nested em amostras de campo positivas para raiva (B)

Figura 27 - Eletroforese em gel de agarose a $2 \%$ corado com brometo de etídeo, referente à aplicação da ténica de multiplex RT-PCR em amostras de campo positivas para EEE

Figura 28 - Eletroforese em gel de agarose a 2\% corado com brometo de etídeo, referente à aplicação da ténica de multiplex hemi-nested RT-PCR em amostras de campo positivas para EEE. 


\section{LISTA DE ANEXOS E APÊNDICES}

ANEXO A - $\quad$ PROTOCOLO PARA EXTRAÇÃO DE RNA ….............................104

ANEXO B - $\quad$ CÓPIA DO ORÇAMENTO DAS ENZIMAS SUPERSCRIPT ${ }^{\circledR} \|$

E TAQ DNA POLIMERASE

APÊNDICE A - PRIMERS TESTADOS PREVIAMENTE

106

APÊNDICE B - CÁLCULO DO CUSTO DE UMA REAÇÃO DE HEMI-NESTED RT-PCR E DE UMA REAÇÃO DE MULTIPLEX HEMI-NESTED

RT-PCR 


\section{LISTA DE ABREVIATURAS, SIGLAS E SÍMBOLOS}

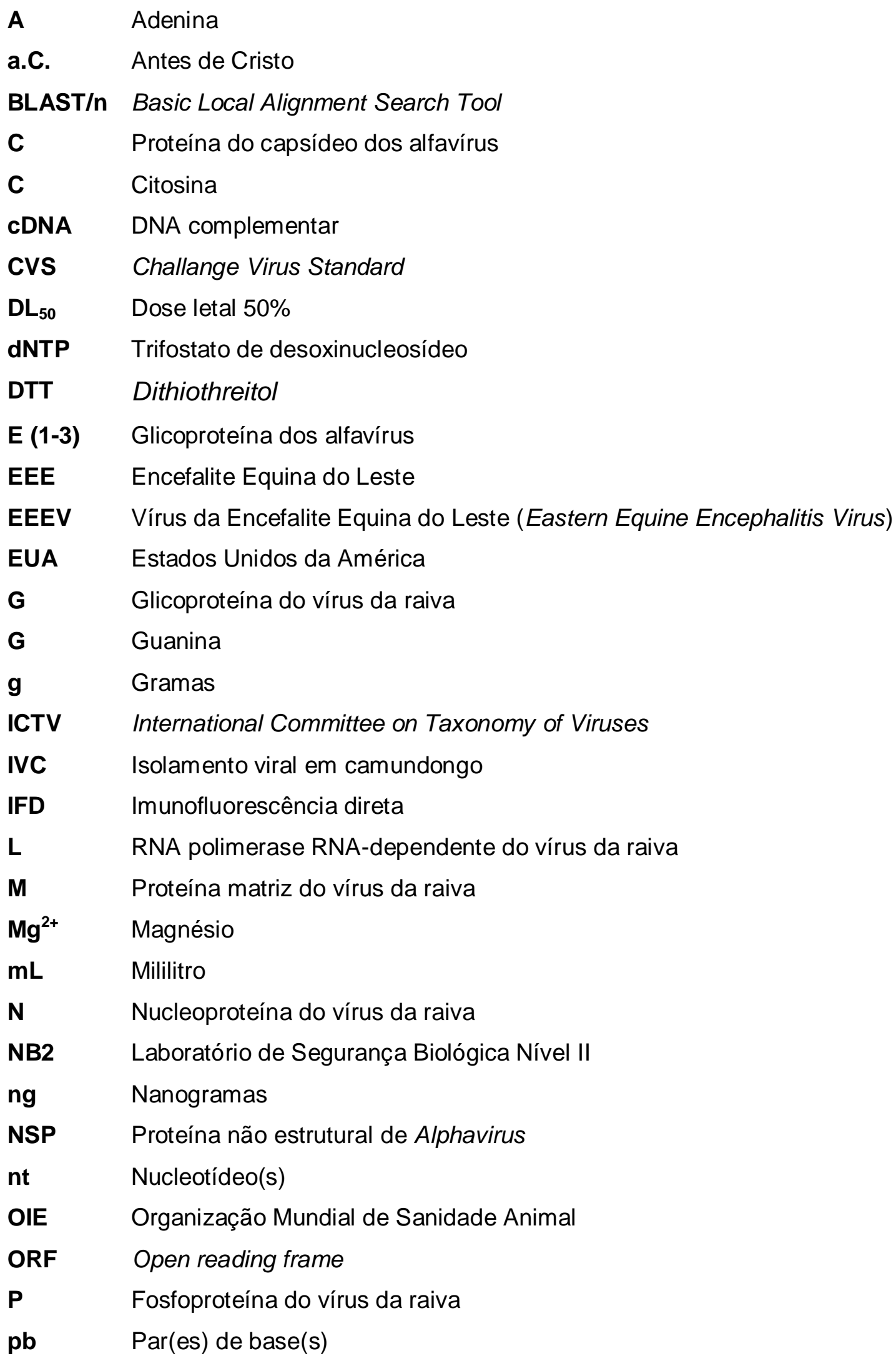




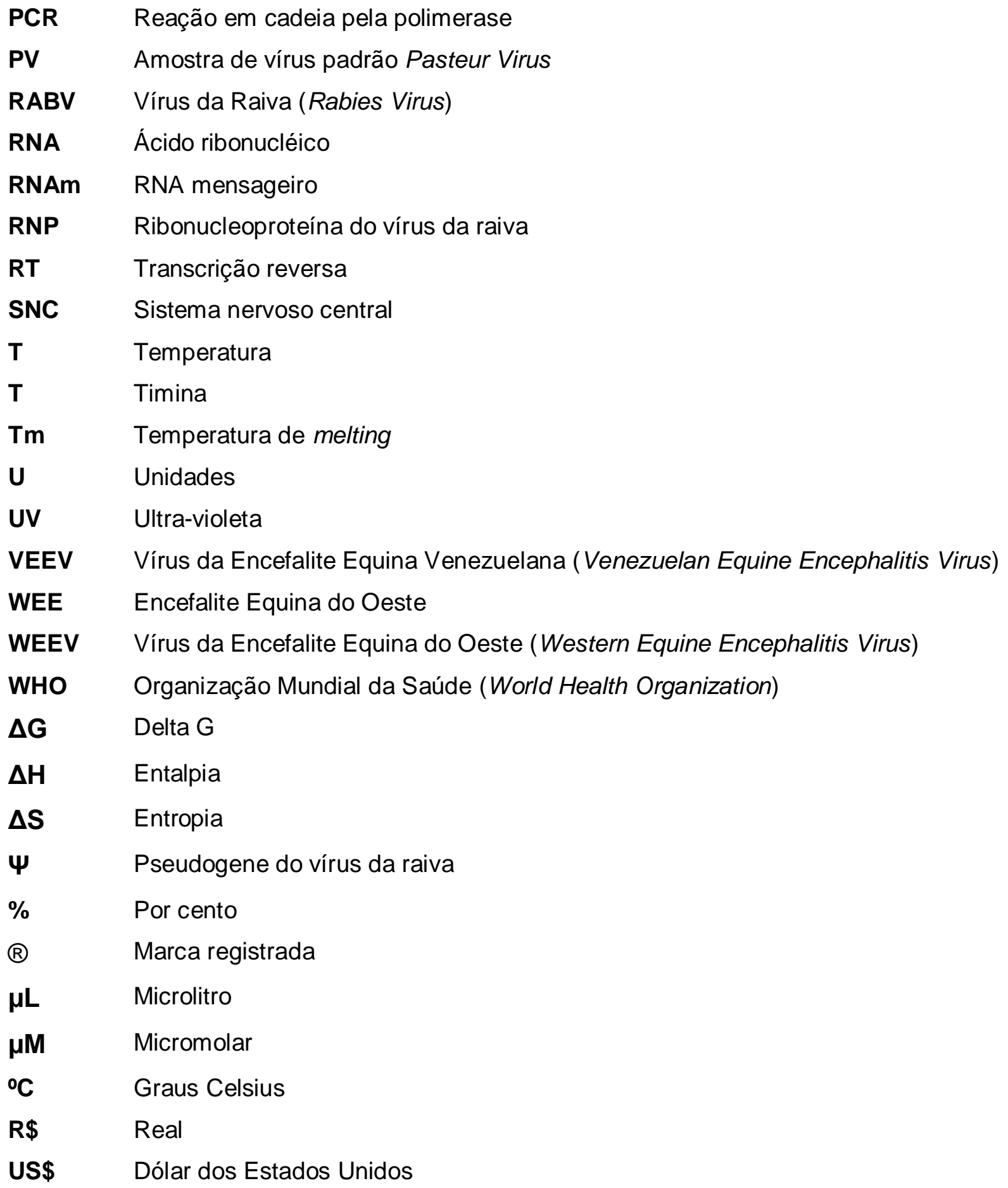




\section{SUMÁRIO}

INTRODUÇÃO

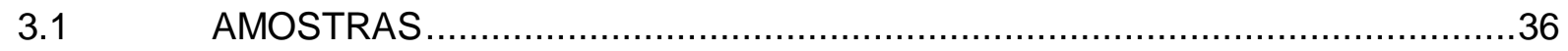

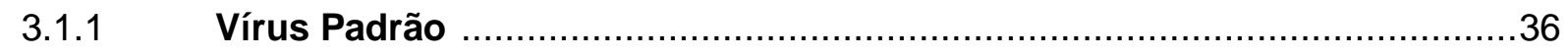

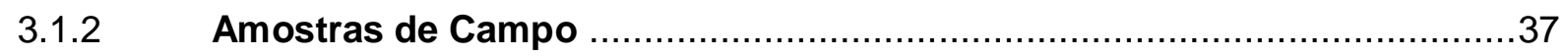

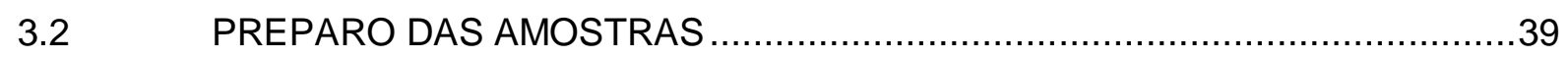

3.2.1 Produção de Lote de Trabalho de Vírus Padrão .......................................40

3.2.1.1 Titulação do Lote de Trabalho de Vírus Padrão .............................................40

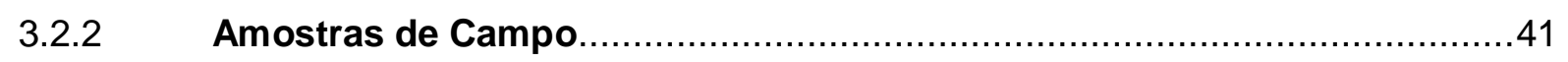

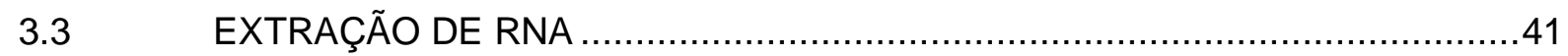

3.4 AVALIAÇÃO PRELIMINAR DOS PRIMERS E UTILIZAÇÃO EM REAÇÃO

DE HEMI-NESTED RT-PCR ........................................................... 42

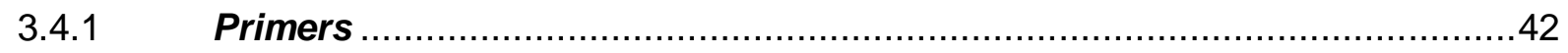

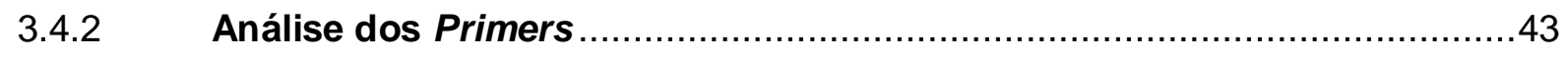

3.4.3 Temperatura Ótima de Anelamento dos Primers ...................................44

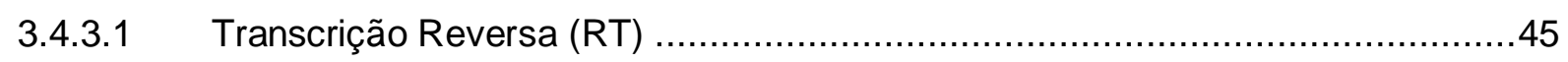

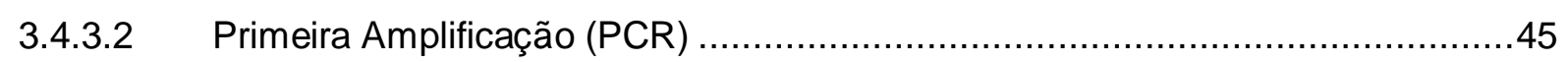

3.4.3.3 Segunda Amplificação (Hemi-nested) .................................................. 46

3.4.4 Determinação do Limiar de Detecção...................................................4 4

3.4.4.1 Amostras de Vírus Padrão......................................................................... 47

3.4.4.2 Amostra Contendo os Três Vírus Padrão .................................................. 48

3.4.5 Aplicação da Técnica de Hemi-Nested RT-PCR em Amostras de Campo...49

3.4.6 Sequenciamento Genético ............................................................ 49

3.5 REAÇÃO DE MULTIPLEX HEMI-NESTED RT-PCR .................................50

3.5.1 Testes com Diferentes Protocolos para a Técnica de Multiplex Hemi-

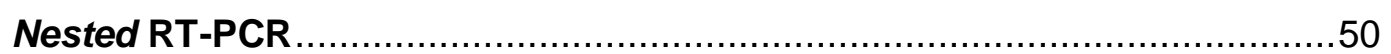

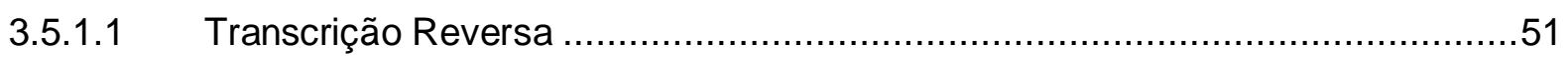

3.5.1.2 Primeira Amplificação ............................................................................ 51

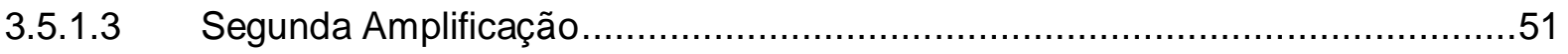

3.5.4 Determinação do Limiar de Detecção.................................................... 53

3.5.4.1 Amostras de Vírus Padrão............................................................... 53

3.5.4.2 Amostra Contendo os Três Vírus Padrão ...................................................53 
3.5.5 Aplicação da Técnica de Multiplex Hemi-Nested RT-PCR em Amostras

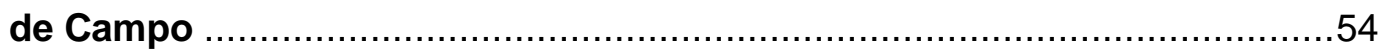

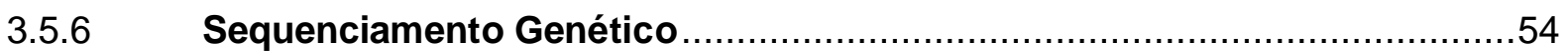

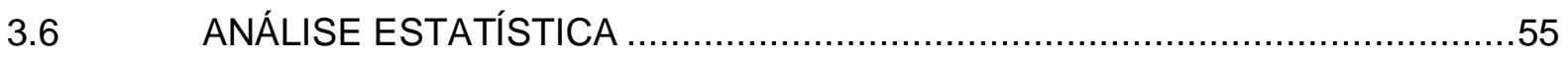

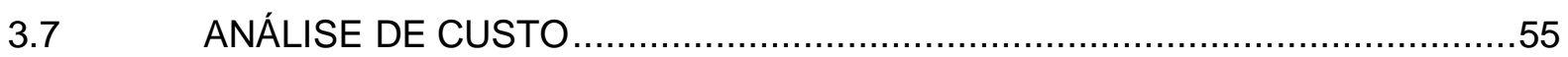

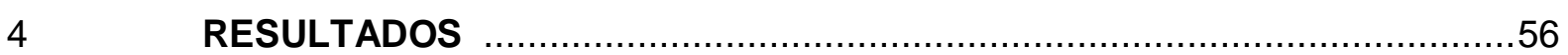

4.1 TITULAÇÃO VIRAL DO LOTE DE TRABALHO DE VÍRUS PADRÃO...............56

4.2 AVALIAÇÃO PRELIMINAR DOS PRIMERS E UTILIZAÇÃO EM REAÇÃO

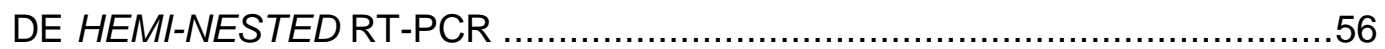

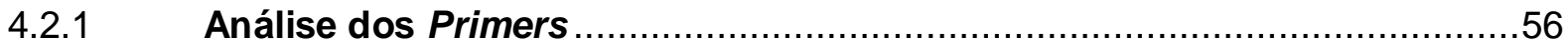

4.2.2 Temperatura Ótima de Anelamento dos Primers ....................................57

4.2.3 Determinação do Limiar de Detecção.....................................................60

4.2.3.1 Amostras de Vírus Padrão............................................................................60

4.2.3.2 Amostra Contendo os Três Vírus Padrão ….................................................62

4.2.4 Aplicação da Técnica de Hemi-Nested RT-PCR em Amostras de Campo...64

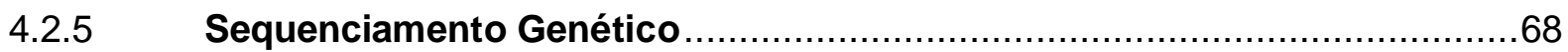

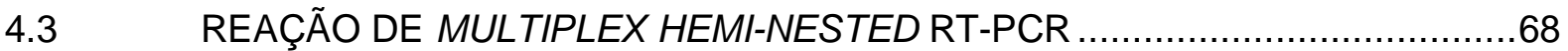

4.3.1 Testes com Diferentes Protocolos para a Técnica de Multiplex Hemi-

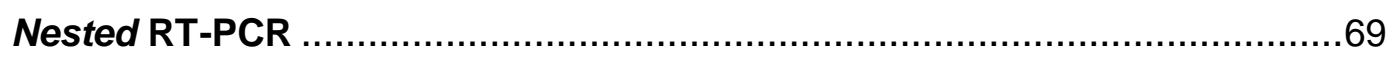

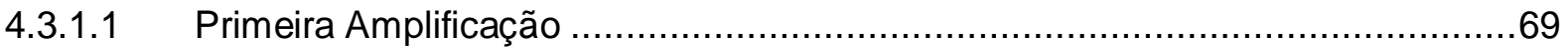

4.3.1.2 Segunda Amplificação ........................................................................ 70

4.3.2 Determinação do Limiar de Detecção .................................................. 72

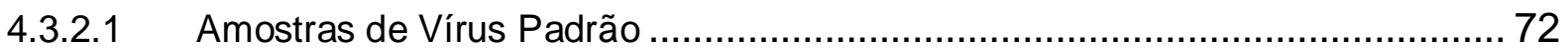

4.3.2.2 Amostra Contendo os Três Vírus Padrão ......................................................73

4.3.3 Aplicação da Técnica de Multiplex Hemi-Nested RT-PCR em Amostras

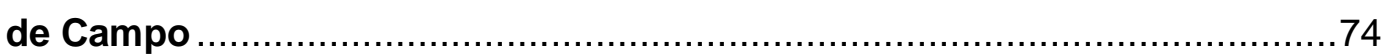

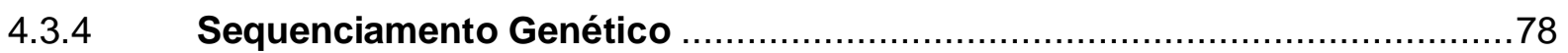

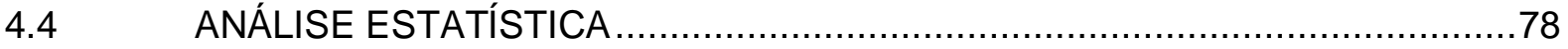

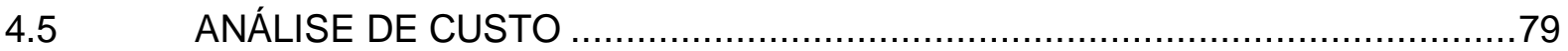

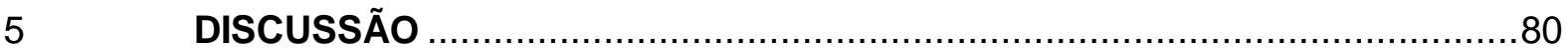

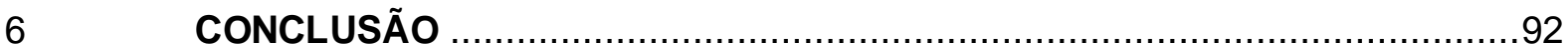

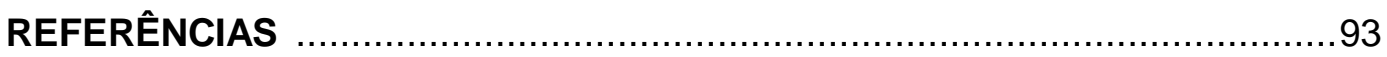

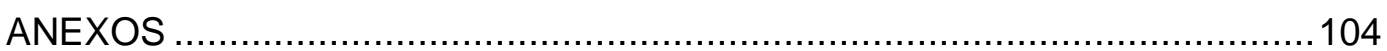

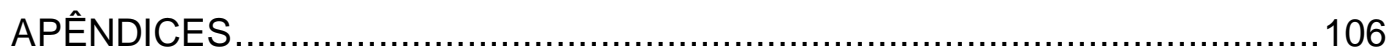




\section{INTRODUÇÃO}

Zooonoses são doenças ou infecções naturalmente transmissíveis de animais vertebrados aos humanos e vice-versa, que podem ser causadas por bactérias, parasitas, fungos, vírus e agentes não convencionais. Essas doenças apresentam uma variedade de mecanismos de transmissão e diferentes vias de infecção (WHO, 2006).

Existem zoonoses virais que ocorrem na espécie equina causando quadros neurológicos, dentre as quais estão a raiva, as encefalites equinas do Leste, Oeste e Venezuelana, a encefalite de Saint Louis, a febre do Nilo Ocidental, a doença de Borna e as encefalites causadas pelos vírus Hendra e Nipah (JORDAN; LIPKIN, 2001; ACHA; SZYFRES, 2003; WILD, 2009). Vale ressaltar que, por apresentarem grande suscetibilidade a diferentes agentes virais, os equinos podem ser utilizados como indicadores ou sentinelas da circulação de determinados vírus em uma região (KOTAIT; BRANDÃO; CARRIERI, 2006).

A raiva é uma das doenças infecciosas mais antigas que se tem conhecimento, sendo que os primeiros relatos são encontrados em documentos da Mesopotâmia, escritos por volta de 2.300 anos a.C. (WILKINSON, 2002). É uma zoonose que se caracteriza por uma encefalite viral aguda geralmente fatal tanto para animais quanto para os seres humanos (RUPPRECHT; HANLON; HEMACHUDHA, 2002; WUNNER, 2007). Apresenta distribuição mundial e poucos países, como o Japão, a Nova Zelândia e pequenas ilhas do Oceano Pacífico, são considerados livres da doença. Apesar do progresso no desenvolvimento de vacinas e no controle da enfermidade, a raiva continua sendo um grave problema de saúde pública e considerada uma das doenças tropicais negligenciadas (WHO, 2010). Estima-se que na Ásia e na África ocorram mais de 55.000 mortes de pessoas por ano (intervalo de confiança de 90\%, 24.500-90.800) causadas por raiva canina (WHO, 2005).

$\mathrm{O}$ vírus da raiva (RABV) é um agente neurotrópico, pertencente à ordem Mononegavirales, família Rhabdoviridae e ao gênero Lyssavirus. Este gênero possui mais dez espécies, além do RABV: Aravan virus, Australian bat lyssavirus, 
Duvenhage virus, European bat lyssavirus 1, European bat lyssavirus 2, Irkut virus, Khujand virus, Lagos bat virus, Mokola virus e West Caucasion bat virus (CARSTENS, 2010; ICTV, 2009). Em 2009, ocorreu o isolamento de vírus denominado de Shimoni virus, o qual foi sugerido como uma nova espécie do gênero Lyssavirus (KUZMIN et al., 2010).

Dentre todas as espécies do gênero Lyssavirus, o RABV, também denominado vírus da raiva clássico, é o mais prevalente e responsável pela maioria das infecções e mortes tanto em animais quanto em humanos (NADIN-DAVIS; FEHLNER-GARDINER, 2008). O RABV é a única espécie do gênero que ocorre nas Américas.

O RABV possui um formato semelhante à bala de revólver $(180 \mathrm{~nm}$ de comprimento por $75 \mathrm{~nm}$ de diâmetro), é envelopado e seu genoma é composto por um ácido ribonucléico (RNA) de fita simples, não segmentado e com polaridade de sentido negativo, o qual codifica cinco proteínas estruturais: a nucleoproteína $(\mathrm{N})$, a RNA polimerase RNA-dependente (L), fosfoproteína (P), que é um co-fator da polimerase, a proteína da matriz (M) e a glicoproteína (G) (FAUQUET et al., 2005a). O RNA encontra-se firmemente encapsidado com as proteínas $\mathrm{N}$, L e a $\mathrm{P}$, formando o complexo da ribonucleoproteína (RNP) ou nucleocapsídeo, que é um modelo funcional para a transcrição e replicação. Entre a RNP e o envelope viral que a envolve, encontra-se a proteína $\mathrm{M}$, que além de atuar como ponte entre as duas estruturas, interage com o RNA, condensando-o no típico formato helicoidal da RNP dos vírions. O envelope viral é formado por uma membrana de bicamada lipídica derivada da célula hospedeira juntamente com as espículas triméricas de G. A proteína $G$ possui um importante papel na adsorção do vírus à membrana celular, assim como na liberação do vírus (WUNNER, 2007; SHCNELL et al., 2010).

Dos 11.932 nucleotídeos (nt) do genoma do RABV (amostra Pasteur virus $\mathrm{PV}$ ), os primeiros $58 \mathrm{nt}$ do final 3' formam a sequência líder não codificante, que funciona como um promotor para o reconhecimento da fita molde pela RNA polimerase. Em seguida, encontram-se os cinco genes que codificam as proteínas estruturais do vírus: $\mathrm{N}$ (1350 nt), P (891 nt), M (606 nt), G (1.515 nt) e L (6426 nt). Os genes são separados por sequências intergênicas não-codificantes (do final 5' de um gene até o início $3^{\prime}$ do gene seguinte), um dinucleotídeo (N-P), dois 
pentanucleotídeos (P-M e M-G) e uma região mais longa (G-L) de 423 nt, também denominado de pseudogene ou $\Psi$. Ao final 5' do genoma, com $70 \mathrm{nt}$, encontra-se outra região não codificante "trailer" (WUNNER, 2007).

Uma vez que o genoma do RABV é um RNA de fita simples com polaridade sentido negativo, o RNA não é infeccioso e não pode ser traduzido diretamente em proteína. Para que ocorra a tradução, é necessária a transcrição do RNA genômico para produzir as moléculas de RNA mensageiro (RNAm), de sentido positivo, de cada gene viral (WUNNER, 2007). A transcrição inicia-se no final 3' do RNA genômico, resultando em um RNA líder "uncapped" e não poliadenilado. Em seguida, são sintetizados os RNAm de final 5' "capped" e poliadenilados, que codificam as proteínas virais (SHCNELL et al., 2010).

A transmissão do RABV ocorre principalmente pela mordida de um animal com raiva, cuja saliva contém o vírus (JACKSON, 2008). Os animais raivosos não transmitem o vírus somente entre os animais da mesma espécie, podendo infectar animais de espécies não similares, sendo este fenômeno denominado de "spill-over" (RUPPRECHT; HANLON; HEMACHUDHA, 2002).

Os mamíferos, em geral, são suscetíveis ao RABV e vários deles desempenham papel de hospedeiro, porém os principais reservatórios pertencem às ordens Carnivora e Chiroptera (RUPPRECHT; HANLON; HEMACHUDHA, 2002). Os morcegos hematófagos foram sugeridos como transmissores da doença pela primeira vez por Carini (1911), o qual os associou com casos de raiva paralítica de bovinos no Estado de Santa Catarina, Brasil. Depois de mais de uma década, nessa mesma região do Brasil, pesquisadores identificaram corpúsculos de Negri no cérebro de um morcego hematófago que se alimentava de bovinos, confirmando a hipótese de Carini (HAUPT; REHAAG, 1925). O morcego hematófago, Desmodus rotundus, ocorre somente na região compreendida entre o México e a Argentina, sendo este considerado a principal fonte de infecção da raiva em herbívoros. Em razão disso, a raiva no gado pode representar um grande impacto econômico e de saúde pública na América Latina (HANLON; NIEZGODA; RUPPRECHT, 2007).

A raiva em equinos tem um período de incubação variável e o início dos sintomas geralmente variam de acordo com o local da exposição. A sintomatologia nessa espécie apresenta uma fase de excitação, com duração e intensidade 
variáveis, seguida de uma fase paralítica, sendo incomum um estágio de raiva furiosa. Durante a fase de excitação, ficam inquietos, com olhar fixo, movem os ouvidos frequentemente, rangem os dentes, espumam pela boca, relincham como se estivesse com grande dor, tensão no intestino e mostram sinais de cólica severa. Podem apresentar ainda uma estimulação sexual exacerbada. Por outro lado, a fase paralítica é marcada por dificuldade de deglutição, quedas repetitivas do animal com incoordenação dos membros (BERAN, 1994; ACHA; SZYFRES, 2003).

Assim como a raiva, as encefalites equinas do Leste e do Oeste, são zoonoses causadas por vírus. Porém, essas doenças fazem parte de um grupo de arboviroses, que são doenças mantidas na natureza em ciclos que envolvem vetores hematófagos que transmitem os vírus aos hospedeiros vertebrados durante a alimentação. Geralmente estão relacionadas com surtos em humanos e com perdas em animais domésticos, representando um sério problema de saúde pública com impactos econômicos e sociais (CALISHER, 1994; BRONZONI et al., 2005). A emergência e reemergência das arboviroses é um fenômeno natural relacionado à adaptação e evolução da espécie. Mudanças ecológicas causadas pelo homem podem aumentar a prevalência do vetor, criar novos reservatórios e induzir a adaptação dos arbovírus em novos ciclos de manutenção. Além disso, como os vetores podem se deslocar por longas distâncias, existe um potencial para gerar o deslocamento de pandemias (FIGUEIREDO, 2007).

Os agentes etiológicos das encefalites equinas pertencem à família Togaviridae e ao gênero Alphavirus. Esse gênero possui 29 espécies, entre as quais encontram-se o Eastern Equine Encephalitis virus (EEEV), Western Equine Encephalitis virus (WEEV) e Venezuelan Equine Encephaltis virus (VEEV) (ICTV, 2010). Os alfavírus são vírus pequenos (70 nm de diâmetro), esféricos, possuem envelope lipídico derivado da célula hospedeira, e seu genoma é composto por um RNA de cadeia simples, não segmentado de sentido positivo (FAUQUET et al., 2005b).

Possuem cinco proteínas estruturais: a proteína do capsídeo NA, E3, E2, 6K e E1. As proteínas do capsídeo formam o nucleocapsídeo de simetria icosaédrica. As glicoproteínas, E3, E2 e E1, estão presentes no envelope, contudo a associação de heterodímeros das glicoproteínas E1 e E2, forma as espículas. As glicoproteínas 
apresentam importante papel na replicação (ligação aos receptores, penetração), nos fatores de virulência, além de possuírem atividade hemaglutinante e de serem alvos de anticorpos neutralizantes (FLORES, 2007; GRIFFIN, 2007). A proteína 6K serve como sinal peptídico para E1, é importante no brotamento do vírion, sendo que pequenas quantidades são incorporadas no mesmo (GRIFFIN, 2007). Além das proteínas estruturais, possuem quatro proteínas não estruturais: NSP1, NSP2, NSP3 e NSP4. A proteína NSP1 está envolvida no encapamento dos RNAs virais e no início da síntese da fita negativa do RNA. As proteínas NSP2 e NSP3 estão envolvidas na replicação do RNA e a NSP4, acredita-se ser a RNA polimerase viral (FAUQUET et al., 2005b).

O genoma dos alfavírus possui uma estrutura cap na extremidade 5' e uma extremidade 3' poliadenilada. Nas extremidades, existem pequenas sequências não traduzidas, cuja importância provavelmente está na transcrição e replicação do genoma. As ORFs (open reading frames) estão divididas em dois módulos: em genes que codificam as proteínas não estruturais, os quais se encontram nos dois terços da extremidade 5', e genes que codificam as estruturais, localizados próximos à extremidade 3 ' (FLORES, 2007).

Após fusão, penetração e desnudamento, ocorre a tradução direta de parte do RNA genômico pelos ribossomos. A ORF das proteínas não estruturais é traduzida em uma poliproteína, cuja clivagem ocorre à medida que vai sendo produzida, dando origem às proteínas NSP1, NSP2, NSP3 e NSP4. Juntamente com outras proteínas não estruturais, a NSP4 forma um complexo replicase, que sintetiza uma molécula de RNA antigenômico. Este funciona como molde para a síntese de cópias do RNA genômico, bem como para a transcrição de RNAm subgenômicos. Os RNAm são traduzidos em uma poliproteína, que é clivada, dando origem às proteínas estruturais C, E3, E2, 6K e E1 (FLORES, 2007).

As encefalites equinas do Leste, Oeste e Venezuelana ocorrem exclusivamente nas Américas, sendo que informações sobre o isolamento do vírus VEEV em alguns países europeus e asiáticos não foram comprovadas (ACHA; SZYFRES, 2003). Em 2009, no Reino Unido, houve o relato de um caso de encefalite equina do Leste em um paciente de 35 anos, porém o mesmo havia passado as férias em New Hampshire e Rhode Island, região Leste dos Estados 
Unidos da América (EUA), o que levou a considerá-lo como um caso importado (HARVALA et al., 2009).

A encefalite equina do Leste foi diagnosticada pela primeira vez em Massachussets, EUA, em 1831 (ACHA; SZYFRES, 2003). O vírus EEEV, no entanto, foi isolado pela primeira vez em 1933, quando causou a morte de 30 pessoas em um surto epidêmico no Nordeste dos EUA, onde também ocorriam casos em equinos (GRIFFIN, 2007). Desde então, a doença se estendeu geograficamente do sudeste do Canadá ao sudeste dos EUA, assim como para a região do Caribe e América do Sul (WEAVER et al., 1999).

No Brasil, existem registros de epizootias em equinos por EEEV (CAUSEY et al., 1962; NILSSON; SUGAY, 1962), sendo o Estado de São Paulo o que possui o maior número de isolamentos e identificação da EEEV em equinos (CARNEIRO, 1937; NILSSON; SUGAY, 1962; KOTAIT et al., 1992; BRANDÃO et al., 2005) e um amplo estudo sorológico em humanos no Vale do Ribeira (IVERSON; ROSA; ROSA, 1981; IVERSON et al. 1982; ROMANO-LIEBER; IVERSON, 2000). No período entre 1996 a 1999, ocorreram casos de equinos com suspeita de encefalomielite em quatro municípios do Estado do Paraná. Procedeu-se a um estudo sorológico e, de 22 amostras de equinos, foram encontrados anticorpos contra o EEEV em 12 foram (FERNÁNDEZ et al., 2000). Em um estudo realizado pelo Instituto Pasteur de São Paulo, entre 2006 e 2009, 18 amostras de equinos foram diagnosticadas positivas para a doença pela técnica de hemi-nested RT-PCR e pelo isolamento de duas amostras. As amostras eram provenientes dos Estados do Mato-Grosso, Pará, Pernambuco, Ceará e Paraíba (OLIVEIRA et al., 2009).

Além dos equinos, o EEEV tem sido isolado de aves silvestres, pequenos mamíferos e mosquitos (CALISHER,1994), sendo as aves consideradas reservatórios. Muitos mosquitos têm sido considerados vetores epizoóticos em potencial com base em seus hábitos alimentares, abundância durante epizootias e em estudos de transmissão em laboratório (WEAVER et al., 1999). No Brasil, o vírus se mantém em ciclos envolvendo aves silvestres e roedores como reservatórios e com o Culex pedroi e o Aedes taeniorhynchus como vetores enzoóticos e epizoóticos, respectivamente (VASCONCELOS et al., 1998). Embora haja uma evidência circunstancial de que a transmissão de equino para equino possa ocorrer, 
dados experimentais de transmissão sugerem que humanos e equinos sejam hospedeiros terminais, pois os títulos de vírus no sangue destes hospedeiros são insuficientes para infectar vetores epizoóticos (SCOTT; WEAVER, 1989).

Em humanos, o início dos sintomas da infecção sistêmica é abrupto, com calafrios e febre, seguido de mal-estar, artralgia e mialgia. A doença perdura por uma ou duas semanas, podendo levar à recuperação completa ou ao envolvimento do sistema nervoso central (SNC). Nos Estados Unidos, a encefalite equina do Leste é considerada a mais severa causada por arbovírus, estimando-se uma mortalidade em torno de 50 a $75 \%$ durante epidemias. A maioria daqueles que se recuperam, apresenta sequelas. O vírus é raramente isolado do sangue ou do líquido cérebroespinal, mas pode ser isolado postmortem do cérebro e de outros tecidos (CALISHER, 1994).

O vírus da encefalite equina do oeste (WEEV) foi isolado pela primeira vez durante um surto em San Joaquim Valley, Califórnia, em 1930 (MEYER et al., 1931). Em 1938, foi isolado do cérebro de uma criança que veio a óbito por encefalite na região oeste dos Estados Unidos (HOWITT, 1938). Nas décadas de 30 e 50, várias epizootias ocorreram nos Estados Unidos e no Canadá, afetando equinos e humanos. Milhares de equinos foram infectados, sendo a taxa de fatalidade maior que 50\% (WEAVER et al., 1999). Apesar dos sintomas serem semelhantes aos observados na encefalite equina do leste, a letalidade em humanos diminuiu para 34\% (WEAVER et al., 1999; ACHA; SZYFRES, 2003).

As aves domésticas e selvagens são consideradas os principais hospedeiros de manutenção e amplificação do WEEV. No Oeste da América do Norte, a WEE é transmitida enzooticamente entre pássaros por vetores, primariamente o Culex tarsalis. (WEAVER et al., 1999). Os humanos, os equídeos e mamíferos silvestres podem se infectar com o vírus, mas não contribuem significantemente para a amplificação viral (CALISHER, 1994).

O vírus WEE foi isolado desde a Argentina (CALISHER et al., 1985) ao oeste do Canadá (WATERS, 1976). Estudos sorológicos e isolamentos virais mostram a atividade do WEEV no Canadá, nos Estados Unidos, no México, assim como em Cuba (SCOTT; WEAVER,1989). Na América do Sul, há ocorrência na Guiana, no Equador, Brasil, Uruguai e Argentina (REISEN; MONATH, 1989), 
apresentando, porém, pequenas epizootias em equinos e ausência de casos em humanos, com exceção da Argentina (WEAVER et al., 1999). Em 2009, no Uruguai, foi reportado um caso fatal de WEE em um garoto de 14 anos, cujo diagnóstico foi realizado a partir de amostras do líquido cefaloraquidiano e plasma, pela técnica de RT-PCR e hemi-nested RT-PCR, seguido de sequenciamento genético (DELFRARO et al., 2011).

No Brasil, o vírus foi isolado em vetores na Floresta da Tijuca, Rio de Janeiro (BRUNO LOBO et al., 1961), e, além disso, anticorpos foram identificados em estudos sorológicos em humanos na região do Vale do Ribeira (IVERSSON; ROSA; ROSA, 1981; IVERSSON et al., 1982). Em um estudo realizado em Nhecolândia no Sul do Pantanal, Centro-Oeste do Brasil, 44 equinos não vacinados e com idade acima de sete meses, foram submetidos ao teste de soroneutralização para WEEV e EEEV, resultando na deteç̧ão de anticorpos neutralizantes para WEEV em 16 animais $(36,4 \%)$, enquanto que para EEEV, 21 animais $(47,7 \%)$ (PAUVOLID-CORRÊA et al., 2010).

Uma vez que o diagnóstico clínico em equinos com quadros neurológicos geralmente não é conclusivo, o diagnóstico laboratorial convencional e por biologia molecular se tornam imprescindíveis (KOTAIT; BRANDÃO; CARRIERI, 2006).

O diagnóstico laboratorial da raiva possui um importante papel no controle e na vigilância da doença, uma vez que o resultado influencia tanto na decisão de se proceder ou não a um tratamento, assim como na decisão de se instituir medidas para o controle de uma epizootia em uma comunidade (MESLIN; KAPLAN, 1996).

A pesquisa microscópica dos corpúsculos de Negri ${ }^{1}$ (1903 apud BERAN, 1994, p.329) por exame histopatológico, achado patognomônico para raiva, é um procedimento simples, rápido e econômico, porém é um método menos sensível, podendo detectar de 75 a $90 \%$ dos casos. Esse exame, quando utilizado isoladamente, pode produzir resultados falsos-negativos, pois nem todos os casos apresentam desenvolvimento de inclusões, ou resultados falsos-positivos devido a corpúsculos de inclusões não específicos (NIETFELD et al., 1989). No entanto, as

\footnotetext{
${ }^{1}$ NEGRI, A. Beitrag zum stadium der aetiolodie der toolwuth. Zentralbl. Hyg. Infekt., v. 43, p.507, 1903.
} 
técnicas histopatológicas têm sido substituídas pela técnica de imunofluorescência direta (IFD) pela maioria dos laboratórios (MESLIN; KAPLAN, 1996).

A técnica de IFD, desenvolvida por Goldwasser e Kissling (1958), posteriormente modificada por Dean, Albelseth e Atanasiu (1996) é considerada como gold-standard na atualidade (WHO, 2005), sendo amplamente utilizada no mundo para a deteç̧ão do antígeno do vírus da raiva. Recomenda-se, ainda, a realização em paralelo do isolamento viral, que pode ser realizado pela técnica de inoculação em camundongos originalmente descrita por Webster e Dawson (1935), ou pela técnica de isolamento em cultivo celular descrita por Webster e Casey (1996), ambos preconizados pelos especialistas da World Health Organization (WHO, 2005). Um dos pontos negativos em relação ao isolamento viral é a questão do tempo para se obter o resultado, pois no isolamento realizado em camundongos, os animais são observados durante 30 dias, sendo que geralmente manifestam a doença entre 10 a 20 dias (KOPROWISK, 1996). O isolamento em cultura celular é mais rápido quando comparado ao isolamento em camundongos, podendo se obter o resultado após 96 horas (CASTILHO et al., 2007).

O diagnóstico laboratorial da raiva em equinos, porém, apresenta uma certa peculiaridade em relação a outras espécies. Em um estudo realizado por Peixoto et al. (2000), corpúsculos de Negri foram observados em amostras de equinos, porém o teste apresentou uma sensibilidade muito baixa (36,9\%) em relação à apresentada em literatura (75 a 90\%). Nesse mesmo estudo, observou-se que a sensibilidade diagnóstica da IFD é menor em amostras de equinos (76,6\%) do que em amostras de bovinos $(94,1 \%)$. Devido a essa maior possibilidade de ocorrer um diagnóstico falso negativo em amostras de equinos, técnicas de biologia molecular constituem uma importante ferramenta auxiliar no diagnóstico da raiva nessa espécie.

As técnicas moleculares de transcrição reversa e reação em cadeia pela polimerase (RT-PCR) apresentam alto nível de sensiblidade, porém necessitam de uma adequação e um minucioso controle de qualidade. Como essa técnica pode produzir resultados falso positivos ou falso negativos, a World Health Organization tem sugerido que ela seja usada em combinação com outras técnicas convencionais para o diagnóstico de raiva (WHO, 2005). 
O diagnóstico laboratorial de EEE e WEE pode ser feito por provas sorológicas, isolamento e identificação viral (ACHA; SZYFRES, 2003). As principais técnicas sorológicas aplicadas são o ELISA, inibição da hemaglutinação, fixação de complemento, soroneutralização. A maioria dos equinos infectados com EEEV e WEEV apresenta altos títulos quando a doença clínica é observada. Porém, pode haver reação cruzada entre anticorpos contra EEEV e WEEV em testes de fixação de complemento e inibição de hemaglutinação (OIE, 2004).

O isolamento viral é o método mais definitivo, podendo ser realizado tanto em camundongos quanto em cultivo celular. No entanto, o isolamento costuma ser muito raro na maioria dos casos, principalmente devido à baixa resistência dos vírus às alterações de temperatura e pH (KOTAIT; BRANDÃO; CARRIERI, 2006). O EEEV pode ser isolado de SNC de equinos que tenham pelo menos cinco dias entre o início dos sinais clínicos e a morte do animal. O WEEV é raramente isolado de tecido, porém o cérebro é o tecido de eleição para o isolamento. Recomenda-se que o material seja refrigerado e enviado em 48 horas após a colheita, caso contrário, o material deve ser congelado (OIE, 2004).

A dificuldade de isolamento e a demora para a obtenção de um resultado são algumas das razões para o desenvolvimento de técnicas moleculares para detecção de RNA viral como diagnóstico para as encefalites equinas causadas por alfavírus. Vodkin et al. (1993) utilizaram a técnica de RT-PCR para detecção de RNA do EEEV em pool de mosquitos e tecidos de aves. Pfeffer et al. (1997) utilizaram a técnica de hemi-nested RT-PCR utilizando primers gênero-específicos, conseguindo a amplificação da região do gene NSP1 de do gênero de várias espécies de alfavírus. Outro estudo, também com o objetivo de detectar alfavírus, utilizou o nested RT-PCR para a amplificação da região do gene NSP4 (SÁNCHEZ-SECO et al., 2001). Bronzoni et al. (2004) sugeriram o uso da técnica de multiplex nested PCR para o diagnóstico de alfavírus brasileiros utilizando primers gênero-específicos na primeira amplificação e primers espécie-específicos na segunda amplificação. Posteriormente, outro trabalho foi realizado, utilizando um multiplex para a identificação de alfavírus e flavivírus brasileiros (BRONZONI et al., 2005).

A técnica de multiplex PCR, descrita pela primeira vez em 1988 (CHAMBERLAIN et al., 1988), é uma variação da técnica da PCR na qual se utiliza 
mais de um par de primers em uma mesma reação, o que viabiliza a amplificação de dois ou mais loci. Desta forma, economiza-se em tempo e em custo com reagentes (SAMBROOK; RUSSEL, 2001). A aplicação dessa técnica é possível em várias áreas da ciência, sendo que na virologia tem sido muito empregada como uma ferramenta de diagnóstico. Existem muitos estudos relacionados ao diagnóstico de meningites e encefalites em humanos, uma vez que estas patologias requerem um diagnóstico rápido para o estabelecimento do protocolo de tratamento e a limitação de procedimentos desnecessários (ELNIFRO, 2000). Sendo assim, existem muitos estudos para a detecção de herpesvírus simplex tipo 1 e 2, vírus varicella-zoster, vírus Epstein-Barr, herpesvírus humano tipo 6, citomegalovírus, entre outros (TENORIO et al., 1993; READ; JEFFERY; BANGHAM, 1997; COYLE et al., 1999; READ; KURTZ; 1999; MARKOULATOS et al., 2000; BERGALLO et al., 2007).

Existem poucos trabalhos utilizando a técnica de multiplex RT-PCR para a detecção do vírus da raiva, sendo que os estudos existentes sugerem o uso da técnica para identificação genética de variantes do RABV (NADIN-DAVIS; HUANG; WANDELER, 1996; SATO et al., 2005).

O Laboratório de Diagnóstico de Raiva do Instituto Pasteur de São Paulo, recebe rotineiramente amostras de SNC de equinos que são enviadas para o diagnóstico de raiva. Entre os anos 2000 a $2010^{2}$ (Quadro 1), o índice de positividade para raiva em amostras de equinos variou entre 9,4\% (2005) a 32,7\% (2008). Nesse período de 11 anos, foram recebidas 2122 amostras e dessas, 522 foram positivas para raiva, resultando em uma média de positividade de $24,6 \%$ (Instituto Pasteur, dados não publicados). Observando-se estes dados, verifica-se que das amostras enviadas, existe uma porcentagem média de $75 \%$ de amostras negativas para a raiva. Assim sendo, a realização de um diagnóstico diferencial para as encefalites equinas causadas por alfavírus se faz importante, uma vez que viabiliza uma vigilância passiva para a EEE e a WEE, utilizando a rotina e a estrutura já existente no laboratório de diagnóstico para raiva. Além disso, técnicas de biologia molecular podem ser aplicadas em amostras de equinos com resultado dúbio para raiva nas técnicas convencionais, como um teste confirmatório no diagnóstico da raiva, assim como para o diagnóstico de EEE e WEE. Portanto, o desenvolvimento

\footnotetext{
${ }^{2}$ Dados do Instituto Pasteur de São Paulo, de janeiro de 2000 a dezembro de 2010.
} 
da técnica de multiplex hemi-nested RT-PCR para o diagnóstico de raiva, EEE e WEE é de grande importância uma vez que pode fornecer rapidez na obtenção do resultado, além de economia no custo do diagnóstico.

\begin{tabular}{|c|c|c|c|}
\hline ANO & $\begin{array}{c}\text { Total de } \\
\text { Amostras }\end{array}$ & $\begin{array}{c}\text { Amostras } \\
\text { Positivas }\end{array}$ & $\begin{array}{c}\text { Índice de } \\
\text { positividade }\end{array}$ \\
\hline $\mathbf{2 0 0 0}$ & 644 & 187 & $29,0 \%$ \\
\hline $\mathbf{2 0 0 1}$ & 544 & 162 & $29,8 \%$ \\
\hline $\mathbf{2 0 0 2}$ & 306 & 69 & $22,5 \%$ \\
\hline $\mathbf{2 0 0 3}$ & 168 & 32 & $19,0 \%$ \\
\hline $\mathbf{2 0 0 4}$ & 116 & 17 & $14,6 \%$ \\
\hline $\mathbf{2 0 0 5}$ & 74 & 07 & $9,4 \%$ \\
\hline $\mathbf{2 0 0 6}$ & 72 & 08 & $11,1 \%$ \\
\hline $\mathbf{2 0 0 7}$ & 64 & 12 & $18,7 \%$ \\
\hline $\mathbf{2 0 0 8}$ & 61 & 20 & $32,7 \%$ \\
\hline $\mathbf{2 0 0 9}$ & 41 & 04 & $9,7 \%$ \\
\hline $\mathbf{2 0 1 0}$ & 32 & 04 & $12,5 \%$ \\
\hline
\end{tabular}

Fonte: Instituto Pasteur, São Paulo

Quadro 1 - Índice de positividade para raiva das amostras de origem equina recebidas no Laboratório de Diagnóstico de Raiva do Instituto Pasteur de São Paulo - jan.2000 / dez. - 2010 


\section{OBJETIVOS}

Os objetivos deste estudo foram:

- Testar a adequação do uso da técnica de multiplex hemi-nested RT-PCR para o diagnóstico de raiva e de encefalites do Leste e Oeste em amostras de SNC de equídeos, procedendo a uma análise comparativa com a técnica de heminested RT-PCR.

- Realizar uma análise de custo das reações de hemi-nested RT-PCR e multiplex hemi-nested RT-PCR, com base nos reagentes utilizados em cada reação. 


\section{MATERIAL E MÉTODOS}

O material e a metodologia utilizados neste trabalho serão descritos nos itens a seguir.

Todos os procedimentos foram realizados nos laboratórios do Instituto Pasteur de São Paulo, seguindo-se as normas de biossegurança. A preparação de amostras e a extração de RNA foram realizadas em Laboratório de Segurança Biológica Nível II (NB2), enquanto que os procedimentos de síntese de cDNA, amplificações e sequenciamento genético foram realizados no Laboratório de Biologia Molecular.

\subsection{AMOSTRAS}

Para a realização deste estudo foram utilizadas amostras de vírus padrão e amostras de campo descritas a seguir.

\subsubsection{Vírus Padrão}

Como amostra padrão da raiva, utilizou-se o vírus fixo Challanger Virus Standard (CVS), cuja identificação é CVS 31/3\#2, lote BR010, proveniente do Instituto Nacional de Controle de Qualidade em Saúde (INCQS), Fiocruz.

As amostras de vírus padrão das encefalites equinas do Leste e Oeste foram fornecidas pelo Instituto Evandro Chagas, onde são mantidas em camundongos, liofilizadas e preservadas à temperatura de $-70^{\circ} \mathrm{C}$. Como vírus padrão do EEEV, utilizou-se a amostra BE AN 7526, isolado de sangue de macaco sentinela Cebus apella em 1957. Já como vírus padrão de WEEV, utilizou-se a amostra BE AN 70100, isolado do sangue de ave Myrmotherula hauxwelli em 1964. 
No laboratório do Instituto Pasteur, os vírus padrão são mantidos em camundongos albinos (Mus musculus) inoculados por via intracerebral, e o título das amostras originais de vírus padrão utilizadas nesse trabalho foram:

- CVS: $10^{6,0} \mathrm{DL}_{50} / 0,03 \mathrm{~mL}$

- BE AN 7526 (EEEV): $10^{6,26} \mathrm{DL}_{50} / 0,03 \mathrm{~mL}$

- BE AN 70100 (WEEV): $10^{5,5} \mathrm{DL}_{50} / 0,03 \mathrm{~mL}$

\subsubsection{Amostras de Campo}

Para este estudo, foram selecionadas 33 amostras de campo diagnosticadas como positivas para raiva ou para EEE, no período entre junho de 2008 a dezembro de 2009. Das 33 amostras de SNC de equídeos, 18 foram positivas para raiva (Quadro 2) e 15, para EEE (Quadro 3). Todas as amostras eram de equinos, com exceção da 5032/08, que era de um muar.

O diagnóstico da raiva foi previamente realizado pela técnica considerada padrão-ouro, a IFD, paralelamente com o teste de isolamento viral em camundongos (IVC), conforme recomendações da WHO (2005). Já para o diagnóstico das encefalites causadas por Alphavirus, foram utilizadas as técnicas de IVC recémnascidos da espécie Mus musculus, e de hemi-nested RT-PCR.

Os primers utilizados na técnica do hemi-nested RT-PCR para detecção de Alphavirus, foram primers gênero-específicos, descritos por Pfeffer et al. (1997). Desta forma, a identificação da espécie foi possível pelo sequenciamento genético, sendo que todas foram identificadas como EEEV. Vale ressaltar que todas foram submetidas tanto ao diagnóstico da raiva quanto ao diagnóstico das encefalites equinas, porém nenhuma apresentou resultado positivo para as duas doenças simultaneamente. 


\begin{tabular}{|lccc|}
\hline $\begin{array}{c}\text { Amostra } \\
\text { Número/ano }\end{array}$ & $\begin{array}{c}\text { Procedência } \\
\text { (Município/Estado) }\end{array}$ & IFD & IVC \\
\hline $5037 / 08$ & Caconde/SP & $\mathrm{P}$ & $\mathrm{N}$ \\
$5790 / 08$ & São Sebastião Gama/SP & $\mathrm{P}$ & $\mathrm{P}$ \\
$6342 / 08$ & Joanópoplis/SP & $\mathrm{P}$ & $\mathrm{P}$ \\
$6347 / 08$ & Piracaia/SP & $\mathrm{P}$ & $\mathrm{N}$ \\
$6875 / 08$ & Joanópolis/SP & $\mathrm{P}$ & $\mathrm{P}$ \\
$7191 / 08$ & Pedra Bela/SP & $\mathrm{P}$ & $\mathrm{P}$ \\
$7955 / 08$ & Ibiuna/SP & $\mathrm{P}$ & $\mathrm{N}$ \\
$9146 / 08$ & Salesópolis/SP & $\mathrm{P}$ & $\mathrm{P}$ \\
$10252 / 08$ & Franca/SP & $\mathrm{P}$ & $\mathrm{N}$ \\
$10542 / 08$ & Franca/SP & $\mathrm{P}$ & $\mathrm{P}$ \\
$11075 / 08$ & Franca/SP & $\mathrm{P}$ & $\mathrm{P}$ \\
$11231 / 08$ & Águas da Prata/SP & $\mathrm{P}$ & $\mathrm{P}$ \\
$11450 / 08$ & Caconde/SP & $\mathrm{P}$ & $\mathrm{P}$ \\
$704 / 09$ & Joanópolis/SP & $\mathrm{P}$ & $\mathrm{P}$ \\
$1532 / 09$ & S. J. Boa Vista/SP & $\mathrm{P}$ & $\mathrm{N}$ \\
$4833 / 09$ & Poços de Caldas/MG & $\mathrm{P}$ & $\mathrm{P}$ \\
$5176 / 09$ & São João Boa Vista/SP & $\mathrm{P}$ & $\mathrm{P}$ \\
$7242 / 09$ & Espírito Santo do Pinhal/SP & $\mathrm{P}$ & $\mathrm{P}$ \\
\hline
\end{tabular}

IFD : Imunofluorescência direta

IVC: Isolamento viral em camundongo

P: Positivo

N: Negativo

Quadro 2 - Amostras diagnosticadas como positivas para raiva pelas técnicas de imunofluorescência direta e isolamento viral em camundongos, no Laboratório de Diagnóstico de Raiva do Instituto Pasteur de São Paulo jun. - 2008 / dez. - 2009 


\begin{tabular}{|lccc|}
\hline $\begin{array}{c}\text { Amostra } \\
\text { Número/ano }\end{array}$ & $\begin{array}{c}\text { Procedência } \\
\text { (Município/Estado) }\end{array}$ & $\begin{array}{c}\text { Hemi-Nested } \\
\text { RT-PCR para } \\
\text { Alphavirus }\end{array}$ & IVC \\
\hline $5032 / 08$ & Cuiabá/MT & $\mathrm{P}$ & $\mathrm{N}$ \\
$2572 / 09$ & Jaguaribe/CE & $\mathrm{P}$ & $\mathrm{N}$ \\
$3499 / 09$ & São João do Rio do Peixe/PB & $\mathrm{P}$ & $\mathrm{N}$ \\
$3500 / 09$ & São João do Rio do Peixe/PB & $\mathrm{P}$ & $\mathrm{N}$ \\
$3501 / 09$ & Coremas/PB & $\mathrm{P}$ & $\mathrm{N}$ \\
$3723 / 09$ & Coremas/PB & $\mathrm{P}$ & $\mathrm{N}$ \\
$3724 / 09$ & Uiraúna/PB & $\mathrm{P}$ & $\mathrm{N}$ \\
$3725 / 09$ & Poço José Moura/PB & $\mathrm{P}$ & $\mathrm{N}$ \\
$3726 / 09$ & Poço José Moura/PB & $\mathrm{P}$ & $\mathrm{N}$ \\
$4084 / 09$ & Ilha do Marajó/PA & $\mathrm{P}$ & $\mathrm{P}$ \\
$4085 / 09$ & Ilha do Marajó/PA & $\mathrm{P}$ & $\mathrm{N}$ \\
$4239 / 09$ & Várzea Alegre/ CE & $\mathrm{P}$ & $\mathrm{N}$ \\
$4240 / 09$ & Várzea Alegre/ CE & $\mathrm{P}$ & $\mathrm{N}$ \\
$5691 / 09$ & Patos/PB & $\mathrm{P}$ & $\mathrm{N}$ \\
$6009 / 09$ & Paulista/PB & $\mathrm{P}$ & $\mathrm{N}$ \\
\hline
\end{tabular}

IVC: Isolamento viral em camundongo

P: Positivo

$\mathrm{N}$ : Negativo

Quadro 3 - Amostras diagnosticadas como positivas para encefalite equina do Leste pelas técnicas de hemi-nested RT-PCR e isolamento viral em camundongos, no Laboratório de Diagnóstico de Raiva do Instituto Pasteur de São Paulo - jun. - 2008 / dez. - 2009

\subsection{PREPARO DAS AMOSTRAS}

A seguir, serão apresentados a produção de lote de trabalho de vírus padrão e o preparo das amostras de campo. 


\subsubsection{Produção de Lote de Trabalho de Vírus Padrão}

Para a produção de um lote de trabalho de vírus padrão CVS, EEEV e WEEV, 50 camundongos albinos (Mus musculus), de 21 dias, foram inoculados com suspensões a 20\% (peso/volume) dos respectivos vírus, em uma diluição com 1000 $\mathrm{DL}_{50}$, no volume de $0,03 \mathrm{~mL}$ por via intracerebral. Após a inoculação, os animais foram observados diariamente e, no momento da observação, os que estavam mortos eram imediatamente recolhidos, enquanto que os que apresentavam sinais avançados de paralisia de membros e/ou dispnéia intensa, eram submetidos à eutanásia em câmara de $\mathrm{CO}_{2}$.

Os cérebros foram coletados, macerados em graal com pistilo e diluídos em uma solução contendo $1 \mathrm{~mL}$ de gentamicina, $20 \mathrm{~mL}$ de sorofetal bovino e $800 \mathrm{~mL}$ de solução fisiológica a $0,85 \%$, para a obtenção de uma suspensão a $20 \%$ (peso/volume), e acondicionados em tubos para centrifugação tipo Falcon de $15 \mathrm{~mL}$ com tampa $\left(\right.$ Corning $^{\circledR}$ ), para evitar a formação de aerossóis. Posteriormente, foram submetidos à centrifugação em rotação de $850 \mathrm{~g}$, à temperatura de $4^{\circ} \mathrm{C}$ por 30 minutos. Após a centrifugação, os sobrenadantes foram coletados, fracionados em tubos de 1,5 mL livres de RNAse ou DNAse, e armazenados em freezer a temperatura de $-80^{\circ} \mathrm{C}$.

\subsubsection{Titulação do Lote de Trabalho de Vírus Padrão}

A partir de amostras dos lotes de trabalho de vírus padrão de CVS, EEEV e

WEEV produzidos, foram realizadas diluições decimais seriadas, de $10^{-5}$ a $10^{-9}$ para CVS, de $10^{-4,7}$ até $10^{-11,7}$ para EEEV, e de $10^{-2,7}$ a $10^{-7,7}$ para WEEV. Cada diluição foi inoculada em um grupo de 10 camundongos albinos (Mus musculus), de 21 dias, utilizando um volume de $0,03 \mathrm{~mL}$ por via intracerebral. Os animais foram observados diariamente por até 15 dias e o cálculo da titulação foi realizado pelo método de Reed-Müench (HABEL, 1996). 


\subsubsection{Amostras de Campo}

Um pool de fragmentos de SNC (córtex, cerebelo, tronco e/ou medula) de cada amostra foi coletado em tubo de $1,5 \mathrm{~mL}$, sendo posteriormente armazenado em freezer à temperatura de -20 ou $-80^{\circ} \mathrm{C}$ até o momento de sua utilização para a extração de RNA.

\subsection{EXTRAÇÃO DE RNA}

As extrações de RNA viral foram realizadas tanto a partir de suspensões a $20 \%$ de cérebro de camundongos inoculados com vírus padrão, quanto diretamente de amostras de SNC de camundongos ou de equinos. Quando realizada a partir de uma suspensão, o volume utilizado foi de $300 \mu \mathrm{L}$. Já em relação às amostras de SNC, foram coletadas pequenas quantidades de diferentes partes do SNC (córtex, cerebelo, tronco e/ou medula), totalizando aproximadamente $0,5 \mathrm{~g}$, sendo então cortadas em pequenos fragmentos com o auxílio de bisturi. Em cada extração foi acrescentado um controle negativo, utilizando $300 \mu \mathrm{L}$ de água destilada UltraPure ${ }^{\circledR}$ livre de RNAse/DNAse (Invitrogen ${ }^{\circledR}$ ), e um controle positivo, utilizando amostras de SNC de camundongos inoculados com o vírus padrão ou suspensão a $20 \%$.

O RNA foi extraído utilizando-se o TRIzo ${ }^{\circledR}$ Reagent $\left(\right.$ Invitrogen ${ }^{\circledR}$ ), de acordo com as instruções descritas no anexo B. O RNA total extraído foi ressuspendido em $25 \mu \mathrm{L}$ de água destilada UltraPure ${ }^{\circledR}$ livre de RNAse/DNAse $\left(\right.$ Invitrogen $^{\circledR}$ ) e armazenado em freezer à temperatura de $-20^{\circ} \mathrm{C}$, até o momento do uso.

No anexo $A$, encontra-se a descrição mais detalhada do protocolo de extração de RNA. 


\subsection{AVALIAÇÃO PRELIMINAR DOS PRIMERS E UTILIZAÇÃO EM REAÇÃO DE HEMI-NESTED RT-PCR}

Realizou-se, primeiramente, uma avaliação dos primers escolhidos e sua utilização em uma reação de hemi-nested RT-PCR.

\subsubsection{Primers}

Para este estudo, foram utilizados primers específicos para detecção do RABV, EEEV e WEEEV já descritos na literatura. Alguns primers foram testados previamente (Apêndice A, Quadros 10 e 11), sendo que a escolha foi baseada na ausência ou na menor formação de banda inespecífica possível. Desta forma, os primers escolhidos para esse estudo estão listados nos quadros 4 e 5 .

Os primers 21G, 304 e 504 são direcionados à região do gene codificador da proteína N, o qual é considerado altamente conservado (NADIN-DAVIS, 2007). Com relação ao tamanho do fragmento esperado, o par de primers $21 \mathrm{G}$ e 304 amplificam um fragmento de $1479 \mathrm{pb}$ (pares de bases), enquanto o primer interno 504 em associação com o primer 304, amplificam um fragmento de 248 pb.

\begin{tabular}{|cccccc|}
\hline Primer & Sentido & Sequência (5'-3') & Região* & Tm (C) & \%GC \\
\hline $21 G$ & senso & ATGTAACACCTCTACAATG & $55-73$ & 45 & 37 \\
304 & antissenso & TTGACGAAGATCTTGCTCAT & $1514-1533$ & 56 & 40 \\
504 & senso & TATACTCGAATCATGATGAATGGAGGTCGACT & $1286-1317$ & 70 & 41 \\
\hline
\end{tabular}

*De acordo com o genoma do vírus PV (TORDO et al., 1986).

Quadro 4 - Primers utilizados para a identificação do vírus da raiva direcionados à região do gene $\mathrm{N}$, segundo o sentido, a sequência, região de anelamento, temperatura de melting e porcentagem de ligações GC 
Para a deteç̧ão do EEEV e do WEEV, foram escolhidos os primers cM3W, $\mathrm{M} 2 \mathrm{~W}, \mathrm{nEEEV}$ e nWEEV, direcionados à região do gene codificador da proteína não estrutural NSP1 (Quadro 5), considerada uma região conservada no genoma (PFEFFER et al., 1997). O primeiro par de primers, cM3W e M2W, é gêneroespecífico e identifica qualquer Alphavirus, tais como EEEV, WEEV e VEEV, apresentando um fragmento amplificado de $434 \mathrm{pb}$. Já os primers internos, nEEEV e nWEEV, são primers espécie-específicos que, em associação com o primer cM3W, produzem fragmentos de $124 \mathrm{pb}$ e $208 \mathrm{pb}$, respectivamente.

\begin{tabular}{|cccccc|}
\hline Primer & Sentido & Sequência (5'-3') & Região* & $\begin{array}{c}\text { Tm } \\
\text { (') }\end{array}$ & \%GC \\
\hline CM3W & antissenso & ACATRAANKGNGTNGTRTCRAANCCDAYCC & $568-597$ & 71 & 44 \\
M2W & senso & YAGAGCDTTTTCGCAYSTRGCHW & $164-186$ & 67 & 44 \\
nEEEV & senso & CCACGGTACCGTTGCC & $474-489$ & 59 & 69 \\
nWEEV & senso & GGCGGCAGACCTGCTGGAA & $390-409$ & 69 & 68 \\
\hline
\end{tabular}

*De acordo com o genoma do vírus da encefalite equina Venezuelana (KINNEY et al., 1989).

Códigos de sequências: $R=A / G ; Y=C / T ; K=G / T ; S=C / G ; W=A / T ; H=A / C / T ; D=A / G / T ; N=$ A/C/T/G (CORNISH-BOWDEN, 1985).

Quadro 5 - Primers utilizados para a identificação do vírus da encefalite equina do Leste e Oeste direcionados à região do gene NSP1, segundo o sentido, a sequência, região de anelamento, temperatura de melting e porcentagem de ligações GC

\subsubsection{Análise dos Primers}

A análise dos primers foi realizada utilizando-se o aplicativo OligoAnalyzer $3.0^{3}$, avaliando-se o valor de delta-G, formação de hairpins, de homodímeros e heterodímeros. Além disso, utilizou-se o BLAST/n (Basic Local Alignment Search $T o o)^{4}$ para a verificação da correspondência dos primers em relação a seus genesalvos.

\footnotetext{
${ }^{3}$ Disponível em: <http://www.idtdna.com>. Acesso em: 01 mar. 2009.

${ }^{4}$ Disponível em: <http://blast.ncbi.nlm.nih.gov/Blast.cgi>. Acesso em: 01 mar. 2009.
} 


\subsubsection{Temperatura Ótima de Anelamento dos Primers}

Para a verificação da temperatura ótima de anelamento dos primers, realizou-se 0 teste de gradiente de temperatura no termociclador Mastercycler ${ }^{\circledR}$ Gradient (Eppendorf ${ }^{\circledR}$ ). Para a realização deste teste foram utilizados RNAs extraídos das suspensões a $20 \%$ de cada vírus padrão. Para a detecção de cada vírus, foram utilizados os respectivos conjuntos de primers, como descrito no quadro 6.

\begin{tabular}{|c|c|c|c|c|}
\hline Vírus & Reação & Primer senso & Primer antissenso & Fragmento (pb) \\
\hline \multirow{2}{*}{ RABV } & RT & $21 G$ & - & - \\
& PCR & $21 G$ & 304 & 1479 \\
& Hemi-nested & 504 & 304 & 248 \\
\hline \multirow{2}{*}{ EEEV } & RT & - & cM3W & - \\
& PCR & M2W & cM3W & 434 \\
& Hemi-nested & nEEEV & cM3W & 124 \\
\hline \multirow{3}{*}{ WEEV } & RT & - & cM3W & - \\
& PCR & M2W & cM3W & 434 \\
& Hemi-nested & nWEEV & cM3W & 208 \\
\hline
\end{tabular}

Quadro 6 - Combinação de primers senso e antissenso utilizados na técnica de hemi-nested RT-PCR de acordo com o vírus, tipo de reação e tamanho de fragmento esperado

Os protocolos utilizados na síntese de cDNA, na primeira e na segunda amplificação foram baseados em um protocolo utilizado para diagnóstico das encefalites equinas (Alphavirus) pela técnica de hemi-nested RT-PCR realizada Laboratório de Biologia Molecular do Instituto Pasteur, cuja descrição também encontra-se no trabalho de Silva et al. (2011). Os detalhes de cada procedimento estão descritos a seguir. 


\subsubsection{Transcrição Reversa (RT)}

Uma vez que os vírus utilizados neste estudo são vírus RNA, a transcrição reversa $(R T)$ se fez necessária para a síntese de DNA complementar (cDNA).

Para cada tubo de $200 \mu \mathrm{L}$, foi acrescentada a seguinte combinação de reagentes: $1 \mathrm{X}$ First Strand Buffer, $0,1 \mathrm{mM}$ de dithiothreitol (DTT), $1 \mu \mathrm{M}$ de primer senso ou anti-senso (Quadro 6), $1 \mathrm{mM}$ de cada dNTP (trifostato de desoxinucleosídeo), 200U da enzima SuperScript ${ }^{\circledR} \| \mathrm{RT}$ (Invitrogen ${ }^{\circledR}$ ) e água destilada UltraPure ${ }^{\circledR}\left(\right.$ Invitrogen $\left.^{\circledR}\right)$ para completar o volume de $13 \mu \mathrm{L}$. Após a mistura dos reagentes, $7 \mu \mathrm{L}$ de RNA extraído foram adicionados ao tubo, totalizando um volume de $20 \mu \mathrm{L}$. Em seguida, os reagentes foram incubados no termociclador a $42^{\circ} \mathrm{C}$, por 60 minutos. Ao final da reação, o cDNA de cada amostra foi armazenado em freezer à temperatura de $-20^{\circ} \mathrm{C}$.

\subsubsection{Primeira Amplificação (PCR)}

Após a síntese de cDNA, realizou-se a primeira amplificação pela técnica de PCR. Em tubos de $200 \mu \mathrm{L}$, foram acrescentados 1x PCR Buffer (Invitrogen ${ }^{\circledR}$ ), 0,2mM de cada dNTP, 0,5 $\mu \mathrm{M}$ de cada primer senso e antissenso (Quadro 6), $2 \mathrm{mM}$ de $\mathrm{MgCl}_{2}, 2,5 \mathrm{U}$ de Taq DNA polimerase $\left(\right.$ Invitrogen $^{\circledR}$ ) e água UltraPure ${ }^{\circledR}$ (Invitrogen $^{\circledR}$ ) para um volume final de $45 \mu \mathrm{L}$. Após o preparo dos reagentes, $5 \mu \mathrm{L}$ de cDNA foram adicionados, totalizando um volume de $50 \mu \mathrm{L}$.

Em seguida, as reações foram incubadas no termociclador, sendo que para o teste de gradiente, a temperatura mediana de anelamento escolhida foi de $55^{\circ} \mathrm{C}$ com um gradiente de $10^{\circ} \mathrm{C}$, ou seja, a partir da temperatura mediana, nas primeiras 6 colunas do bloco do termociclador, ocorreu uma variação de $10^{\circ} \mathrm{C}$ abaixo de $55^{\circ} \mathrm{C}$, enquanto que nas 6 colunas seguintes, uma variação de $10^{\circ} \mathrm{C}$ acima de $55^{\circ} \mathrm{C}$. As reações foram levadas ao termociclador e submetidas ao seguinte ciclo: $94^{\circ} \mathrm{C} / 2 \mathrm{~min}$; 35 ciclos de $94^{\circ} \mathrm{C} / 20 \mathrm{~s}, 45-65^{\circ} \mathrm{C} / 30 \mathrm{~s}, 72^{\circ} \mathrm{C} / 1 \mathrm{~min} ; 72^{\circ} \mathrm{C} / 10 \mathrm{~min}$. 
Os produtos da PCR foram submetidos à eletroforese em gel de agarose a $2 \%$, em tampão UltraPure TBE $1 \mathrm{X}\left(\right.$ Invitrogen $\left.^{\circledR}\right)$ contendo brometo de etídeo na concentração de $0,45 \mathrm{mg} / \mathrm{mL}$ de tampão. Posteriormente, o gel foi visualizado em um transiluminador de luz ultra-violeta (UV).

Com base no resultado obtido, optou-se pela melhor temperatura de anelamento para a primeira amplificação, levando-se em consideração a intensidade do brilho da banda esperada e a menor formação de banda inespecífica possível, caso houvesse formação de banda inespecífica.

Os produtos da PCR foram mantidos em um freezer específico para 0 armazenamento de produtos amplificados à temperatura de $-20^{\circ} \mathrm{C}$, localizado na sala de eletroforese.

\subsubsection{Segunda Amplificação (Hemi-nested)}

A segunda amplificação foi realizada pela hemi-nested, que é uma variação da PCR em que se utiliza primers internos em relação aos produtos da PCR. O procedimento foi realizado em cabines de fluxo laminar e as amostras e os reagentes foram mantidos em gelo.

Em tubos de $500 \mu \mathrm{L}$, foram acrescentados 1x PCR Buffer (Invitrogen ${ }^{\circledR}$ ), $0,2 \mathrm{mM}$ de cada dNTP, $0,5 \mu \mathrm{M}$ de cada primer senso e antissenso (quadro 5), $2 \mathrm{mM}$ de $\mathrm{MgCl}_{2}, 2,5 \mathrm{U}$ de Taq DNA polimerase recombinante (Invitrogen ${ }^{\circledR}$ ) e água UltraPure $^{\circledR}\left(\right.$ Invitrogen $\left.{ }^{\circledR}\right)$ para um volume final de $90 \mu \mathrm{L}$. Após o preparo dos reagentes, $10 \mu \mathrm{L}$ de cDNA, foram adicionados, totalizando um volume final de $100 \mu \mathrm{L}$.

Da mesma forma que na PCR, as reações de hemi-nested foram incubadas no termociclador. Para o teste de gradiente das reações para RABV e para WEEV, a temperatura mediana de anelamento foi de $55^{\circ} \mathrm{C}$ com um gradiente de $10^{\circ} \mathrm{C}$. Para 0 teste de gradiente das reações para EEEV, a temperatura mediana $60^{\circ} \mathrm{C}$ com um gradiente de $10^{\circ} \mathrm{C}$. Desta forma, as reações foram submetidas a $94^{\circ} \mathrm{C} / 2 \mathrm{~min} ; 35$ ciclos de $94^{\circ} \mathrm{C} / 20 \mathrm{~s}, 45-65,6^{\circ} \mathrm{C}$ ou $50-70^{\circ} \mathrm{C} / 30 \mathrm{~s}, 72^{\circ} \mathrm{C} / 1 \mathrm{~min} ; 72^{\circ} \mathrm{C} / 10 \mathrm{~min}$, com uma rampa de $0,3^{\circ} \mathrm{C} / \mathrm{s}$ na mudança de cada fase da $\mathrm{PCR}$. 
Os produtos das reações de hemi-nested foram submetidos à eletroforese em gel de agarose a $2 \%$, em tampão UltraPure ${ }^{\circledR}$ TBE $1 \mathrm{X}\left(\right.$ Invitrogen $^{\circledR}$ ) contendo brometo de etídeo na concentração de $0,45 \mathrm{mg} / \mathrm{mL}$ de tampão. Posteriormente, o gel foi visualizado em um transiluminador de luz UV.

Com base no resultado obtido, optou-se pela melhor temperatura de anelamento para a segunda amplificação, levando-se em consideração a intensidade do brilho da banda esperada e a menor formação de banda inespecífica possível, caso houvesse formação de banda inespecífica.

Os produtos das reações de hemi-nested RT-PCR foram mantidos em congelamento à temperatura de $-20^{\circ} \mathrm{C}$ em um freezer específico para 0 armazenamento de produtos amplificados.

\subsubsection{Determinação do Limiar de Detecção}

O teste de limiar de detecção foi realizado para avaliar a sensibilidade analítica da reação de hemi-nested RT-PCR.

\subsubsection{Amostras de Vírus Padrão}

A partir de suspensões a $20 \%$ (peso/volume) de cada vírus padrão foram realizadas diluições decimais seriadas até $10^{-4,7}$, utilizando como diluente a mesma solução descrita no item 3.2.1. Como controle positivo, foi utilizado RNA extraído de fragmento de cérebro de camundongo inoculado com o respectivo vírus, e água como controle negativo.

A extração de RNA foi realizada para cada diluição e o procedimento foi o mesmo descrito no item 3.3. O RNA extraído foi posteriormente submetido à RT, PCR e reação de hemi-nested, seguindo-se os mesmos protocolos descritos nos itens 3.4.3.1, 3.4.3.2 e 3.4.3.3 respectivamente. O conjunto de primers utilizados em 
cada reação está descrito no quadro 5 . Com relação à temperatura de anelamento da PCR e da reação de hemi-nested, a escolha foi baseada no resultado obtido no teste de gradiente de temperatura.

No momento da preparação da hemi-nested, a cada três amostras, foram acrescentadas reações com água ultrapura, utilizadas como um controle negativo para deteç̧ão de alguma contaminação durante a manipulação de produtos amplificados pela PCR.

\subsubsection{Amostra Contendo os Três Vírus Padrão}

Realizou-se também o teste de limiar de detecção a partir de amostras contendo os três vírus padrões. Com esse teste, além de avaliar a sensibilidade analítica, avaliou-se a especificidade dos primers utilizados.

Em um tubo de ensaio de 5,0 mL, foi adicionado 1,0 mL de suspensão a $20 \%$ (peso/volume) de cada vírus padrão. Em seguida, foi realizada uma diluição decimal seriada até $10^{-4,7}$, com a solução descrita no item 3.2.1. Como controle positivo, utilizou-se RNA extraído de fragmento de cérebro de camundongo inoculado com o respectivo vírus, e água como controle negativo.

A extração de RNA foi realizada para cada diluição e o procedimento foi o mesmo descrito no item 3.3. O RNA extraído foi posteriormente submetido à RT, PCR e reação de hemi-nested, seguindo-se o mesmo protocolo descrito nos itens 3.4.3.1, 3.4.3.2 e 3.4.3.3 respectivamente. Em cada reação, utilizou-se o conjunto de primers específico para cada vírus, conforme descrito no quadro 5 . Com relação à temperatura de anelamento da PCR e da reação de hemi-nested, a escolha foi baseada no resultado obtido no teste de gradiente de temperatura.

No momento da preparação da hemi-nested, a cada três amostras, foram acrescentadas reações com água ultrapura, utilizadas como um controle negativo para detecção de alguma contaminação durante a manipulação de produtos amplificados pela PCR. 


\subsubsection{Aplicação da Técnica de Hemi-Nested RT-PCR em Amostras de Campo}

A técnica de hemi-nested RT-PCR foi aplicada nas amostras de campo positivas para raiva e para EEE, utilizando o mesmo protocolo do item 3.4.3, com o objetivo de verificar a reprodutibilidade da técnica na amplificação dos fragmentos esperados.

\subsubsection{Sequenciamento Genético}

O sequenciamento genético foi realizado com o intuito de analisar a especificidade analítica da técnica de hemi-nested RT-PCR, quando utilizados os primers descritos anteriormente.

Os fragmentos obtidos no teste de limiar de detecção da técnica de heminested RT-PCR, tanto das amostras de cada vírus padrão quando das amostras contendo os três vírus padrão, e na aplicação da hemi-nested RT-PCR em amostras de campo, foram purificados a partir do gel utilizando-se o GFX ${ }^{\oplus}$ PCR DNA and Gel Band Purification Kit (GE Healthcar ${ }^{\circledR}$ ) de acordo com as instruções do fabricante. Após a purificação dos produtos da reação de hemi-nested RT-PCR, realizou-se a quantificação de cada amostra pela eletroforese em gel de agarose a $2 \%$ corado com brometo de etídeo. Como referência para a quantificação, utilizou-se o High DNA Mass Ladder ${ }^{\circledR}\left(\right.$ Invitrogen $\left.{ }^{\circledR}\right)$.

Posteriormente, a reação de sequenciamento foi realizada, utilizando-se $4 \mu \mathrm{L}$ de BigDye ${ }^{\circledR}$ Terminator v3.1 (Applied Biosystems ${ }^{\circledR}$ ), 0,32 $\mu \mathrm{M}$ de primer senso ou antissenso, sendo realizada uma reação para cada primer separadamente. Foram adicionados de 3 a $10 \mathrm{ng}$ de DNA alvo e água ultrapura para completar o volume de $10 \mu \mathrm{L}$. Em seguida, as reações foram levadas ao termociclador a $96^{\circ} \mathrm{C} / 1 \mathrm{~min}$ e 35 ciclos de $96^{\circ} \mathrm{C} / 10 \mathrm{~s}, 50^{\circ} \mathrm{C} / 5 \mathrm{~s}, 60^{\circ} \mathrm{C} / 4 \mathrm{~min}$, com rampa de $1^{\circ} \mathrm{C} / \mathrm{s}$ entre as mudanças de temperatura. 
A purificação da reação de sequenciamento foi realizada com Sephade ${ }^{\circledR}$ G50 (GE Healthcare ${ }^{\circledR}$ ), em placas de 96 orifícios com filtro Multiscreen ${ }^{\circledR} \mathrm{HV}$ (Millipore ${ }^{\circledR}$ ). Após a purificação, a placa contendo as reações foi levada ao termociclador a uma temperatura de $95^{\circ} \mathrm{C}$ até a completa evaporação da água. As amostras foram ressuspendidas em $10 \mu \mathrm{L}$ de formamida $\mathrm{Hi}-\mathrm{Di}^{\circledR}$ (Applied Biosystems ${ }^{\circledR}$ ), levadas ao termociclador a uma temperatura de $95 \stackrel{\circ}{\circ} \mathrm{C}$ por 5 minutos, em seguida, colocadas em gelo por 5 minutos, e por fim, colocadas no analisador genético automático ABI 3130 (Applied Biosystems ${ }^{\circledR}$ ).

Os cromatogramas gerados foram analisados, primeiramente, no software Chromas versão 2.24. Em seguida, obteve-se a sequência contig de cada amostra a partir das sequências gerada pelos primers senso e antissenso, por meio do aplicativo CAP-contig do editor de alinhamento de sequências Bioedit 7.0.5.3 (HALL, 1999). As sequências contig foram, então, submetidas ao aplicativo BLAST/n para a confirmação do sequenciamento pela comparação da sequência contig obtida com sequências disponíveis no GenBank.

\subsection{REAÇÃO DE MULTIPLEX HEMI-NESTED RT-PCR}

Nesta seção serão apresentados os testes realizados para a adequação da técnica de multiplex hemi-nested RT-PCR.

\subsubsection{Testes com Diferentes Protocolos para a Técnica de Multiplex Hemi- Nested RT-PCR}

Para a realização dos testes, além das amostras de cada vírus padrão, foram utilizadas uma amostra de campo positiva para raiva (7955/08), uma amostra de campo positiva para EEE (4084/09) e a diluição $10^{-0,7}$ de WEEV. 


\subsubsection{Transcrição Reversa}

Para a síntese de c-DNA pela RT, foi estabelecido um único protocolo, semelhante ao protocolo de RT utilizado na reação de hemi-nested RT-PCR, porém, utilizando o primer senso para o RABV e o primer antissenso para EEEV e WEEV.

Em tubos de $200 \mu \mathrm{L}$, acrescentou-se a seguinte combinação de reagentes: 1X First Strand Buffer, 0,1 mM de dithiothreitol (DTT), $1 \mu \mathrm{M}$ de primer 21G, $1 \mu \mathrm{M}$ de primer CM3W, $1 \mathrm{mM}$ de cada dNTP (trifostato de desoxinucleosídeo), 200U da enzima SuperScript ${ }^{\circledR}$ II RT (Invitrogen $^{\circledR}$ ), totalizando um volume de $13 \mu \mathrm{L}$. Após a mistura dos reagentes, $7 \mu \mathrm{L}$ de RNA extraído foram adicionados ao tubo, resultando em um volume de $20 \mu \mathrm{L}$. Logo após, os reagentes foram incubados no termociclador à $42^{\circ} \mathrm{C}$, por 60 minutos. Ao final da reação, os cDNAs de foram armazenados em freezer à temperatura de $-20^{\circ} \mathrm{C}$.

\subsubsection{Primeira Amplificação}

Na primeira amplificação (multiplex RT-PCR), foram testados 3 protocolos em que foram alterados os volumes dos primers, conforme observado no quadro 7 . As reações foram submetidas a $94^{\circ} \mathrm{C} / 2 \mathrm{~min}, 35$ ciclos de $94^{\circ} \mathrm{C} / 20 \mathrm{~s}, 55,8^{\circ} \mathrm{C} / 1 \mathrm{~min}$, $72^{\circ} \mathrm{C} / 1 \mathrm{~min}$, seguido de uma extensão a $72^{\circ} \mathrm{C} / 10 \mathrm{~min}$, com uma rampa de $0,3^{\circ} \mathrm{C} / \mathrm{s}$ na mudança de cada fase.

\subsubsection{Segunda Amplificação}

Para a segunda amplificação (multiplex hemi-nested RT-PCR), foram testados os protocolos descritos no quadro 8. O programa de ciclagem foi o mesmo utilizado na primeira amplificação (item 3.5.1.2). O protocolo escolhido foi testado também com a adição de $5 \mu \mathrm{L}$ do produto de PCR, ao invés de $10 \mu \mathrm{L}$. 


\begin{tabular}{|c|c|c|c|c|}
\hline \multirow{4}{*}{ Reação } & Reagentes & \multicolumn{3}{|c|}{ Protocolos } \\
\hline \multirow{4}{*}{$\begin{array}{c}\text { Multiplex } \\
\text { PCR }\end{array}$} & Buffer & $1 \mathrm{X}$ & $1 \mathrm{X}$ & $\mathbf{3}$ \\
\cline { 2 - 5 } & $\mathrm{dNTP}(\mathrm{mM})$ & 0,2 & 0,2 & 0,2 \\
\cline { 2 - 5 } & $\mathrm{Mg}^{2+}(\mathrm{mM})$ & 2 & 2 & 2 \\
\cline { 2 - 5 } & $\begin{array}{c}\text { Primer } 21 \mathrm{G} \\
(\mu \mathrm{M})\end{array}$ & 0,5 & 0,4 & 0,3 \\
\cline { 2 - 5 } & $\begin{array}{c}\text { Primer } 304 \\
(\mu \mathrm{M})\end{array}$ & 0,5 & 0,4 & 0,3 \\
\cline { 2 - 5 } & $\begin{array}{c}\text { Primer } \mathrm{M} 2 \mathrm{~W} \\
(\mu \mathrm{M})\end{array}$ & 0,5 & 0,6 & 0,7 \\
\cline { 2 - 5 } & $\begin{array}{c}\text { Primer } \mathrm{cM} 3 \mathrm{~W} \\
(\mu \mathrm{M})\end{array}$ & 0,5 & 0,6 & 0,7 \\
\cline { 2 - 5 } & $\begin{array}{c}\text { Taq } \\
\text { Polimerase }(\mathrm{U})\end{array}$ & 2,5 & 2,5 & 2,5 \\
\cline { 2 - 5 } & $\mathrm{c}-\mathrm{DNA}(\mu \mathrm{l})$ & 5 & 5 & 5 \\
\cline { 2 - 5 } & Água q.s.p $(\mu \mathrm{l})$ & 50 & 50 & 50 \\
\hline
\end{tabular}

Quadro 7 - Protocolos testados pela técnica de multiplex RT-PCR, utilizando diferentes volumes de primers

\begin{tabular}{|c|c|c|c|c|c|c|c|c|c|c|c|}
\hline \multirow{2}{*}{ Reação } & \multirow{2}{*}{ Reagentes } & \multicolumn{10}{|c|}{ Protocolos } \\
\hline & & 1 & 2 & 3 & 4 & 5 & 6 & 7 & 8 & 9 & 10 \\
\hline \multirow{11}{*}{$\begin{array}{c}\text { Multiplex } \\
\text { Hemi- } \\
\text { nested }\end{array}$} & Buffer & $1 \mathrm{X}$ & $1 X$ & $1 \mathrm{X}$ & $1 X$ & $1 X$ & $1 X$ & $1 \mathrm{X}$ & $1 X$ & $1 \mathrm{X}$ & $1 X$ \\
\hline & $\mathrm{dNTP}(\mathrm{mM})$ & 0,2 & 0,2 & 0,2 & 0,2 & 0,2 & 0,2 & 0,25 & 0,3 & 0,2 & 0,2 \\
\hline & $\mathrm{Mg}^{2+}(\mathrm{mM})$ & 2 & 2 & 2 & 2 & 2 & 2 & 2 & 2 & 3 & 4 \\
\hline & $\begin{array}{l}\text { Primer } 504 \\
(\mu \mathrm{M})\end{array}$ & 0,5 & 0,4 & 0,4 & 0,3 & 0,3 & 0,3 & 0,3 & 0,3 & 0,3 & 0,3 \\
\hline & $\begin{array}{c}\text { Primer } 304 \\
(\mu \mathrm{M})\end{array}$ & 0,5 & 0,4 & 0,4 & 0,3 & 0,3 & 0,3 & 0,3 & 0,3 & 0,3 & 0,3 \\
\hline & $\begin{array}{c}\text { Primer } \mathrm{nEEE} \\
(\mu \mathrm{M})\end{array}$ & 0,5 & 0,6 & 0,6 & 0,7 & 0,7 & 0,7 & 0,7 & 0,7 & 0,7 & 0,7 \\
\hline & $\begin{array}{c}\text { Primer nWEE } \\
(\mu \mathrm{M})\end{array}$ & 0,5 & 0,6 & 0,5 & 0,7 & 0,5 & 0,5 & 0,5 & 0,5 & 0,5 & 0,5 \\
\hline & $\begin{array}{c}\text { Primer cM3W } \\
(\mu \mathrm{M})\end{array}$ & 0,5 & 0,6 & 0,6 & 0,7 & 0,7 & 1,0 & 1,0 & 1,0 & 1,0 & 1,0 \\
\hline & $\begin{array}{c}\text { Taq } \\
\text { Polimerase(U) }\end{array}$ & 2,5 & 2,5 & 2,5 & 2,5 & 2,5 & 2,5 & 2,5 & 2,5 & 2,5 & 2,5 \\
\hline & DNA $(\mu \mathrm{l})$ & 10 & 10 & 10 & 10 & 10 & 10 & 10 & 10 & 10 & 10 \\
\hline & Água q.s.p ( $\mu \mathrm{l})$ & 100 & 100 & 100 & 100 & 100 & 100 & 100 & 100 & 100 & 100 \\
\hline
\end{tabular}

Quadro 8 - Protocolos testados pela técnica de multiplex hemi-nested RT-PCR, utilizando diferentes combinações de reagentes 


\subsubsection{Determinação do Limiar de Detecção}

O teste de limiar de detecção foi realizado com diluições seriadas de cada amostra de vírus padrão e com diluições seriadas com uma amostra contendo os três vírus padrão.

\subsubsection{Amostras de Vírus Padrão}

Realizaram-se diluições decimais seriadas até $10^{-4,7}$ a partir de suspensões a $20 \%$ (peso/volume) de cada vírus padrão, utilizando como diluente a mesma solução descrita no item 3.2.1. Como controle positivo, foi utilizado RNA extraído de fragmento de cérebro de camundongo inoculado com o respectivo vírus, e água ultrapura como controle negativo.

A extração de RNA foi realizada para cada diluição e o procedimento foi o mesmo descrito no item 3.3. O RNA extraído foi posteriomente submetido à RT, cujo protocolo está descrito no item 3.5.1.1. O protocolo para a primeira e para a segunda amplificação foi o estabelecido nos itens 3.5.1.2 e 3.5.1.3.

No momento da preparação da segunda amplificação, a cada três amostras, foram acrescentadas reações com água ultrapura, utilizadas como um controle negativo para detecção de alguma contaminação durante a manipulação de produtos amplificados pela PCR.

\subsubsection{Amostra Contendo os Três Vírus Padrão}

Realizou-se também o teste de limiar de detecção a partir de amostras contendo os três vírus padrões, onde foi observada a detecção simultânea dos três vírus. Com esse teste, além de avaliar a sensibilidade analítica, avaliou-se a especificidade dos primers utilizados. 
Em um tubo de ensaio de 5,0 mL, foi adicionado 1,0 mL de suspensão a 20\% (peso/volume) de cada vírus padrão. Em seguida, realizou-se uma diluição decimal seriada até $10^{-4,7}$, com a solução descrita no item 3.2.1. Como controle positivo, utilizou-se um RNA extraído de fragmento de cérebro de camundongo inoculado com o respectivo vírus, e água ultrapura como controle negativo.

A extração de RNA foi realizada para cada diluição e o procedimento foi o mesmo descrito no item 3.3. O RNA extraído foi posteriomente submetido à RT, cujo protocolo está descrito no item 3.5.1.1. O protocolo para a primeira e para a segunda amplificação foi o estabelecido nos itens 3.5.1.2 e 3.5.1.3.

No momento da preparação da segunda amplificação, a cada três amostras, foram acrescentadas reações com água ultrapura, utilizadas como um controle negativo para detecção de alguma contaminação durante a manipulação de produtos amplificados pela PCR.

\subsubsection{Aplicação da Técnica de Multiplex Hemi-Nested RT-PCR em Amostras de Campo}

A técnica de multiplex hemi-nested RT-PCR foi aplicada nas amostras de campo positivas para raiva (Quadro 2) e EEE (Quadro 3), utilizando-se o protocolo estabelecido no item 3.5.1.

\subsubsection{Sequenciamento Genético}

Para verificar a especificidade analítica da técnica de multiplex hemi-nested RT-PCR, realizou-se o sequenciamento genético dos fragmentos obtidos no teste determinação do limiar de detecção nas amostras de cada vírus padrão (item 3.5.4.1). Os procedimentos para a realização do sequenciamento e da análise das sequências obtidas foram os mesmos descritos no item 3.4.6. 


\subsection{ANÁLISE ESTATÍSTICA}

A comparação entre os resultados obtidos em amostras de campo pela técnica de hemi-nested RT-PCR e de multiplex hemi-nested RT-PCR foi realizada pelo emprego do teste exato de Fisher (BERQUÓ; SOUZA; GOETLIEB, 1981; CALEGARI-JACQUES, 2003). Para o teste, foram consideradas as proporções de amostras positivas detectadas, sendo $\mathrm{P} 1=$ proporção de amostras positivas detectadas pela técnica de hemi-nested $\mathrm{RT}-\mathrm{PCR}$ e $\mathrm{P} 2=$ proporção de amostras detectadas pela técnica de multiplex hemi-nested RT-PCR. Logo, as hipóteses a serem testadas foram:

$$
\begin{aligned}
& \mathrm{H}_{0}: \mathrm{P} 1=\mathrm{P} 2 \\
& \mathrm{H}_{1}: \mathrm{P} 1>\mathrm{P} 2
\end{aligned}
$$

Para a realização do cálculo de $P$, considerou-se $\alpha=0,05$ e utilizou-se o aplicativo QuickCalcs disponível no site do Graphpad Software ${ }^{5}$.

\subsection{ANÁLISE DE CUSTO}

Realizou-se uma análise de custo da reação de hemi-nested RT-PCR e da reação de multiplex hemi-nested RT-PCR, levando-se em consideração apenas os reagentes utilizados em cada etapa das reações. Para isso, foi realizado um orçamento junto à empresa para a verificação do preço. Em seguida, realizou-se o cálculo do valor do reagente proporcional ao volume utilizado em uma reação. Para o cálculo da reação de hemi-nested RT-PCR, tomou-se como base o protocolo de reação utilizado para detecção do RABV.

Todos os reagentes utilizados eram provenientes da Invitrogen ${ }^{\circledR}$. Os orçamentos das enzimas e dos primers foram realizados em entre março e julho de 2011. Para a verificação do valor da reação em dólar americano, utilizou-se a cotação do dólar comercial do dia 28/03/2011 ${ }^{6}$, que foi cotado em US $\$ 1,66$.

\footnotetext{
${ }^{5}$ Disponível em:<http:// www.graphpad.com/quickcalcs/index.cfm>. Acesso em: 20 jun. 2011.

${ }^{6}$ Disponível em : < http://economia.uol.com.br/cotacoes/cambio/dolar-comercial-estados-unidoshistorico.jhtm>. Acesso em: 09 jul. 2011
} 


\section{RESULTADOS}

Nesta seção, serão apresentados os resultados obtidos a partir da metodologia proposta.

\subsection{TITULAÇÃO VIRAL DO LOTE DE TRABALHO DE VÍRUS PADRÃO}

O título viral obtido no lote de trabalho produzido para cada vírus padrão foi de:

- CVS: $10^{6,1} \mathrm{DL}_{50} / 0,03 \mathrm{~mL}$

- EEEV: $10^{9,4} \mathrm{DL}_{50} / 0,03 \mathrm{~mL}$;

- WEEV: $10^{6,7} \mathrm{DL}_{50} / 0,03 \mathrm{~mL}$.

\subsection{AVALIAÇÃO PRELIMINAR DOS PRIMERS E UTILIZAÇÃO EM REAÇÃO DE HEMI-NESTED RT-PCR}

A seguir, serão apresentados os resultados da análise dos primers, dos testes de gradiente e de limiar de detecção, do sequenciamento genético e da aplicação da técnica em amostras de campo.

\subsubsection{Análise dos Primers}

$\mathrm{Na}$ análise realizada pelo OligoAnalyzer 3.0, tomando como base os valores de delta $G$, não foram encontrados valores que indicassem a formação de hairpins, homodímeros e heterodímeros. 
As sequências dos primers cM3W e M2W não puderam ser analizadas pelo $\mathrm{BLAST} / \mathrm{n}$, devido ao fato de serem degenerados. Com relação aos primers $21 \mathrm{G}$, 304, 504, nEEEV e nWEEV, todas as sequências foram submetidos ao BLAST/n, de forma que foram encontradas sequências correspondentes aos agentes estudados.

\subsubsection{Temperatura Ótima de Anelamento dos Primers}

No teste de gradiente realizado com as amostras de CVS (Figura 1-A), observou-se, na PCR, a presença do fragmento esperado de tamanho de $1479 \mathrm{pb}$ entre as temperaturas 45 à $61^{\circ} \mathrm{C}$, não sendo possível observar o sinal a partir desta última temperatura. Observou-se, também, a presença de uma banda inespecífica próximo à $500 \mathrm{pb}$, cuja intensidade do brilho diminui conforme a temperatura de anelamento aumenta, praticamente não sendo mais visualizada a $61^{\circ} \mathrm{C}$. Desta forma, para o par de primers $21 \mathrm{G}$ e 304 , o intervalo de temperatura de anelamento considerado foi entre $55,8^{\circ} \mathrm{C}$ e $58,5^{\circ} \mathrm{C}$, sendo que a temperatura escolhida para a realização da PCR para segunda amplificação foi de $58^{\circ} \mathrm{C}$.

$\mathrm{Na}$ hemi-nested (Figura 1-B) em que o par de primers foi 504 e 304, a formação da banda esperada, de $248 \mathrm{pb}$, foi igualmente observada em todas as temperaturas testadas. A banda inespecífica também foi observada na hemi-nested, porém com menor intensidade, principalmente nas temperaturas acima de $55,8^{\circ} \mathrm{C}$. Assim sendo, considerou-se o intervalo de temperatura entre 55,8 à $65,6^{\circ} \mathrm{C}$.

Nas PCRs realizadas em amostras de EEEV (Figura 2-A), em que se utilizou os primers $\mathrm{CM} 3 \mathrm{~W}$ e M2W, observou-se a presença da banda esperada de 434pb. Houve formação de bandas inespecíficas maiores que 1200pb, de baixa intensidade de brilho. A intensidade de brilho da banda esperada apresentou-se constante até $55,8^{\circ} \mathrm{C}$, sendo que nas temperaturas seguintes, uma diminuição do brilho foi verificada. Desta forma, optou-se pela temperatura de $55,8^{\circ} \mathrm{C}$ para a PCR que foi utilizada na segunda amplificação.

Nas reações de hemi-nested (Figura 2-B), os primers utilizados foram cM3W e nEEEV, sendo que a banda esperada de $124 \mathrm{pb}$ foi observada com intenso do 
brilho até a temperatura de $60,8^{\circ} \mathrm{C}$, verificando-se uma diminuição na intensidade nas temperaturas seguintes. Porém, foram observadas a presença de algumas bandas inespecíficas, além de bandas correspondentes à PCR.

Nas PCRs realizadas em amostras de WEEV (Figura 3-A), em que foram utilizado os primers cM3W e M2W, a banda esperada de $434 \mathrm{pb}$ foi observada até a temperatura de $61^{\circ} \mathrm{C}$, sendo que as melhores formações, com ausência de banda inespecífica, foram observadas nas temperaturas de $55,8^{\circ} \mathrm{C}$ e $58,5^{\circ} \mathrm{C}$. Optou-se pela temperatura de $58,5^{\circ} \mathrm{C}$ para a realização da $\mathrm{PCR}$, que foi utilizada na segunda amplificação.

Nas reações de hemi-nested realizadas em amostras amplificadas de WEEV (Figura 3-B), a observação das bandas esperadas de 208pb ocorreu em todas as temperaturas com exceção da última $\left(65^{\circ} \mathrm{C}\right)$. Bandas inespecíficas próximas a $900 \mathrm{pb}$ foram observadas até $58,5^{\circ} \mathrm{C}$, enquanto que outras abaixo de $200 \mathrm{pb}$, foram observadas a partir desta mesma temperatura.

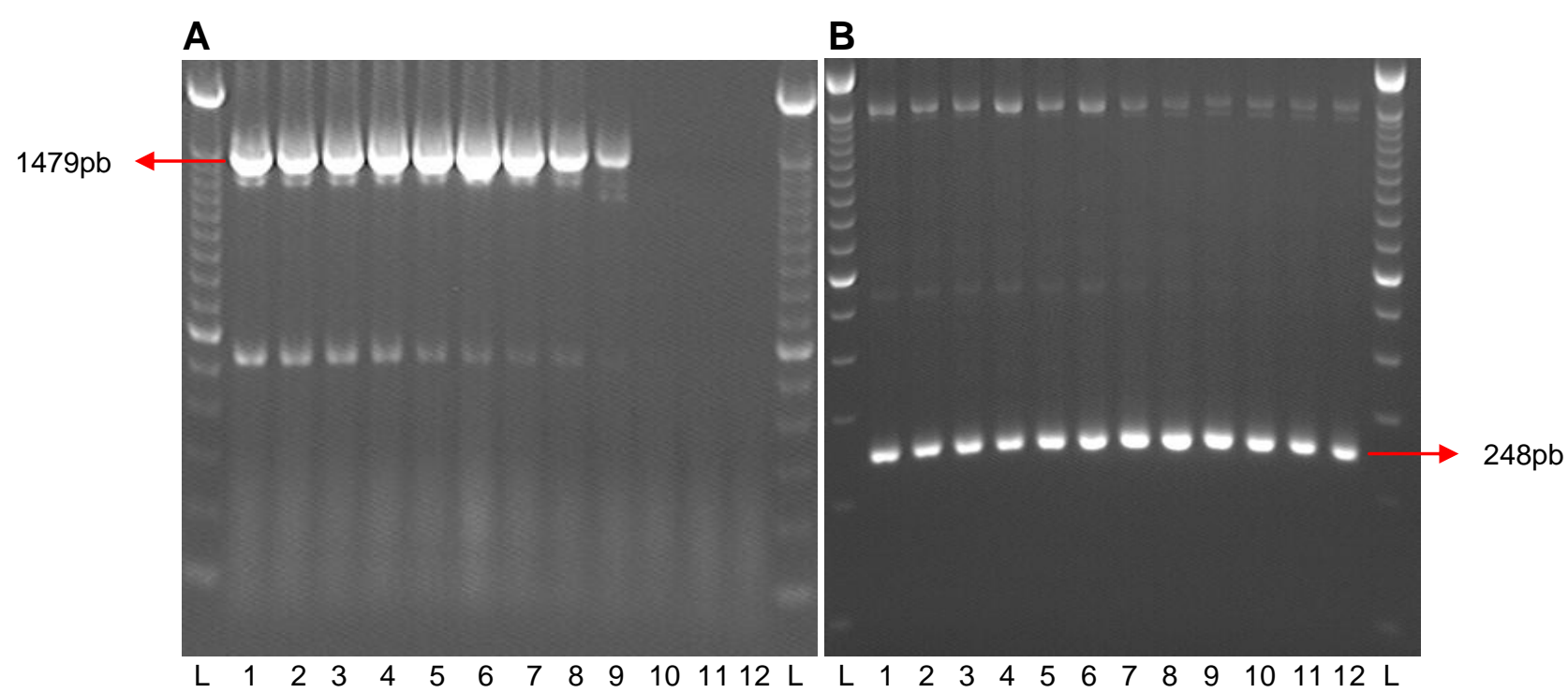

Legenda: A. PCR: primers 21G e 304. B. Hemi-nested: primers 504 e 304. L-

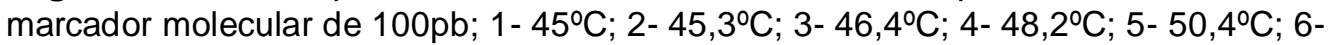
$53^{\circ} \mathrm{C} ; 7-55,8^{\circ} \mathrm{C} ; 8^{-5}-58,5^{\circ} \mathrm{C} ; 9-61^{\circ} \mathrm{C} ; 10-63,1^{\circ} \mathrm{C} ; 11-64,7^{\circ} \mathrm{C} ; 12-65,6^{\circ} \mathrm{C}$.

Figura 1 - Eletroforese em gel de agarose a 2\% corado com brometo de etídeo, referente ao teste de gradiente de temperatura em amostras de CVS, pela técnica de heminested RT-PCR 


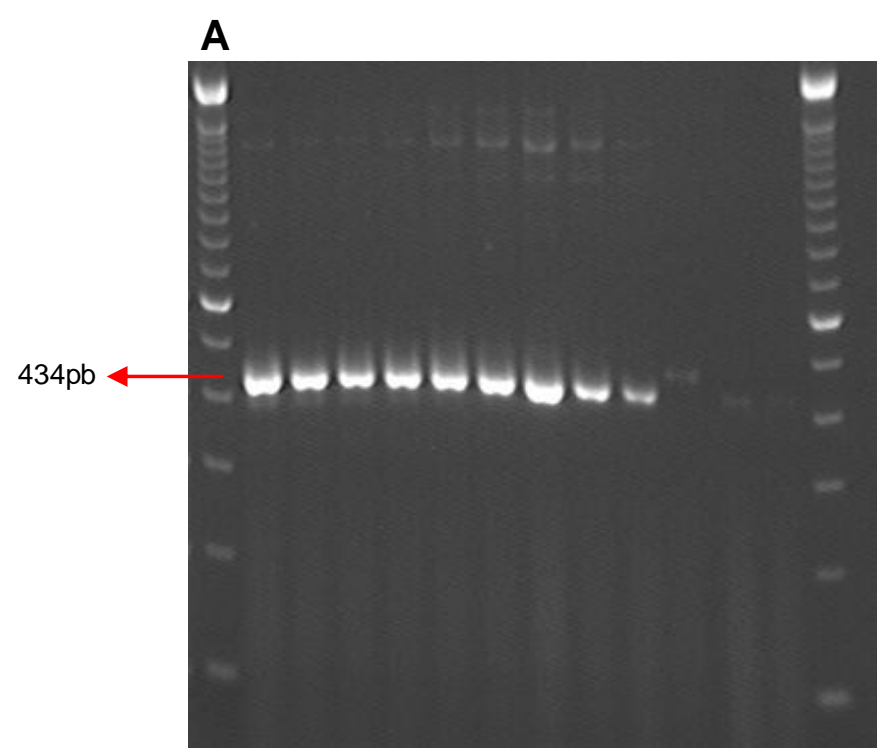

B

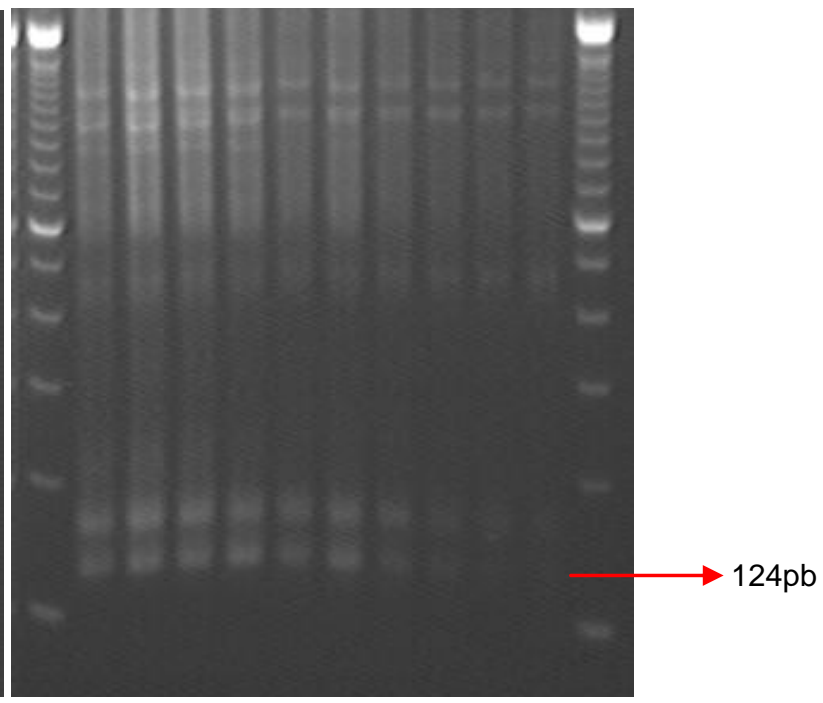

$\begin{array}{llllllllllllll}\mathrm{L} & 1 & 2 & 3 & 4 & 5 & 6 & 7 & 8 & 9 & 10 & 11 & 12 & \mathrm{~L}\end{array}$

$\begin{array}{lllllllllllll}\mathrm{L} & 1 & 2 & 3 & 4 & 5 & 6 & 7 & 8 & 9 & 10 & \mathrm{~L}\end{array}$

Legenda: A. PCR: primers cM3W e M2W. L- marcador molecular de 100pb; 1 - 45우의

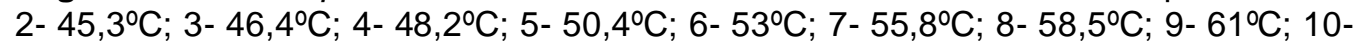
$63,1^{\circ} \mathrm{C} ; 11-64,7^{\circ} \mathrm{C} ; 12-65,6^{\circ} \mathrm{C}$. B. Hemi-nested: primers cM3W e nEEEV. L- marcador

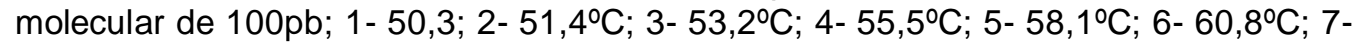
$63,5^{\circ} \mathrm{C} ; 8-66,0^{\circ} \mathrm{C} ; 9-68,1^{\circ} \mathrm{C} ; 10-69,7^{\circ} \mathrm{C}$.

Figura 2 - Eletroforese em gel de agarose a 2\% corado com brometo de etídeo, referente ao teste de gradiente de temperatura em amostras de EEEV, pela técnica de heminested RT-PCR

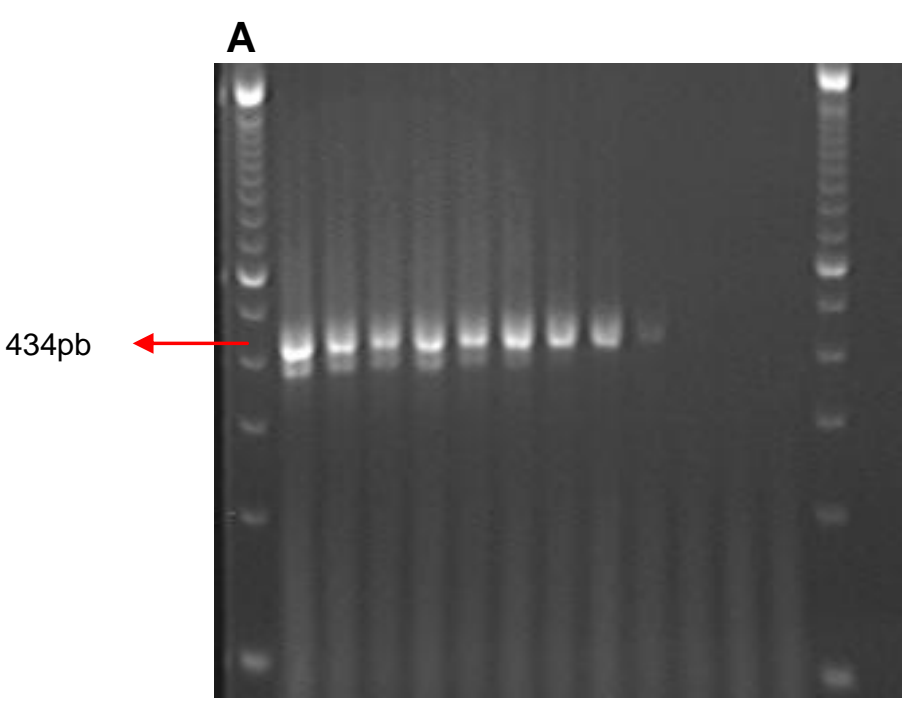

$\begin{array}{lllllllllllllll}\mathrm{L} & 1 & 2 & 3 & 4 & 5 & 6 & 7 & 8 & 9 & 10 & 11 & 12 & \mathrm{~L}\end{array}$
B

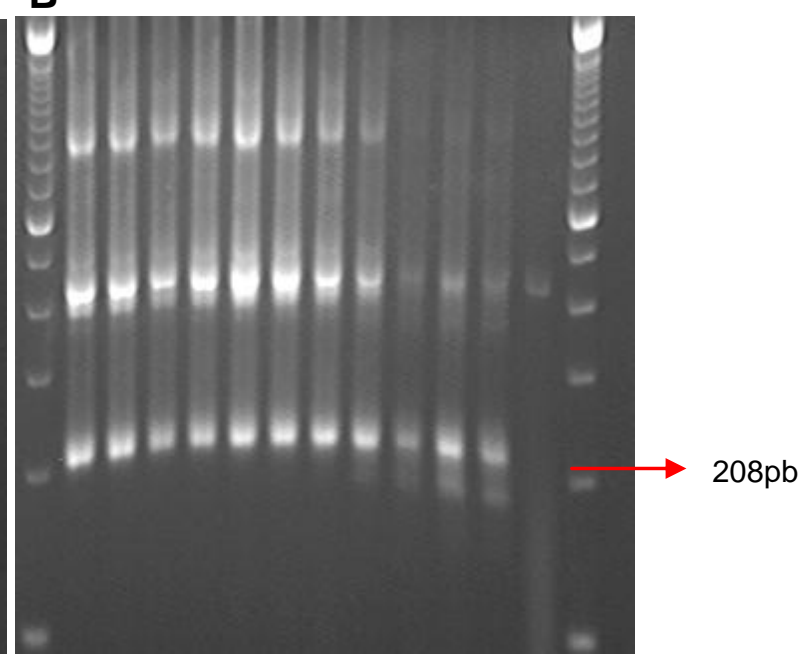

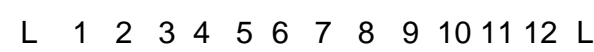

Legenda: A. PCR: primers CM3W e M2W. B. Hemi-nested: primers CM3W e nWEEV.

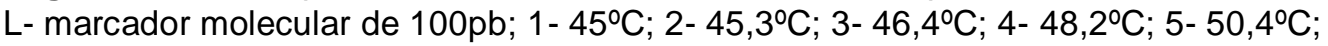

6- 53ํㅡ; 7- 55,8ํㅡ; 8- 58, $5^{\circ} \mathrm{C} ; 9$ - $61^{\circ} \mathrm{C} ; 10-63,1^{\circ} \mathrm{C} ; 11-64,7^{\circ} \mathrm{C} ; 12-65,6^{\circ} \mathrm{C}$.

Figura 3 - Eletroforese em gel de agarose a 2\% corado com brometo de etídeo, referente ao teste de gradiente de temperatura em amostras de WEEV, pela técnica de heminested RT-PCR 
No quadro 9, são apresentados os intervalos de temperaturas que apresentaram um bom resultado, considerando-se a intensidade do brilho da banda esperada e a menor formação de banda inespecífica possível. Com base nesses resultados observados, considerou-se a temperatura de $55,8^{\circ} \mathrm{C}$ como a temperatura ótima para o anelamento, tanto para a reação de PCR quanto para a hemi-nested, realizadas em testes posteriores.

\begin{tabular}{|c|c|c|}
\hline Vírus Padrão & PCR $\left({ }^{\circ} \mathbf{C}\right)$ & Hemi-nested $\left({ }^{\circ} \mathbf{C}\right)$ \\
\hline CVS & $55,8-58,5$ & $55,8-65,6$ \\
\hline EEEV & $45,0-55,8$ & $50,3-60,8$ \\
\hline WEEV & $55,8-58,5$ & $45,0-55,8$ \\
\hline
\end{tabular}

Quadro 9 - Intervalos de temperaturas utilizados para a escolha da temperatura ótima de anelamento segundo amostra de vírus padrão e reação (PCR e Hemi-nested)

\subsubsection{Determinação do Limiar de Detecção}

A seguir, serão apresentados os resultados obtidos nos testes de limiar de deteção realizado pela técnica de hemi-nested RT-PCR.

\subsubsection{Amostras de Vírus Padrão}

No teste de limiar de detecção, nas amostras de CVS e de WEEV observouse na reação de PCR uma sensibilidade analítica de $10^{-0,7}$, enquanto que na amostra de EEEV, de $10^{-1,7}$. Com relação à reação de hemi-nested de cada vírus padrão, a sensibilidade analítica foi de $10^{-1,7}$ (Figuras 4,5 e 6 ). 


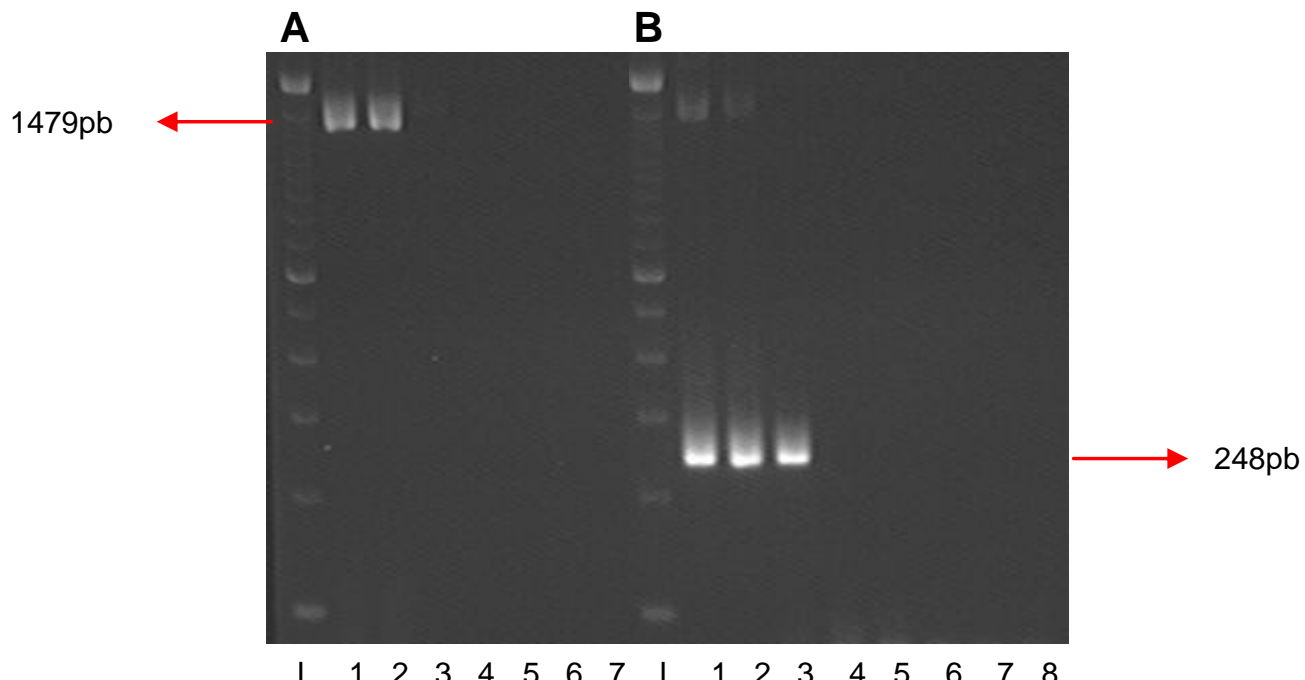

Legenda: A. PCR: primers $21 \mathrm{G}$ e 304 . L- marcador molecular de $100 \mathrm{pb} ; 1$ - SNC de camundongo; $2-10^{-0,7} ; 3-10^{-1,7} ; 4-10^{-2,7}$; $5-10^{-3,7} ; 6-10^{-4,7} ; 7-\mathrm{H}_{2} \mathrm{O}$. B. Hemi-nested: primers 504 e 304 . Lmarcador molecular de 100pb; 1 - SNC de camundongo; 2- 10 ${ }^{0,7}$; 3- $10^{-1,7}$; 4- $\mathrm{H}_{2} \mathrm{O}-1$; $5-10^{-2,7} ; 6-10^{-3,7} ; 7-10^{-4,7} ; 8-\mathrm{H}_{2} \mathrm{O}$.

Figura 4 - Eletroforese em gel de agarose a 2\% corado com brometo de etídeo, referente ao teste de limiar de detecção para CVS, pela técnica de hemi-nested RT-PCR

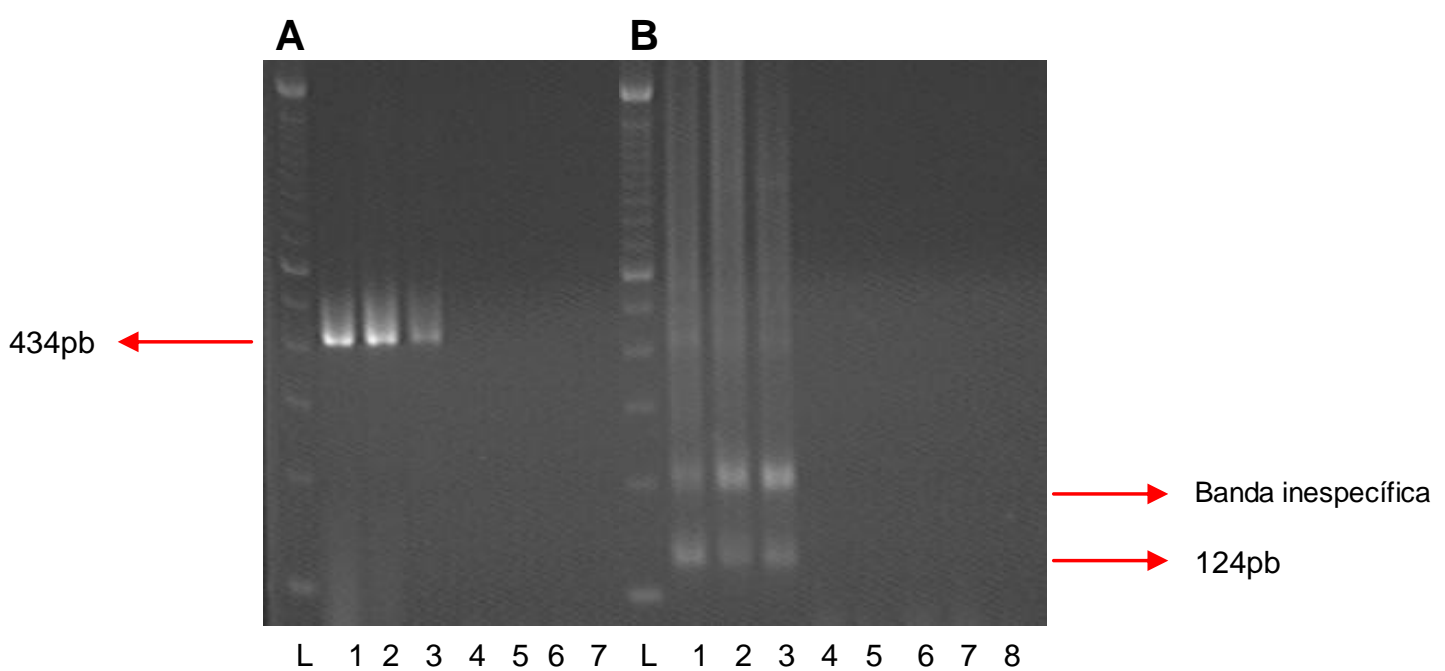

Legenda: A. PCR: primers CM3W e M2W. L- marcador molecular de $100 \mathrm{pb} ; 1$ - SNC de camundongo; $2-10^{-0,7} ; 3-10^{-1,7} ; 4-10^{-2,7} ; 5-$ $10^{-3,7} ; 6-10^{-4,7} ; 7-\mathrm{H}_{2} \mathrm{O}$. B. Hemi-nested: primers cM3W e nEEEV.

L- marcador molecular de 100pb; 1- SNC de camundongo; 2- 10-

0,7 ; $-10^{-1,7} ; 4-\mathrm{H}_{2} \mathrm{O}-1 ; 5-10^{-2,7} ; 6-10^{-3,7} ; 7-10^{-4,7} ; 8-\mathrm{H}_{2} \mathrm{O}$.

Figura 5 - Eletroforese em gel de agarose a 2\% corado com brometo de etídeo, referente ao teste de limiar de detecção para EEEV, pela técnica de hemi-nested RT-PCR 


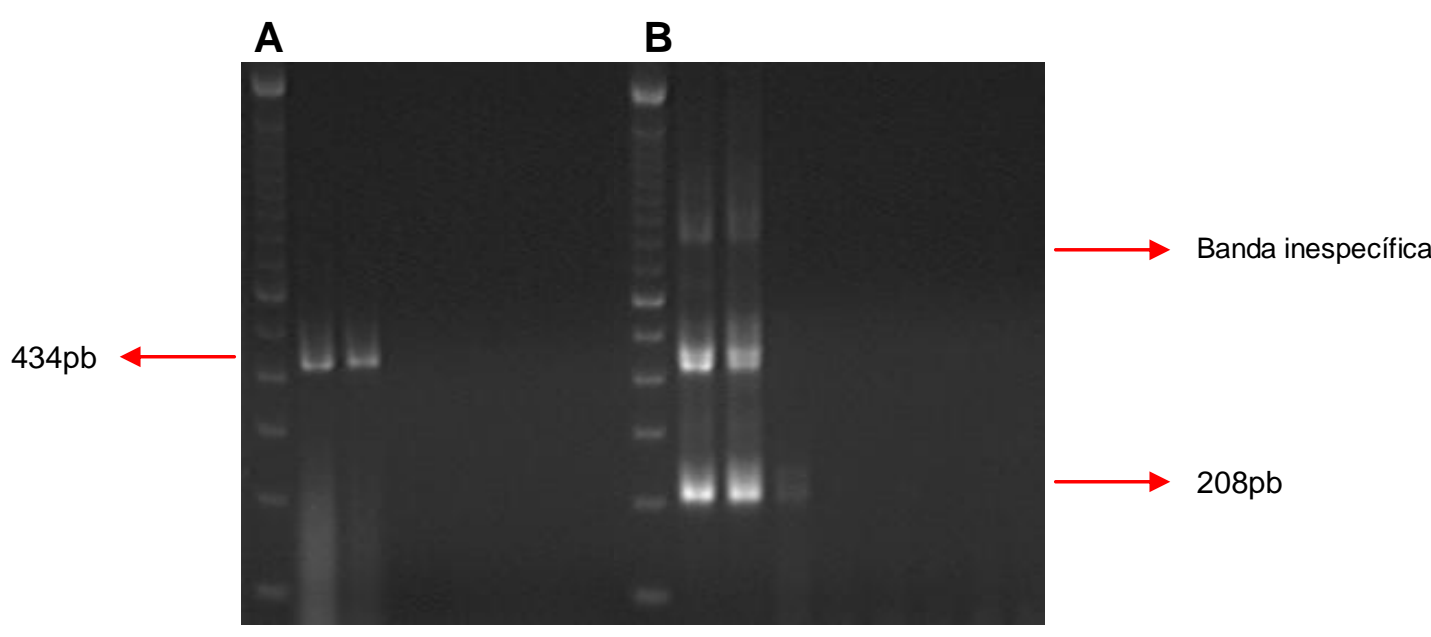

$\begin{array}{lllllllllllllllll}\mathrm{L} & 1 & 2 & 3 & 4 & 5 & 6 & 7 & \mathrm{~L} & 1 & 2 & 3 & 4 & 5 & 6 & 7 & 8\end{array}$

Legenda: A. PCR: primers $\mathrm{CM} 3 \mathrm{~W}$ e M2W. L- marcador molecular de $100 \mathrm{pb} ; 1-$ SNC de camundongo; $2-10^{-0,7} ; 3-10^{-1,7}$; 4- $10^{-2,7} ; 5-10^{-3,7} ; 6-10^{-4,7} ; 7-\mathrm{H}_{2} \mathrm{O}$. B. Hemi-nested: primers CM3W e nWEEV. L- marcador molecular de 100pb; 1 - SNC de camundongo; $2-10^{-0,7} ; 3-10^{-1,7} ; 4-\mathrm{H}_{2} \mathrm{O}-1 ; 5-10^{-2,7} ; 6-10^{-3,7} ; 7-$ $10^{-4,7} ; 8-\mathrm{H}_{2} \mathrm{O}$.

Figura 6 - Eletroforese em gel de agarose a $2 \%$ corado com brometo de etídeo, referente ao teste de limiar de detecção para WEEV, pela técnica de hemi-nested RT-PCR

\subsubsection{Amostra Contendo os Três Vírus Padrão}

No teste de limiar de detecção aplicada nas diluições contendo os três RNAs virais, a sensibilidade analítica nas três reações de hemi-nested, cada qual com o conjunto de primers para o respectivo vírus, foi de $10^{-1,7}$. Observa-se, ainda, que em cada reação de hemi-nested, foi possível observar a banda esperada. (Figuras 7, 8 e 9). 


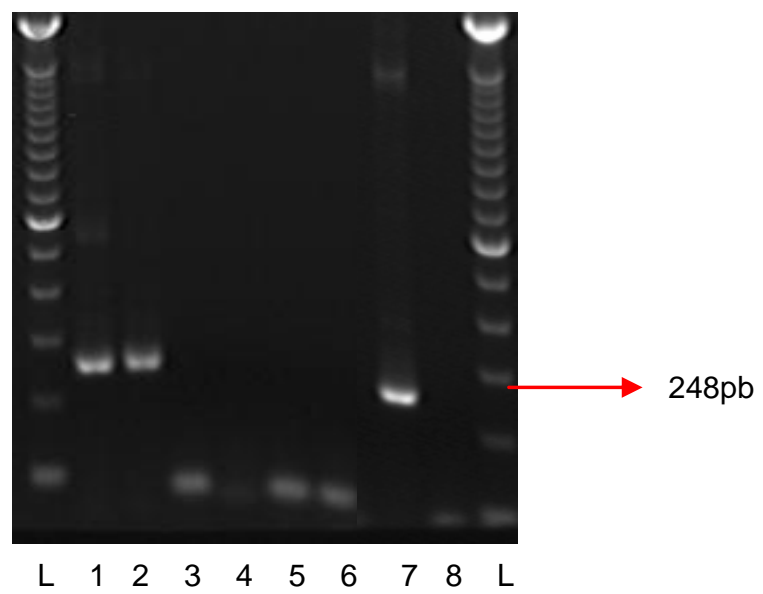

Legenda: L- marcador molecular de 100pb; $1-10^{-0,7} ; 2-10^{-1,7} ; 3-$ $10^{-2,7}$;4- H2O; 5- $10^{-3,7}$; 6- $10^{-4,7} ; 7$ - SNC de camundongo; 8$\mathrm{H}_{2} \mathrm{O}$; L- marcador molecular de $100 \mathrm{pb}$.

Figura 7 - Eletroforese em gel de agarose a $2 \%$ corado com brometo de etídeo, referente ao teste de limiar de detecção em amostras contendo os três RNAs virais, pela técnica de hemi-nested RT-PCR, utilizando primers 504 e 304

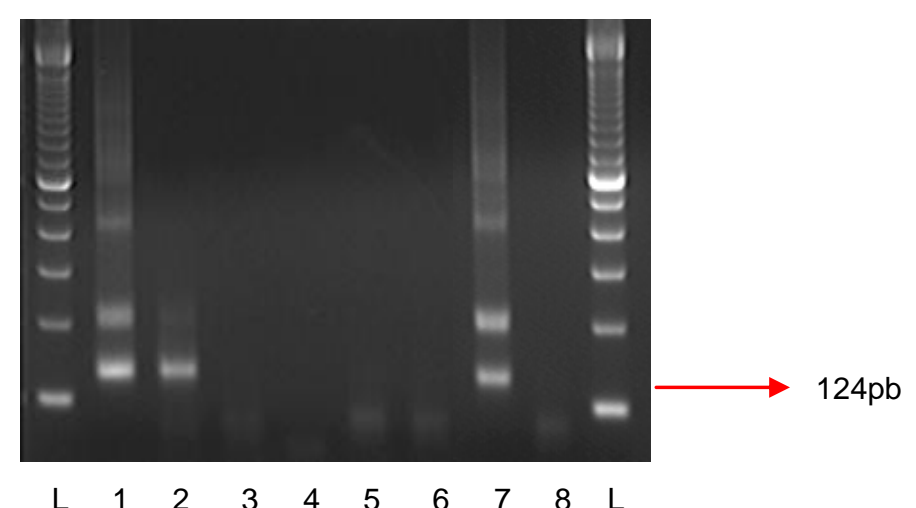

Legenda: L- marcador molecular de $100 \mathrm{pb} ; 1-10^{-0,7} ; 2-10^{-1,7} ; 3-$ $10^{-2,7}$;4- H2O; 5- $10^{-3,7}$; 6- $10^{-4,7}$; 7- SNC de camundongo; 8$\mathrm{H}_{2} \mathrm{O}$; L- marcador molecular de 100pb.

Figura 8 - Eletroforese em gel de agarose a 2\% corado com brometo de etídeo, referente ao teste de limiar de detecção em amostras contendo os três RNAs virais, pela técnica de hemi-nested RT-PCR, utilizando primers nEEE e cM3W 


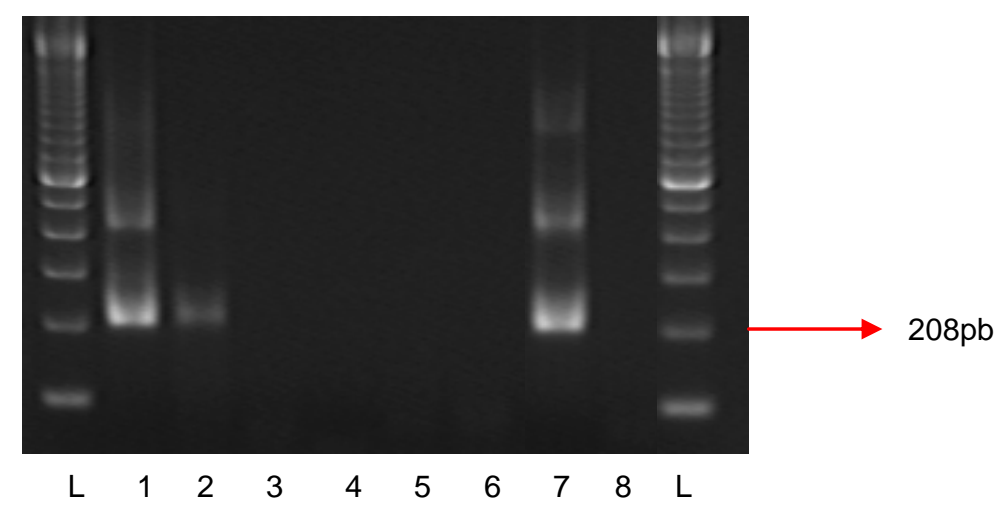

Legenda: L- marcador molecular de $100 \mathrm{pb} ; 1-10^{-0,7} ; 2-10^{-1,7} ; 3-$ $10^{-2,7} ; 4-\mathrm{H} 2 \mathrm{O} ; 5-10^{-3,7}$; 6- $10^{-4,7}$; 7- SNC de camundongo; 8- $\mathrm{H}_{2} \mathrm{O}$; L- marcador molecular de 100pb.

Figura 9 - Eletroforese em gel de agarose a $2 \%$ corado com brometo de etídeo, referente ao teste de limiar de detecção em diluições contendo os três RNAs virais, pela técnica de hemi-nested RT-PCR, utilizando primers nWEE e cM3W

\subsubsection{Aplicação da Técnica de Hemi-Nested RT-PCR em Amostras de Campo}

Das 18 amostras positivas para raiva, seis $(33,3 \%)$ apresentaram a banda esperada de $1479 \mathrm{pb}$ na primeira amplificação, como se observa na figura 10 (5790/08, 6875/08, 7955/08, 9146/08, 10252/08) e na figura 11 (4833/09). Contudo, a intensidade do fragmento da amostra 5790/08 foi baixa, o que dificultou a sua visualização na foto.

Após a segunda amplificação (Figura 8), em que se utilizou a técnica de hemi-nested, o fragmento esperado de 248pb foi observado em 17 (94,4\%) (Figuras 12 e 13), sendo que apenas a amostra 6347/08 não apresentou o sinal tanto na primeira (Figura 7) quanto na segunda amplificação (Figura 8). Desta forma, foi realizada repetição da extração e da hemi-nested RT-PCR da amostra 6347/08, que novamente apresentou resultado negativo. 


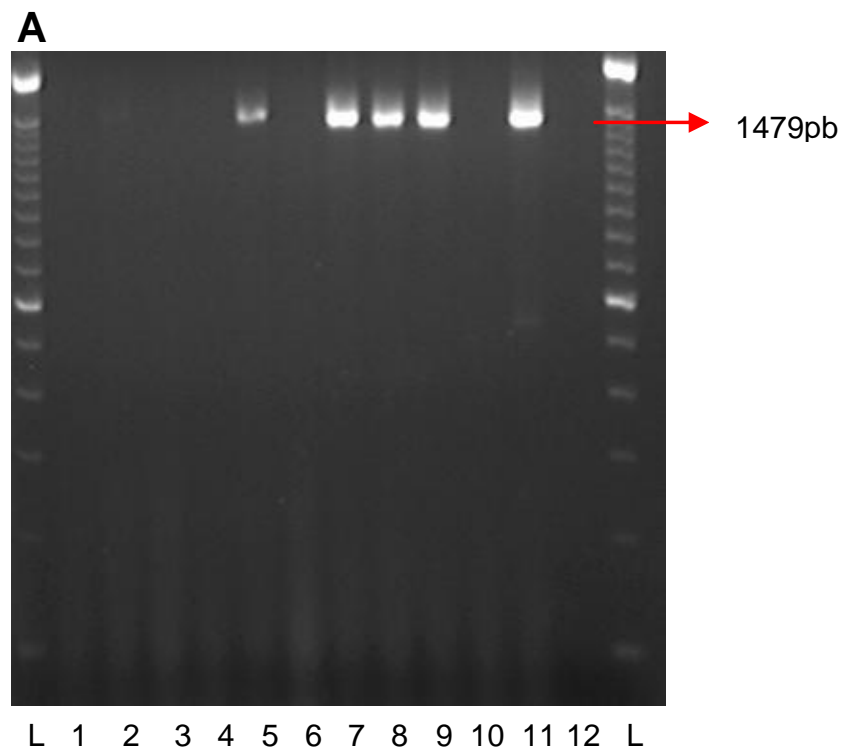

Legenda: A. L- marcador molecular de 100pb; 1- 5037/08; 2 5790/08; 3- 6342/08; 4- 6347/08; 5- 6875/08; 6- 7191/08; 77955/08; 8- 9146/08; 9-10252/08; 10- 10542/08; 11- CVS; 12$\mathrm{H}_{2} \mathrm{O}$.

Figura 10 - Eletroforese em gel de agarose a $2 \%$ corado com brometo de etídeo, referente à aplicação da ténica de RT-PCR em amostras de campo positivas para RABV (A)

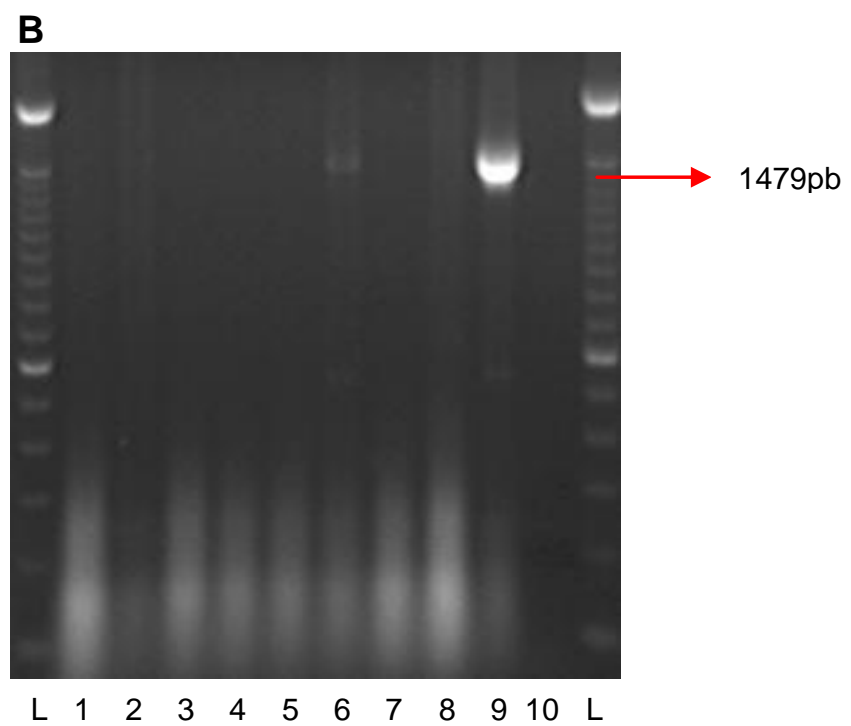

Legenda: B. L- marcador molecular de 100pb; 1- 11075/08; 211231/08; 3- 11450/08; 4- 704/09; 5- 1532/09; 6- 4833/09; 75176/09; 8- 7242/09; 9-CVS; 10- $\mathrm{H} 2 \mathrm{O} \mathrm{H}_{2} \mathrm{O}$.

Figura 11 - Eletroforese em gel de agarose a $2 \%$ corado com brometo de etídeo, referente à aplicação da ténica de RT-PCR em amostras de campo positivas para RABV (B) 


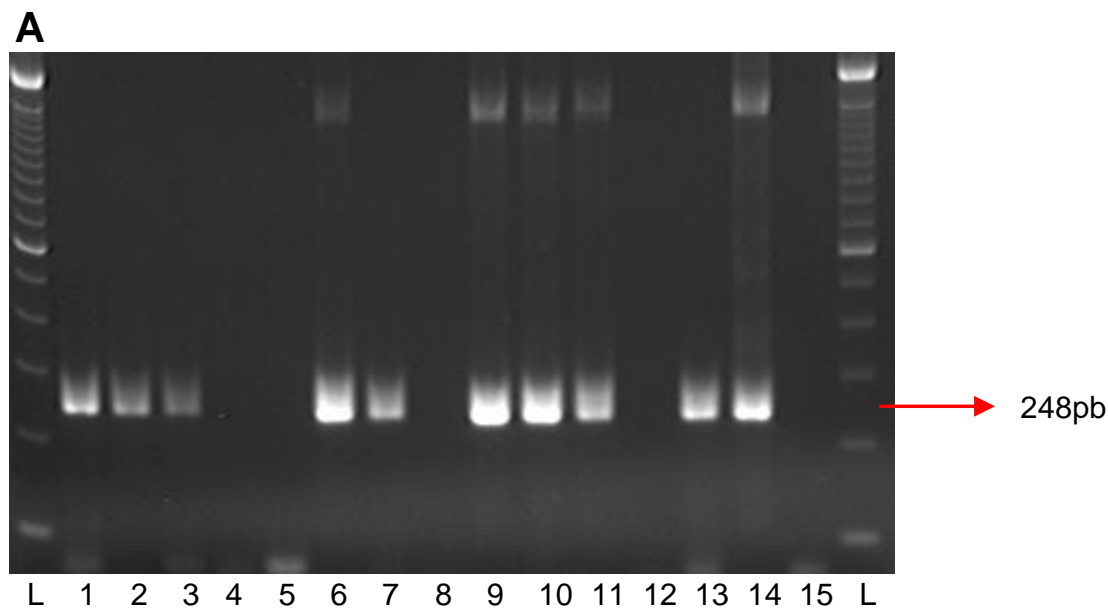

Legenda: A. L- marcador molecular de $100 \mathrm{pb} ; 1$ - 5037/08; 2- 5790/08; 3 6342/08; 4- $\mathrm{H}_{2} \mathrm{O}-1$; 5- 6347/08; 6- 6875/08; 7- 7191/08; 8- $\mathrm{H}_{2} \mathrm{O}-2$; 9- 7955/08; 10- 9146/08; 11-10252/08; 12- $\mathrm{H}_{2} \mathrm{O}-3$; 13- 10542/08; 14- CVS; 15- $\mathrm{H}_{2} \mathrm{O}$.

Figura 12 - Eletroforese em gel de agarose a $2 \%$ corado com brometo de etídeo, referente à aplicação da ténica de hemi-nested em amostras de campo positivas para RABV (A)

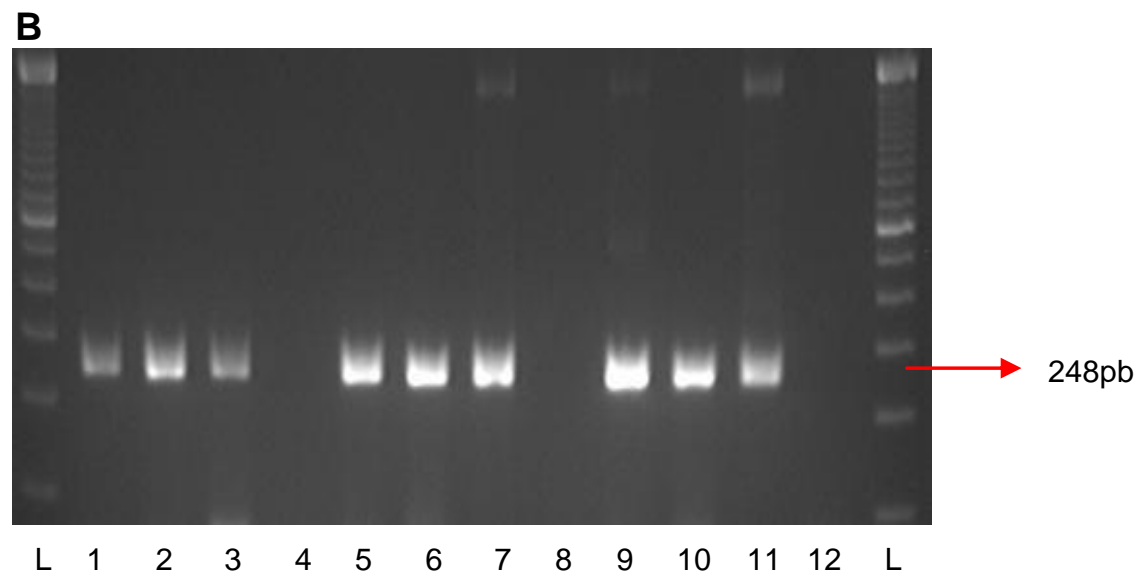

Legenda: B. L- marcador molecular de 100pb; 1- 11075/08; 2- 11231/08; 311450/08; 4- $\mathrm{H}_{2} \mathrm{O}-1$; 5- 704/09; 6- 1532/09; 7- 4833/09; 8- $\mathrm{H}_{2} \mathrm{O}-2$; 9- 5176/09; 10- 7242/09; 11 - CVS; $12-\mathrm{H}_{2} \mathrm{O}$.

Figura 13 - Eletroforese em gel de agarose a $2 \%$ corado com brometo de etídeo, referente à aplicação da técnica de hemi-nested em amostras de campo positivas para $\operatorname{RABV}(\mathrm{B})$ 
Com relação às amostras positivas para EEEV, das 15 amostras testadas, 2 $(13,3 \%)$ apresentaram a banda esperada de $434 \mathrm{pb}$, as amostras $4084 / 09$ e a 3500/09. Esta, porém, apresentou uma intensidade de brilho muito fraca, como pode ser observado na figura 14. Contudo, após a segunda amplificação, todas as 15 amostras (100\%) apresentaram o fragmento esperado de 124 pb (Figuras 15 e 16).

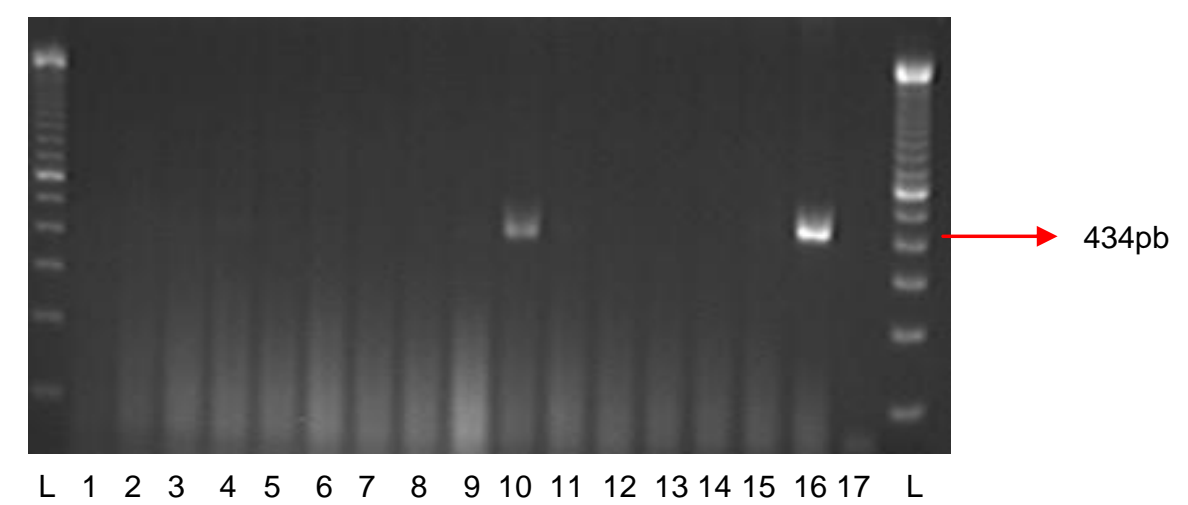

Legenda: L- marcador molecular de 100pb; 1- 5032/08; 2- 2572/09; 3$3499 / 09$; 4- 3500/09; 5- 3501/09; 6- 3723/09; 7- 3724/09; 8- 3725/09; 9 3726/09; 10- 4084/09; 11 - 4085/09; 12- 4239/09; 13- 4240/09; 14- 5691/09; 15 6009/09; 16- EEEV; $17-\mathrm{H}_{2} \mathrm{O}$.

Figura 14 - Eletroforese em gel de agarose a $2 \%$ corado com brometo de etídeo, referente à aplicação da ténica de RT-PCR em amostras de campo positivas para EEEV

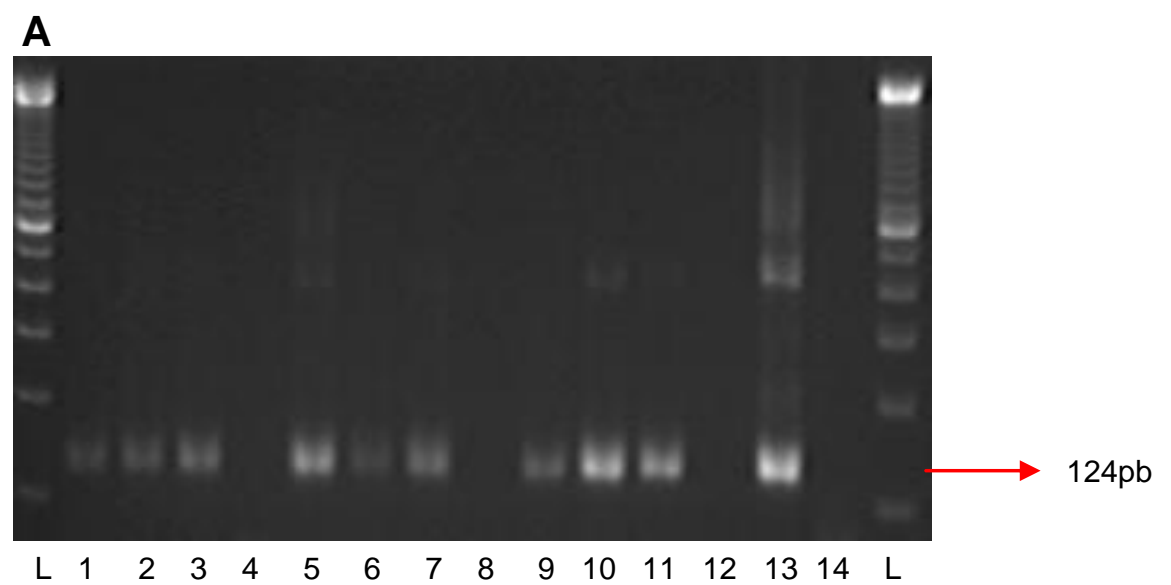

Legenda: A. L- marcador molecular de $100 \mathrm{pb} ; 1-5032 / 08$; 2- 2572/09; 3 3499/09; 4- $\mathrm{H}_{2} \mathrm{O}-1$; 5- 3500/09; 6- 3501/09; 7- 3723/09; 8- $\mathrm{H}_{2} \mathrm{O}-2$; 9- 3724/09; 10-3725/09; $11-3726 / 09 ; 12-\mathrm{H}_{2} \mathrm{O}-3$; 13- EEEV; $14-\mathrm{H}_{2} \mathrm{O}$.

Figura 15 - Eletroforese em gel de agarose a $2 \%$ corado com brometo de etídeo, referente à aplicação da ténica de hemi-nested em amostras de campo positivas para EEEV (A) 
B

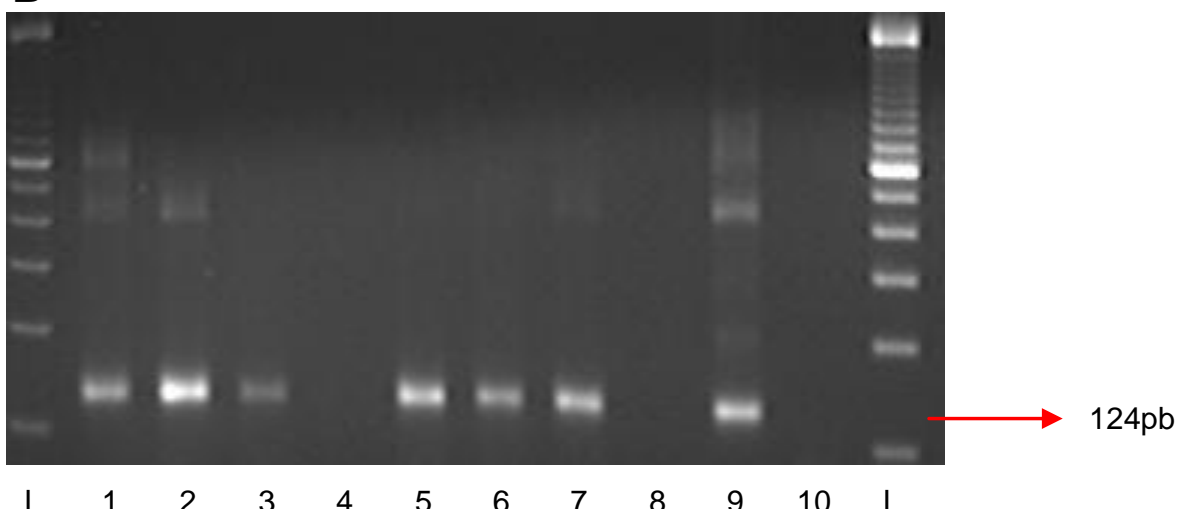

Legenda: B. L- marcador molecular de $100 \mathrm{pb} ; 1$ - 4084/09; 2- 4085/09; 3 4239/09; 4- $\mathrm{H}_{2} \mathrm{O}-1$; 5- 4240/09; 6- 5691/09; 7- 6009/09; 8- $\mathrm{H}_{2} \mathrm{O}-2$; 9- EEEV; 10$\mathrm{H}_{2} \mathrm{O}$.

Figura 16 - Eletroforese em gel de agarose a $2 \%$ corado com brometo de etídeo, referente à aplicação da ténica de hemi-nested em amostras de campo positivas para EEEV (B)

\subsubsection{Sequenciamento Genético}

O sequenciamento genético dos fragmentos esperados amplificados na reação de hemi-nested, tanto das amostras de cada vírus padrão quanto das amostras contendo os três vírus padrão, e das amostras de campo confirmou a identificação dos mesmos pelo aplicativo BLAST/n.

As bandas inespecíficas observadas nas amostras de vírus padrão de EEEV (Figura 5) e WEEV (Figura 6) foram também sequenciadas, sendo as mesmas identificadas como EEEV e WEEV, respectivamente.

\subsection{REAÇÃO DE MULTIPLEX HEMI-NESTED RT-PCR}

Serão apresentados, a seguir, os resultados obtidos nos testes para a adequação da técnica de multiplex hemi-nested RT-PCR. 


\subsubsection{Testes com Diferentes Protocolos para a Técnica de Multiplex Hemi- Nested RT-PCR}

Nos itens a seguir, serão apresentados os resultados da primeira amplificação e da segunda amplificação dos testes com diferentes protocolos da técnica multiplex hemi-nested RT-PCR, além do protocolo estabelecido para esse estudo.

\subsubsection{Primeira Amplificação}

Dos três protocolos testados para a primeira amplificação, apresentados no quadro 7 , o que apresentou o melhor resultado foi o protocolo 3 , sendo este 0 protocolo escolhido. Com a aplicação dos protocolos 1 e 2, não foi possível visualizar a banda de 434pb na amostra de campo 4084/09. No entanto, com o protocolo 3, essa banda foi observada (Figura 17).

Com relação às amostras 7955/08, CVS, EEEV, WEEV e diluição $10^{-0,7}$ de WEEV, foi possível observar a banda esperada nos três protocolos aplicados.

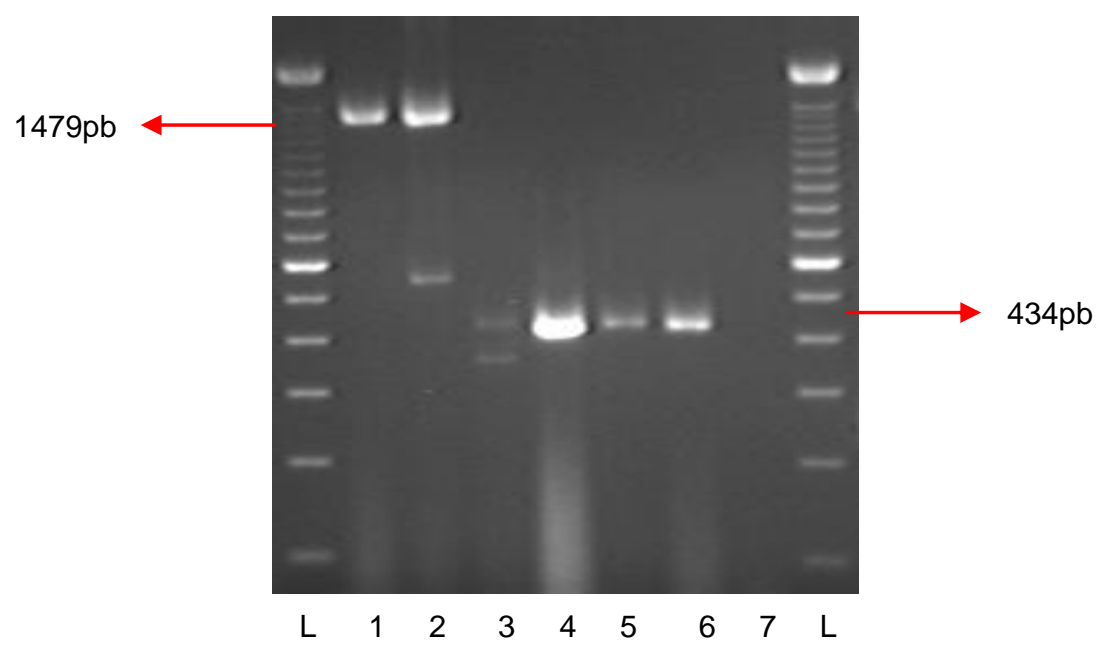

Legenda: L- marcador molecular de 100pb; 1- 7955/08; 2- CVS;

3- 4084/09; 4- EEEV; 5- WEEV 10-0,7; 6- WEEV; $7-\mathrm{H}_{2} \mathrm{O}$.

Figura 17 - Eletroforese em gel de agarose a $2 \%$ corado com brometo de etídeo, referente à aplicação da ténica de multiplex RT-PCR em amostras de campo e vírus padrão 


\subsubsection{Segunda Amplificação}

Na segunda amplificação (multiplex hemi-nested RT-PCR), o protocolo eleito por apresentar o melhor resultado foi o número 5 , cuja descrição encontra-se no quadro 8. Na figura 18, observa-se o resultado da eletroforese, em que é possível observar que as bandas referentes às amostras 4084/09 e EEEV são visualizadas, porém apresentam uma intensidade de brilho menos nítida em relação às amostras positivas para RABV e para WEEV. Esse mesmo protocolo foi testado acrescentando-se $5 \mu \mathrm{L}$ de c-DNA, porém, o protocolo em que foram acrescentados $10 \mu \mathrm{L}$ apresentou um resultado melhor.

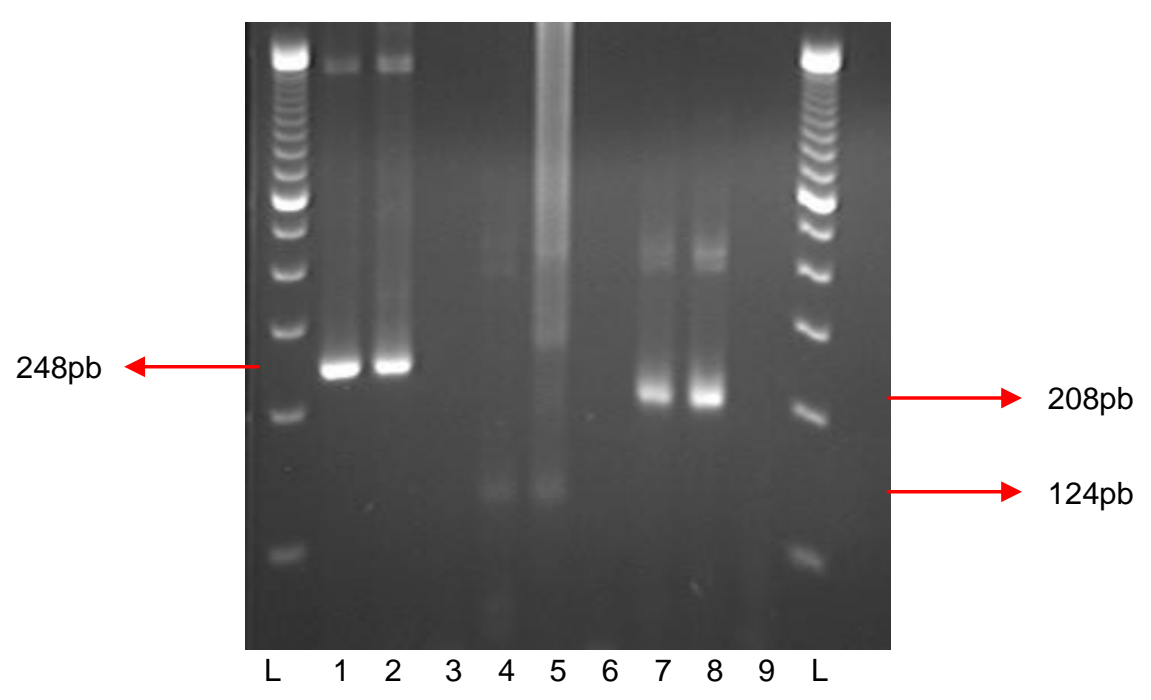

Legenda: L- marcador molecular de 100pb; 1 - 7955/08; 2- CVS; 3- $\mathrm{H}_{2} \mathrm{O}-1$; 4- 4084/09; 5- EEEV; 6- $\mathrm{H}_{2} \mathrm{O}-2$; 7- WEEV 10,7 ; 8 WEEV; $9-\mathrm{H}_{2} \mathrm{O}$.

Figura 18 - Eletroforese em gel de agarose a $2 \%$ corado com brometo de etídeo, referente à aplicação da ténica de multiplex hemi-nested RT-PCR em amostras de campo e vírus padrão

Nos protocolos de 1 a 3, não houve a formação da banda esperada na amostra 4084/09, enquanto que no protocolo 4 , houve a formação, porém com baixa intensidade de brilho. Nos protocolos de 6 a 10 (Quadro 8), foi utilizada uma concentração alta do primer nEEEV $(1,0 \mu \mathrm{M})$, além de serem testadas as alterações na concentração de dNTP e magnésio $\left(\mathrm{Mg}^{2+}\right)$. Foi verificado um incremento na 
intensidade de brilho das bandas referentes às amostras 4084/09 em relação ao protocolo 5, principalmente quando acrescentado $\circ \mathrm{Mg}^{2+}$ na concentração de 4,0 $\mu \mathrm{M}$ (protocolo 10). Porém, nesse mesmo protocolo, não foi possível a observação da banda esperada no controle positivo de EEEV, sendo possível visualizar somente sua banda inespecífica (aproximadamente $300 \mathrm{pb}$ ), que por sua vez também apresentou uma intensidade de brilho ainda mais intensa.

Vale ressaltar que em todos os protocolos testados e descritos no quadro 8, as amostras 7955/08, CVS, WEEV na diluição $10^{-0,7}$ e WEEV apresentaram bandas com uma forte intensidade de brilho.

Sendo assim, o protocolo final da reação de multiplex hemi-nested RT-PCR ficou estabelecido da seguinte forma:

- Transcrição Reversa: 1X First Strand Buffer, 0,1mM de dithiothreitol (DTT), $1 \mu \mathrm{M}$ de primer $21 \mathrm{G}, 1 \mu \mathrm{M}$ de primer $\mathrm{CM} 3 \mathrm{~W}, 1 \mathrm{mM}$ de cada dNTP (trifostato de desoxinucleosídeo), 200U da enzima SuperScript ${ }^{\circledR}$ || RT (Invitrogen ${ }^{\circledR}$ ), $7 \mu \mathrm{L}$ de RNA extraído, totalizando um volume de $20 \mu \mathrm{L}$.

- Primeira Amplificação: 1x PCR Buffer (Invitrogen ${ }^{\circledR}$ ), 0,2mM de cada dNTP, $0,3 \mu \mathrm{M}$ de primer $21 \mathrm{G}$ e $304,0,7 \mu \mathrm{M}$ de primer M2W e cM3W, $2 \mathrm{mM}$ de $\mathrm{MgCl}_{2}, 2,5 \mathrm{U}$ de Taq DNA polimerase $\left(\right.$ Invitrogen $\left.^{\circledR}\right), 5 \mu \mathrm{L}$ de cDNA e água UltraPure ${ }^{\circledR}\left(\right.$ Invitrogen $\left.^{\circledR}\right)$ para um volume final de $50 \mu \mathrm{L}$.

- Segunda Amplificação: 1x PCR Buffer (Invitrogen $\left.{ }^{\circledR}\right), 0,2 \mathrm{mM}$ de cada

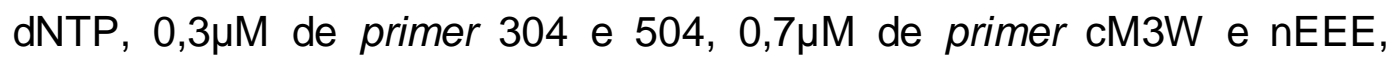
$0,5 \mu \mathrm{M}$ de primer nWEE, $2 \mathrm{mM}$ de $\mathrm{MgCl}_{2}, 2,5 \mathrm{U}$ de Taq DNA polimerase $\left(\right.$ Invitrogen $\left.^{\circledR}\right), 10 \mu \mathrm{L}$ de cDNA e água UltraPure ${ }^{\circledR}\left(\right.$ Invitrogen $\left.^{\circledR}\right)$ para um volume final de $100 \mu \mathrm{L}$. 


\subsubsection{Determinação do Limiar de Detecção}

A seguir, serão apresentados os resultados obtidos nos testes de limiar de deteção realizado pela técnica de multiplex hemi-nested RT-PCR.

\subsubsection{Amostras de Vírus Padrão}

No teste de limiar de detecção, nas amostras de CVS e de WEEV observouse na reação de multiplex PCR uma sensibilidade analítica de $10^{-0,7}$, enquanto que na amostra de EEEV, de $10^{-1,7}$. Com relação à reação de multiplex hemi-nested de cada vírus padrão, a sensibilidade analítica foi de 10 1,7 (Figuras 19, 20 e 21).

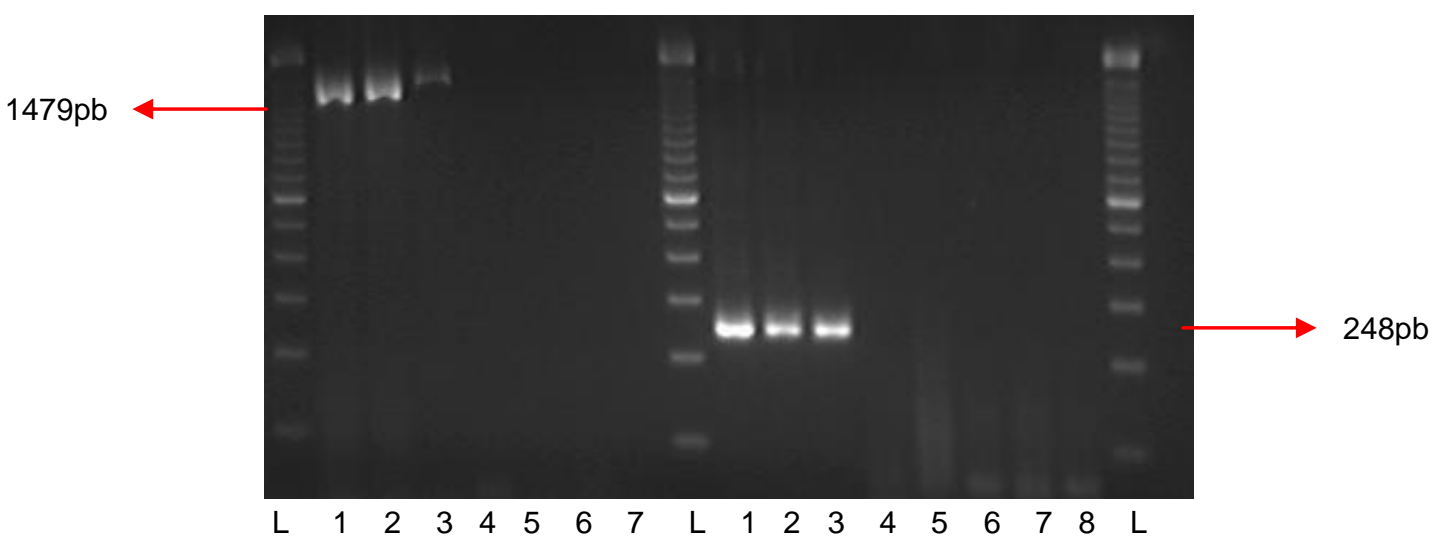

Legenda: A. PCR. L- marcador molecular de 100pb; 1- SNC de camundongo; 2- $10^{-0,7}$; 3- $10^{-1,7}$; 4- $10^{-2,7}$;5- $10^{-3,7} ; 6-10^{-4,7} ; 7-\mathrm{H}_{2} \mathrm{O}$. B. Hemi-nested. Lmarcador molecular de $100 \mathrm{pb} ; 1$ - SNC de camundongo; $2-10^{-0,7} ; 3-10^{-1,7} ; 4$ $\mathrm{H}_{2} \mathrm{O}-1 ; 5-10^{-2,7} ; 6-10^{-3,7} ; 7-10^{-4,7} ; 8-\mathrm{H}_{2} \mathrm{O}$.

Figura 19 - Eletroforese em gel de agarose a $2 \%$ corado com brometo de etídeo, referente ao teste de limiar de detecção para CVS, pela técnica de multiplex hemi-nested RT-PCR 


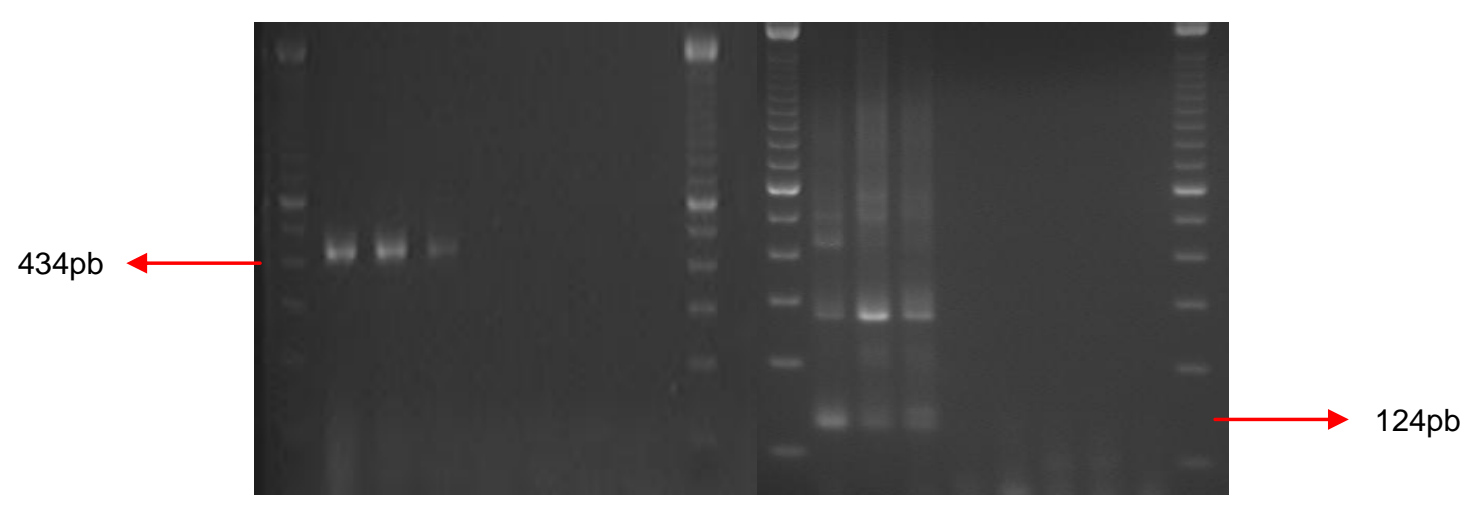

$\begin{array}{llllllllllllllllllll}\mathrm{L} & 1 & 2 & 3 & 4 & 5 & 6 & 7 & \mathrm{~L} & \mathrm{~L} & 1 & 2 & 3 & 4 & 5 & 6 & 7 & 8 & \mathrm{~L}\end{array}$

Legenda: A. PCR. L- marcador molecular de 100pb; 1 - SNC de camundongo; 2- $10^{-0,7} ; 3-10^{-1,7} ; 4-10^{-2,7} ; 5-10^{-3,7} ; 6-10^{-4,7} ; 7-\mathrm{H}_{2} \mathrm{O}$. B. Hemi-nested. Lmarcador molecular de $100 \mathrm{pb} ; 1$ - SNC de camundongo; 2- $10^{-0,7} ; 3-10^{-1,7} ; 4-$ $\mathrm{H}_{2} \mathrm{O}-1 ; 5-10^{-2,7} ; 6-10^{-3,7} ; 7-10^{-4,7} ; 8-\mathrm{H}_{2} \mathrm{O}$.

Figura 20 - Eletroforese em gel de agarose a $2 \%$ corado com brometo de etídeo, referente ao teste de limiar de detecção para EEEV, pela técnica de multiplex hemi-nested RT-PCR

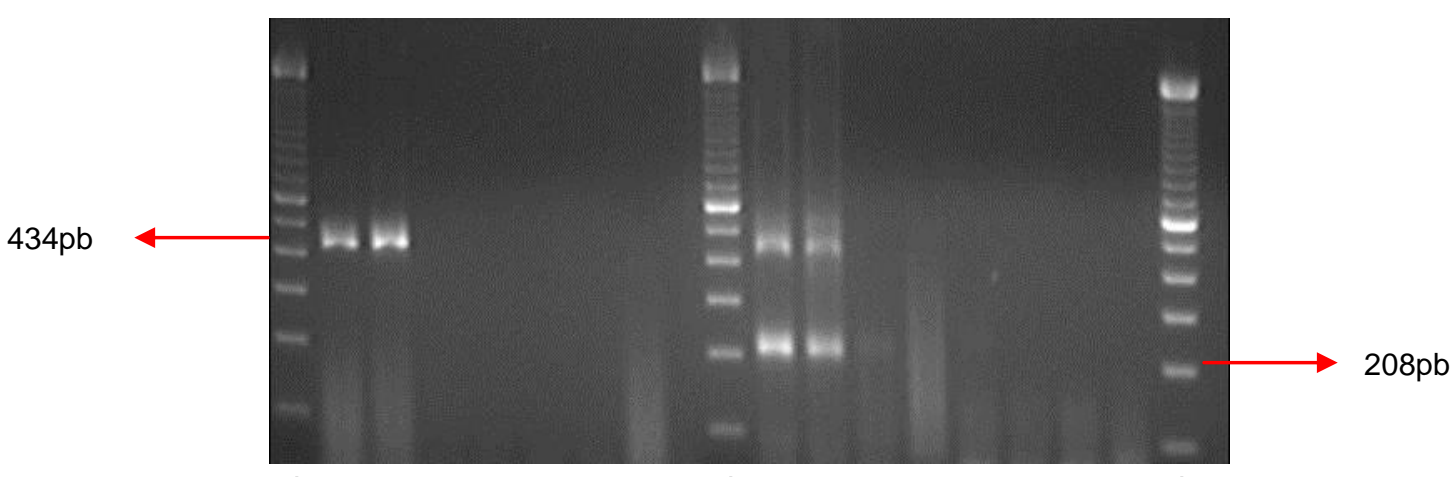

$\begin{array}{llllllllllllllllll}\mathrm{L} & 1 & 2 & 3 & 4 & 5 & 6 & 7 & \mathrm{~L} & 1 & 2 & 3 & 4 & 5 & 6 & 7 & 8 & \mathrm{~L}\end{array}$

Legenda: A. PCR. L- marcador molecular de 100pb; 1 - SNC de camundongo; 2- $10^{-0,7} ; 3-10^{-1,7} ; 4-10^{-2,7} ; 5-10^{-3,7} ; 6-10^{-4,7} ; 7-\mathrm{H}_{2} \mathrm{O}$. B. Hemi-nested. Lmarcador molecular de $100 \mathrm{pb} ; 1-\mathrm{SNC}$ de camundongo; $2-10^{-0,7} ; 3-10^{-1,7} ; 4$ $\mathrm{H}_{2} \mathrm{O}-1 ; 5-10^{-2,7}$; 6- $10^{-3,7}$; 7- $10^{-4,7}$; 8- $\mathrm{H}_{2} \mathrm{O}$.

Figura 21 - Eletroforese em gel de agarose a $2 \%$ corado com brometo de etídeo, referente ao teste de limiar de deteç̧ão para WEEV, pela técnica de multiplex hemi-nested RT-PCR

\subsubsection{Amostra Contendo os Três Vírus Padrão}

No teste de limiar de detecção aplicada nas diluições contendo os três RNAs virais, a sensibilidade analítica da reação de multiplex hemi-nested RT-PCR 
foi de $10^{-0,7}$ na amostra de WEEV, e de $10^{-1,7}$ nas amostras de CVS e EEEV, sendo que a intensidade do brilho da banda correspondente à EEEV nesta diluição fraca (Figura 22). Vale ressaltar que, nesse teste, foi possível observar a detecção simultânea dos três vírus.

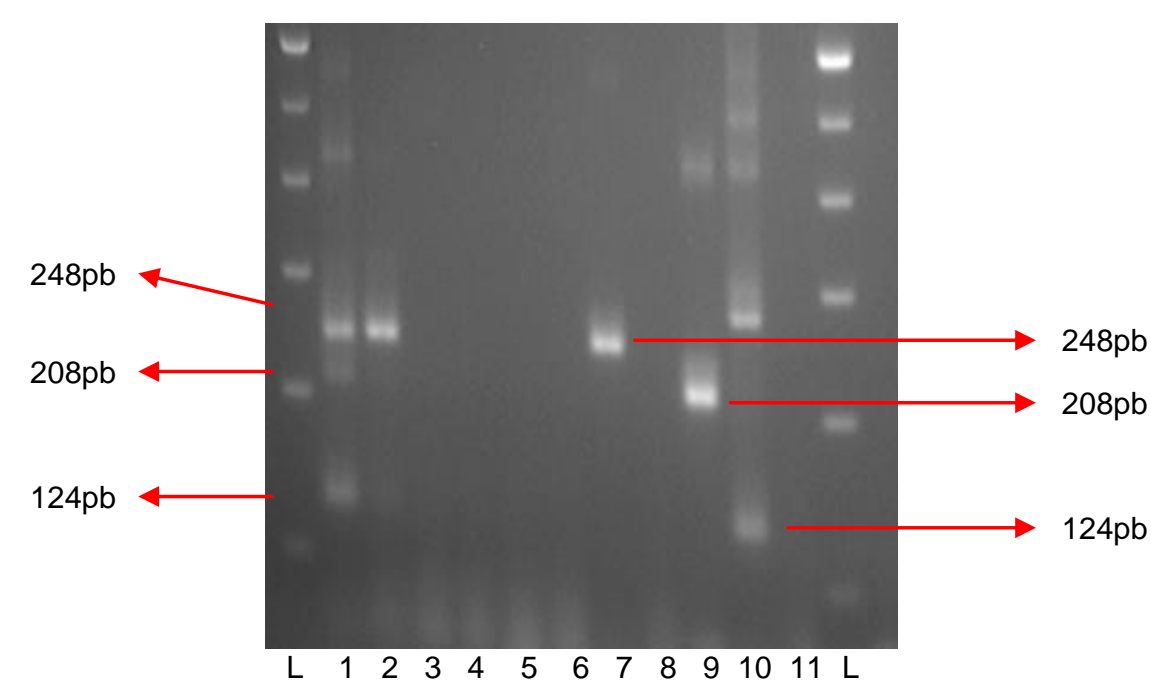

Legenda: L- marcador molecular de 100pb; $1-10^{-0,7} ; 2-10^{-1,7} ; 3-$ $10^{-2,7} ; 4-\mathrm{H} 2 \mathrm{O} ; 5-10^{-3,7} ; 6-10^{-4,7} ; 7$ - CVS; 8- $\mathrm{H}_{2} \mathrm{O}$; 9- WEEV; $10-$ EEEV; 11- H2O; L- marcador molecular de 100pb.

Figura 22 - Eletroforese em gel de agarose a $2 \%$ corado com brometo de etídeo, referente ao teste de limiar de detecção em amostras contendo os três RNAs virais, pela técnica de multiplex hemi-nested RT-PCR

\subsubsection{Aplicação da Técnica de Multiplex Hemi-Nested RT-PCR em Amostras de Campo}

Das 18 amostras positivas para raiva, seis $(33,3 \%)$ apresentaram uma banda de $1479 \mathrm{pb}$ na primeira amplificação, como demonstrado na figura 23 (6875/08, 7955/08, 9146/08, 10252/08) e na figura 24 (11231/08, 4833/09).

Após a segunda amplificação, foi possível visualizar a banda de $248 \mathrm{pb}$ em 16 amostras (88,8\%), não sendo possível, porém, a visualização da mesma banda nas amostras 6342/08 e 6347/08 (Figuras 25 e 26). 


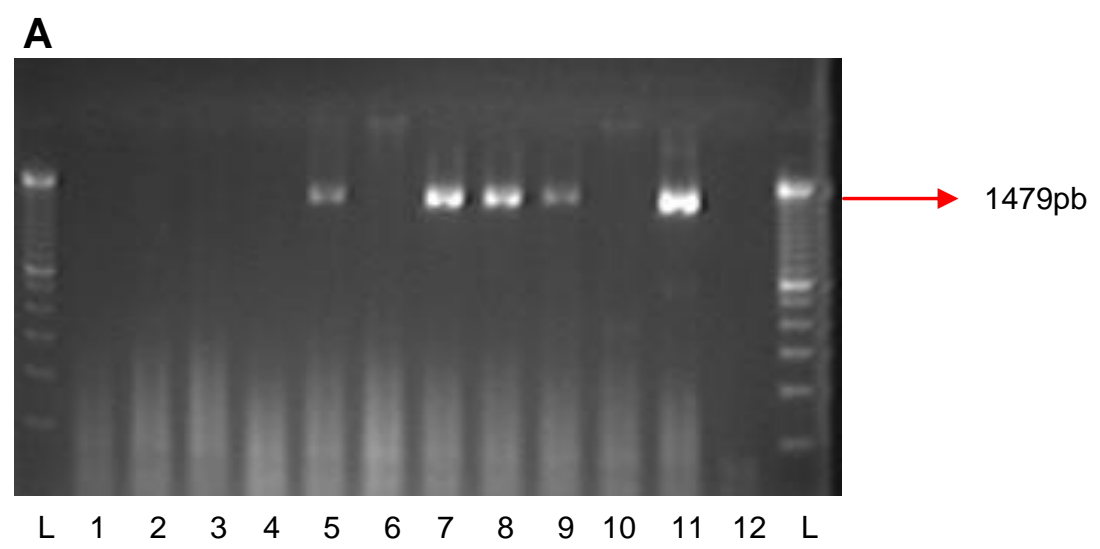

Legenda: A. L- marcador molecular de 100pb; 1 - 5037/08; 2- 5790/08; 3$6342 / 08$; 4- 6347/08; 5- 6875/08; 6- 7191/08; 7- 7955/08; 8- 9146/08; 910252/08; 10- 10542/08; 11-CVS; $12-\mathrm{H}_{2} 0$.

Figura 23 - Eletroforese em gel de agarose a $2 \%$ corado com brometo de etídeo, referente à aplicação da ténica de multiplex RT-PCR em amostras de campo positivas para raiva $(A)$

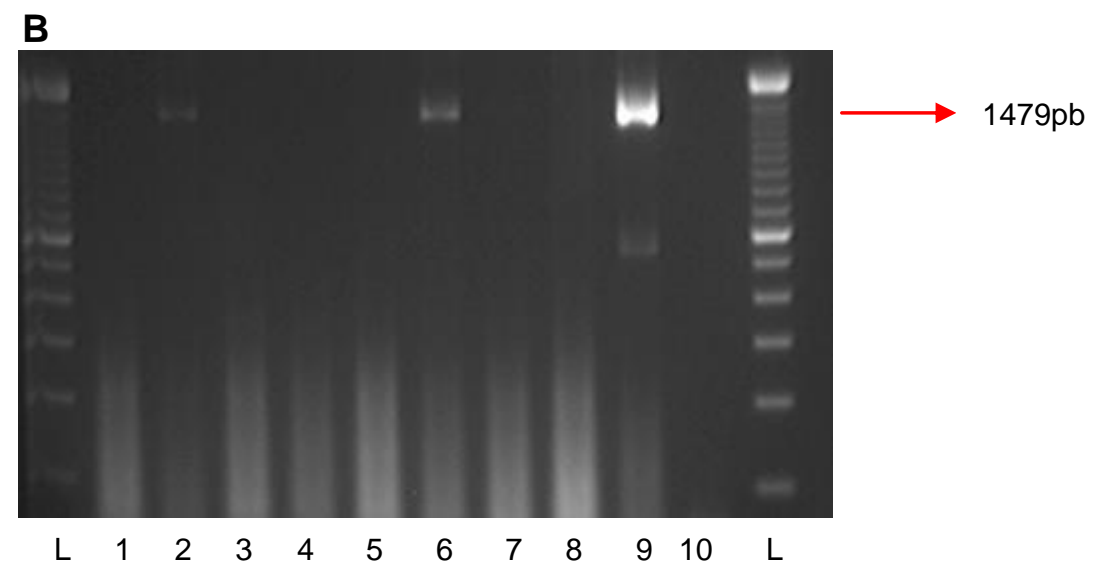

Legenda: B. L- marcador molecular de 100pb; 1- 11075/08; 2- 11231/08; 311450/08; 4- 704/09; 5- 1532/09; 6- 4833/09; 7- 5176/09; 8- 7242/09; 9- CVS; 10- $\mathrm{H}_{2} \mathrm{O}$.

Figura 24 - Eletroforese em gel de agarose a $2 \%$ corado com brometo de etídeo, referente à aplicação da ténica de multiplex RT-PCR em amostras de campo positivas para raiva $(B)$ 


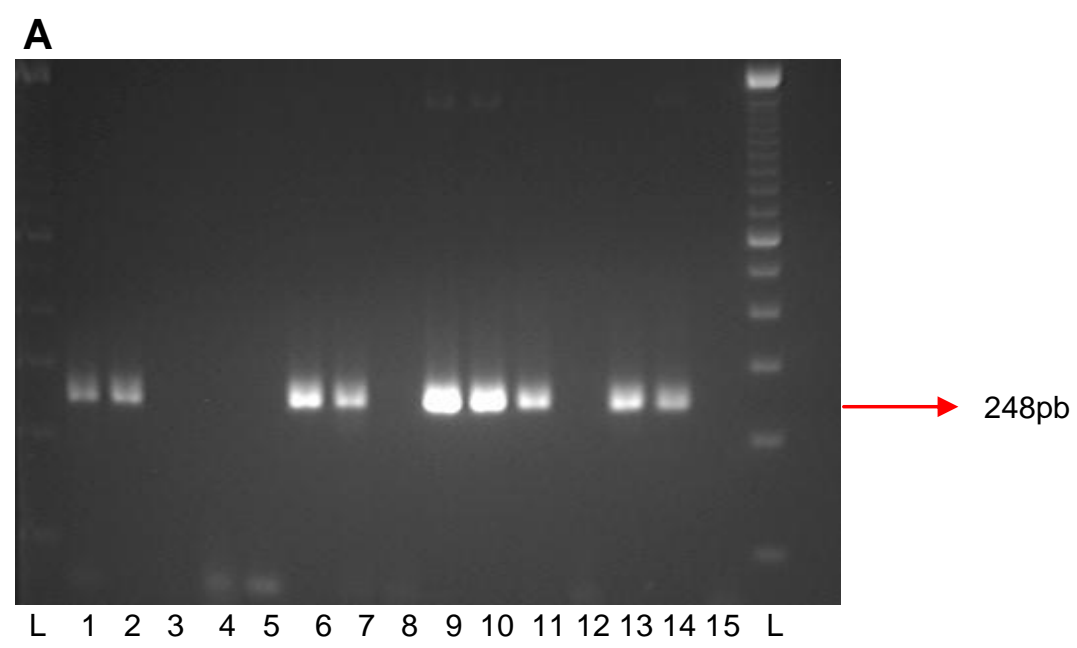

Legenda: A. L- marcador molecular de 100pb; 1 - 5037/08; 2- 5790/08; $3-$ 6342/08;4- $\mathrm{H}_{2} 0-1$; 5- 6347/08; 6- 6875/08; 7- 7191/08; $8-\mathrm{H}_{2} 0-2$; 9- 7955/08; 10- 9146/08; 11- 10252/08; 12- $\mathrm{H}_{2} 0-2$; 13- 10542/08; 14-CVS; 15- $\mathrm{H}_{2} \mathrm{O}$.

Figura 25 - Eletroforese em gel de agarose a $2 \%$ corado com brometo de etídeo, referente à aplicação da ténica de multiplex hemi-nested RT-PCR em amostras de campo positivas para raiva $(A)$

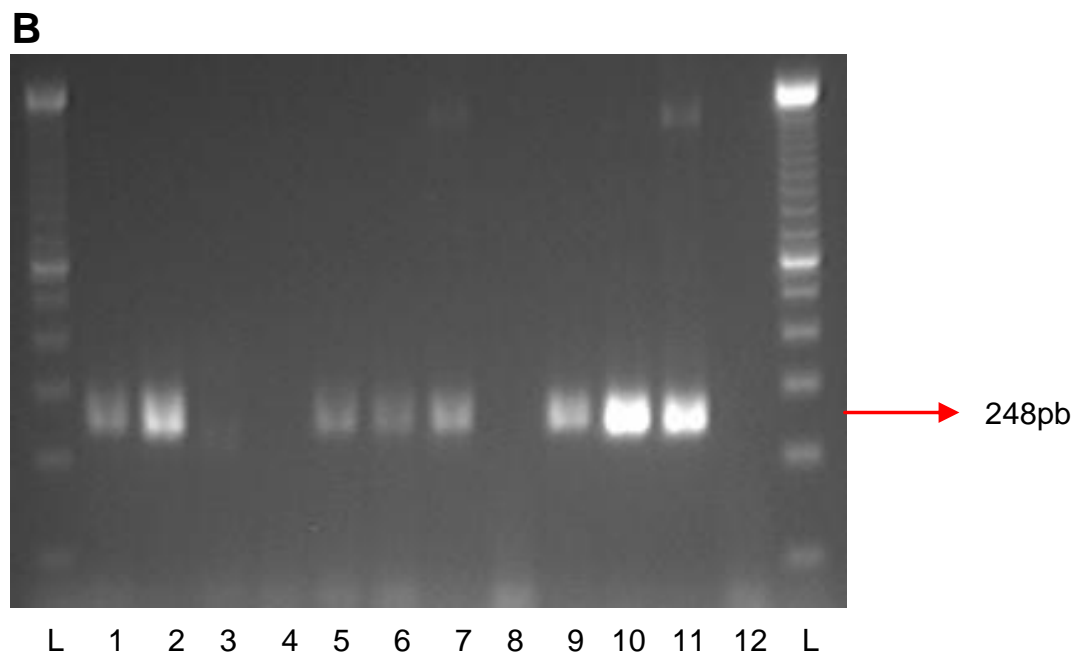

Legenda: B. L- marcador molecular de 100pb; 1- 11075/08; 2- 11231/08; 311450/08; 4- $\mathrm{H}_{2} \mathrm{O}-1$; 5- 704/09; 6- 1532/09; 7- 4833/09; 8- $\mathrm{H}_{2} \mathrm{O}-2$; 9- 5176/09; 10- 7242/09; 11- CVS; $12-\mathrm{H}_{2} \mathrm{O}$.

Figura 26 - Eletroforese em gel de agarose a $2 \%$ corado com brometo de etídeo, referente à aplicação da ténica de multiplex hemi-nested em amostras de campo positivas para raiva $(\mathrm{B})$ 
Com relação às amostras de campo positivas para EEEV, na primeira amplificação somente quatro amostras $(26,6 \%)$ apresentaram a banda esperada de 434pb. A amostra 4084/09 apresentou uma intensidade de brilho mais evidente, enquanto que as amostras 3500/09, 3726/09 e 4085/09 apresentaram uma intensidade fraca, como observado na figura 27.

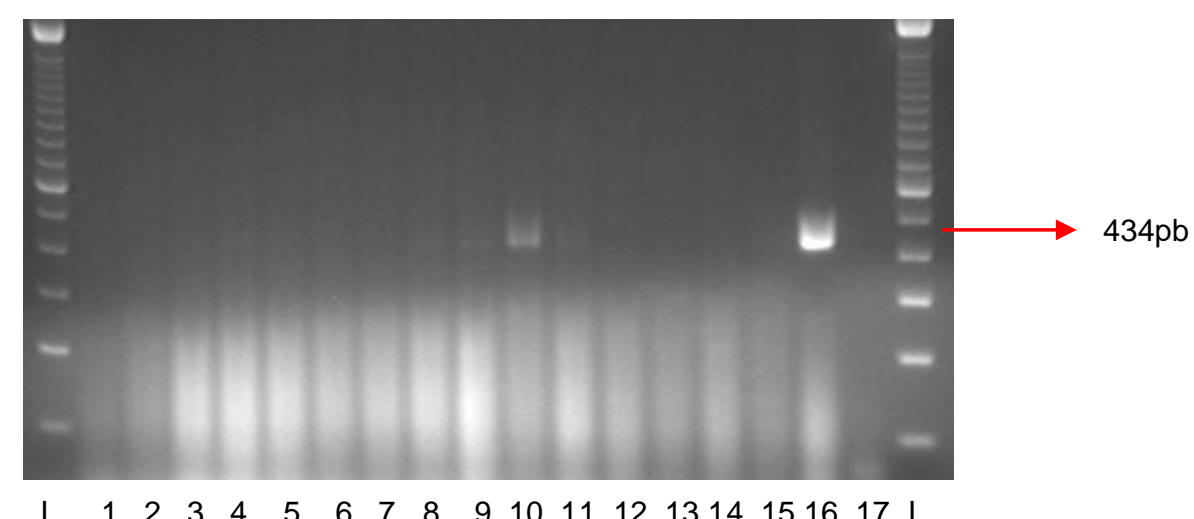

Legenda: L- marcador molecular de 100pb; 1- 5032/08; 2- 2572/09; 3$3499 / 09$; 4- 3500/09; 5- 3501/09; 6- 3723/09; 7- 3724/09; 8- 3725/09; 93726/09; 10- 4084/09; 11 - 4085/09; 12- 4239/09; 13- 4240/09; 14- 5691/09; 156009/09; 16- EEEV; $17-\mathrm{H}_{2} \mathrm{O}$.

Figura 27 - Eletroforese em gel de agarose a 2\% corado com brometo de etídeo, referente à aplicação da ténica de multiplex RT-PCR em amostras de campo positivas para EEE

Após a segunda amplificação pela técnica de multiplex hemi-nested RT-PCR das amostras de campo positivas para EEEV, a visualização das bandas foi possível somente em quatro amostras (26,6\%), sendo elas 3500/09, 3725/09, 4084/09 e 4085/09. As duas primeiras, apresentaram uma intensidade de brilho muito baixa, de forma que não foi possível seu registro em foto. Já as amostras 4084/09 e 4085/09 apresentaram uma intensidade de brilho evidente, como pode ser observado na figura 28. 


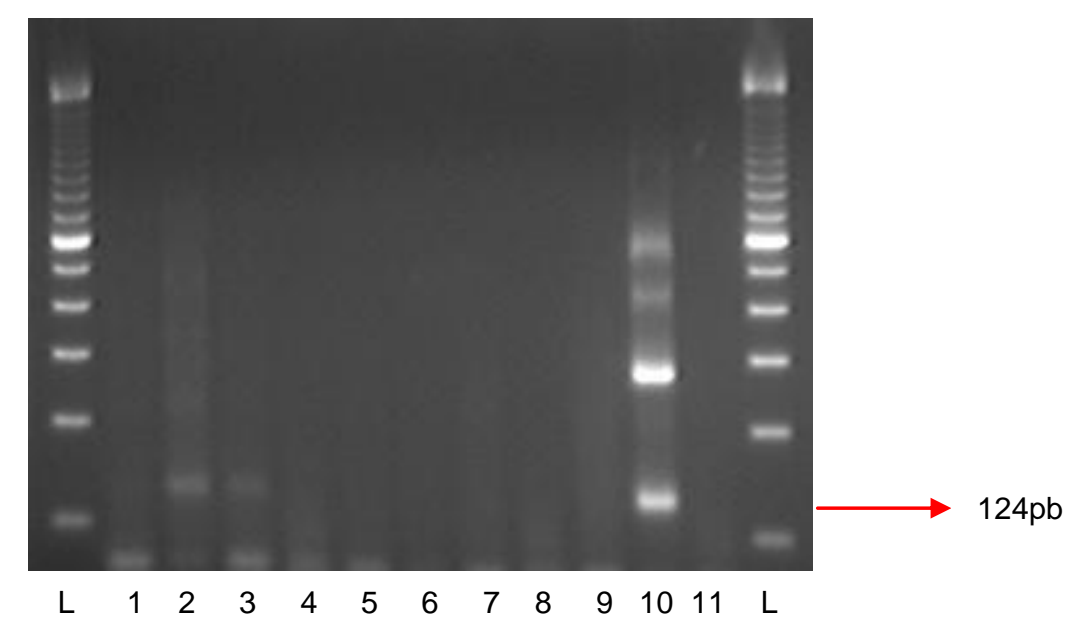

Legenda: L- marcador molecular de 100pb; 1 - 3726/09; 2- 4084/09; 34085/09; 4- $\mathrm{H}_{2} \mathrm{O}$; 5- 4239/09; 6- 4240/09; 7- 5691/09; 8- $\mathrm{H}_{2} \mathrm{O}$; 9- 6009/09; 10 EEEV; $11-\mathrm{H}_{2} \mathrm{O}$.

Figura 28 - Eletroforese em gel de agarose a $2 \%$ corado com brometo de etídeo, referente à aplicação da ténica de multiplex hemi-nested RT-PCR em amostras de campo positivas para EEE

\subsubsection{Sequenciamento Genético}

O sequenciamento genético dos fragmentos obtidos no teste de limiar de detecção de cada vírus padrão (item 4.3.2.1), por meio do aplicativo BLAST/n, confirmou que cada fragmento obtido correspondia ao respectivo vírus.

\subsection{ANÁLISE ESTATÍSTICA}

$\mathrm{Na}$ comparação entre os resultados obtidos em amostras de campo positivas para raiva pela técnica de hemi-nested RT-PCR e pela multiplex heminested RT-PCR, obteve-se um $\mathrm{P}=1,0000$, que indica um resultado não significante, aceitando-se $H_{0}$. Já na comparação entre os resultados obtidos em amostras positivas para EEE, obteve-se um $\mathrm{P}<0,0001$, que por sua vez é um resultado significante, e consequentemente, aceita-se $\mathrm{H}_{1}$. 


\subsection{ANÁLISE DE CUSTO}

Pelo cálculo realizado com base nos reagentes (Apêndice B, Quadros $12 \mathrm{e}$ 13, e Anexo B) uma reação de hemi-nested RT-PCR tem um custo de aproximadamente $R \$ 20,47$ (US\$12,33), enquanto que uma reação de multiplex hemi-nested RT-PCR, o custo é de aproximadamente $R \$ 20,81$ (U\$S12,53). 


\section{DISCUSSÃO}

O estudo teve seu início pela escolha e avaliação dos primers e pela adequação em uma reação de hemi-nested RT-PCR, ajustando o parâmetro da temperatura de anelamento.

Os primers escolhidos para o estudo (Quadros 4 e 5 ) foram submetidos ao aplicativo Oligoanalyser 3.0, sendo que não foram encontrados valores de delta $G$ que indicassem condição favorável à formação de hairpins, homodímeros e heterodímeros. $O$ valor de delta $G(\Delta G)$ designa a mudança em energia livre de Gibbs, que indica a troca de energia entre o sistema e o meio. Pode ser descrita pela equação: $\Delta \mathrm{G}=\Delta \mathrm{H}-\mathrm{T}$. $\Delta \mathrm{S}$, onde $\Delta \mathrm{H}$ (entalpia) representa a energia total trocada entre o sistema e o ambiente; $\Delta S$ (entropia), a energia gasta pelo sistema para se organizar; $T$ corresponde à temperatura do sistema. Desta forma, o valor de $\Delta G$ é dependente da temperatura. Se a uma dada temperatura o valor de $\Delta G$ for positivo, o sistema favorecerá a formação de reagentes. Valores negativos, por outro lado, levam o sistema ao favorecimento da formação do produto, o que levará os primers à composição de uma dupla fita. $O$ valor de $\Delta G$ igual a zero indica que o sistema está em equilíbrio, sendo este o valor encontrado na Tm (MANTHEY, 2005). Como o menor valor de $\Delta G$ foi de aproximadamente $-11,0 \mathrm{kca} / \mathrm{mole}$, considerou-se pequena a probabilidade de se ocorrer a formação de hairpins, homodímeros e heterodímeros, indicando uma considerável especificidade analítica teórica.

Outros parâmetros importantes na análise dos primers são os dados de porcentagem de ligações GC e temperatura de melting (Tm), cujos valores encontram-se nos quadros 4 e 5 . De acordo com a literatura, considera-se ideal que os primers sejam desenhados com um tamanho entre 15 a $30 \mathrm{pb}$ e que possuam entre 35 a 60\% de ligações GC (CHA; THILLY, 1993; HENEGARIU et al., 1997). Todos os primers escolhidos encontravam-se dentro dos parâmetros exigidos.

Em uma reação de multiplex, considera-se importante que as temperaturas ótimas de anelamento dos primers utilizados sejam semelhantes (ELNIFRO et al., 2000), sendo que a temperatura ótima de anelamento ocorre geralmente de 3 a $5^{\circ} \mathrm{C}$ abaixo da Tm (SAMBROOK; RUSSEL, 2001). As Tm dos primers escolhidos para o 
estudo apresentavam uma variação entre $45^{\circ} \mathrm{C}$ (primer $\left.21 \mathrm{G}\right)$ a $71^{\circ} \mathrm{C}$ (primer $\left.\mathrm{cM} 3 \mathrm{~W}\right)$, o que, consequentemente, poderia acarretar em temperaturas de anelamento muito diferentes. No entanto, ao se realizar o teste de gradiente de temperatura (item 4.2.1), observou-se que, apesar das $\mathrm{Tm}$ dos primers $21 \mathrm{G}$ e 304 serem 45 e $56^{\circ} \mathrm{C}$, respectivamente, na eletroforese foi possível constatar o brilho do fragmento esperado até $61^{\circ} \mathrm{C}$ (Figura 1-A). Na reação de hemi-nested (Figura 1-B), em que foram utilizados os primers 304 e 504, as bandas esperadas foram observadas em todas as temperaturas, sendo a diferença na intensidade de brilho praticamente imperceptível.

O mesmo teste de gradiente de temperatura foi realizado com os primers escolhidos para identificação do EEEV e do WEEV (Quadro 4 e Figuras 2 e 3). A variação da $\mathrm{Tm}$ entre esses primers era menor, sendo observada uma variação maior somente entre os primers $\mathrm{CM} 3 \mathrm{~W}\left(71^{\circ} \mathrm{C}\right)$ e nEEEV $\left(59^{\circ} \mathrm{C}\right)$. No quadro 9 , encontram-se os intervalos de temperaturas em que foram obtidos os melhores resultados, levando-se em consideração a intensidade do brilho da banda esperada e a menor formação de banda inespecífica possível. Desta forma, apesar de os primers apresentarem Tm com uma variação considerável, foi possível estabelecer uma temperatura ótima de anelamento comum a todos os primers, sendo escolhida a maior temperatura de anelamento possível, determinada em $55,8^{\circ} \mathrm{C}$.

Nas eletroforeses dos testes de gradiente de temperatura, foram observadas bandas inespecíficas, além de bandas correspondentes à primeira amplificação. No entanto, nos resultados de eletroforese dos testes de limiar de detecção, que foram realizados já com a temperatura ótima de anelamento estabelecida, foi observada uma diminuição na formação de bandas inespecíficas (Figuras 4, 5 e 6). Portanto, o estabelecimento da temperatura ótima de anelamento é um fator crítico e o ajuste deste parâmetro na reação pode diminuir a formação de bandas inespecíficas. Isso demonstra que em temperaturas mais elevadas, há um aumento da dificuldade na ligação dos primers que pode resultar em uma baixa amplificação. Por outro lado, se a temperatura estiver muito baixa, a ligação dos primers é favorecida e anelamentos não específicos podem ocorrer (SAMBROOK; RUSSEL, 2001).

A mesma temperatura de anelamento $\left(55,8^{\circ} \mathrm{C}\right)$ estabelecida para a heminested RT-PCR também foi utilizada no desenvolvimento do protocolo de multiplex 
hemi-nested RT-PCR. Além da temperatura de anelamento, o protocolo estabelecido para a reação de hemi-nested RT-PCR também foi utilizado como base para o início dos testes de multiplex hemi-nested RT-PCR, cujo protocolo inicial utilizou as mesmas concentrações de reagentes, inclusive dos primers.

Nos testes realizados para se estabelecer o protocolo para a reação de multiplex hemi-nested RT-PCR, tanto na primeira amplificação quanto na segunda (Quadros 7 e 8), o parâmetro principal que foi alterado foi a concentração dos primers. Em uma reação do tipo multiplex, é comum verificar pares de primers que não amplificam ou amplificam deficitariamente a região alvo, enquanto que outros pares de primers reagem normalmente, como no caso dos primers utilizados para a detecção do RABV. Nesse caso, é recomendado o aumento progressivo da concentração de primer que apresenta um desempenho ruim, enquanto se reduz progressivamente a concentração do primer com bom desempenho (HENEGARIU et al., 1997; SAMBROOK; RUSSEL, 2001). Primeiramente, os testes foram iniciados com uma concentração equimolar dos primers $(0,5 \mu \mathrm{M})$. A partir dos resultados observados na eletroforese, realizou-se, de forma empírica, um aumento da concentração dos primers correspondentes às bandas não observadas ou com baixa intensidade de brilho, e uma diminuição dos primers correspondentes às bandas com forte intensidade de brilho.

$\mathrm{Na}$ primeira amplificação, todas as bandas esperadas foram observadas quando aplicados os três protocolos, com exceção da banda esperada de 434pb da amostra 4084/09, que não foi visualizada ao se utilizar os protocolos 1 e 2 (Quadro 7). No entanto, ao diminuir a concentração dos primers $21 \mathrm{G}$ e 304 para $0,3 \mu \mathrm{M}$ e aumentar a concentração dos primers $\mathrm{cM} 3 \mathrm{~W}$ e M2W para $0,7 \mu \mathrm{M}$, foi possível observar a banda esperada dessa amostra, como demonstrado na coluna 3 da figura 17.

Já na segunda amplificação, além da dificuldade na amplificação da amostra 4084/09, também foi observada uma baixa intensidade de brilho na banda referente ao vírus padrão EEEV. Nos protocolos 1 e 2 (Quadro 8), não foi possível a visualização da banda referente à amostra 4084/09. A partir do protocolo 3 , foi possível observar um brilho discreto da referida banda, sendo uma melhor observação realizada quando houve a diminuição da concentração dos primers 504 


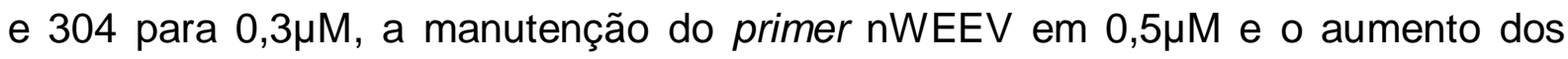
primers cM3W e nEEEV em 0,7 $\mu \mathrm{M}$. Porém, apesar de ser possível a visualização das bandas das amostras 4084/09 e EEEV, estas ainda apresentavam um brilho com uma intensidade menor em relação às amostras positivas para raiva e WEEV.

Dos protocolos de 6 a 10 (Quadro 8), verificou-se um incremento na intensidade de brilho das bandas, em especial às correspondentes as amostras 4084/09 e EEEV em relação ao protocolo 5, principalmente ao aumentar a concentração do primer nEEEV $(1,0 \mu \mathrm{M})$ e do $\mathrm{Mg}^{2+}(4,0 \mu \mathrm{M})$. Porém, observou-se que no controle positivo de EEEV utilizado na mesma reação, não foi possível visualizar a banda esperada, podendo ser visualizada somente sua banda inespecífica (aproximadamente $300 \mathrm{pb}$ ), que por sua vez apresentou uma intensidade de brilho ainda mais intensa. No sequenciamento genético desta banda inespecífica, também observada no teste de limiar de detecção (Figura 5), verificou-se que a mesma era formada pelo anelamento do primer nEEEV e identificada como EEEV pelo $\mathrm{BLAST} / \mathrm{n}$. Desta forma, é provável que ao aumentar a concentração desse primer e do $\mathrm{Mg}^{2+}$, pode ter ocorrido o favorecimento na formação dessa banda em relação à banda esperada. Em uma reação de multiplex, devido à presença de mais de um par de primers, aumenta-se a chance de se obter produtos inespecíficos, sendo estes, muitas vezes, amplificados mais eficientemente que o alvo, consumindo reagentes e prejudicando o anelamento e a extensão (BROWNIE et al., 1997; ELNIFRO et al., 2000).

No teste de limiar de detecção realizado com amostras de cada vírus padrão tanto da reação de multiplex hemi-nested RT-PCR (Figuras 19, 20 e 21) quanto da hemi-nested RT-PCR (Figuras 4, 5 e 6), obteve-se um resultado semelhante. $\mathrm{Na}$ primeira amplificação das amostras de CVS e de WEEV a sensibilidade analítica foi de $10^{-0,7}$, enquanto que para a PCR da amostra de EEEV, de 10 ${ }^{-1,7}$. Apesar de ter sido observada uma banda na diluição $10^{-1,7}$ na primeira amplificação da reação de multiplex hemi-nested RT-PCR em amostras de CVS (Figura 19), a mesma foi considerada uma banda inespecífica por estar localizada acima das outras bandas correspondentes a $1479 \mathrm{pb}$. Por esse motivo, a sensibilidade analítica na amostra de CVS nessa reação foi considerada de $10^{-0,7}$. A diferença da sensibilidade analítica observada entre as amostras de CVS, WEEV e EEEV pode estar relacionada com o título da amostra, uma vez que o título viral das amostras de CVS e do WEEV 
estava em $10^{6,0} \mathrm{DL}_{50} / 0,03 \mathrm{~mL}$ e $10^{6,7} \mathrm{DL}_{50} / 0,03 \mathrm{~mL}$, respectivamente, enquanto que o título da amostra de EEEV estava em $10^{9,4} \mathrm{DL}_{50} / 0,03 \mathrm{~mL}$.

Já na segunda amplificação tanto da reação de multiplex hemi-nested RTPCR quanto da hemi-nested RT-PCR, a sensibilidade analítica foi de $10^{-1,7}$ para os três vírus padrão. A semelhança nos resultados obtidos nas reações de hemi-nested RT-PCR e de multiplex hemi-nested RT-PCR, sugeriria uma semelhança na sensibilidade analítica das duas técnicas, ressaltando-se, porém, que foi observada uma diminuição na intensidade do brilho das bandas referentes às amostras de EEEV e WEEV obtidas na reação de multiplex hemi-nested RT-PCR em relação às obtidas pela hemi-nested RT-PCR.

No teste de limiar de detecção realizado a partir de uma amostra contendo os três vírus, foi possível avaliar não somente a sensibilidade analítica, mas principalmente, a especificidade analítica. Com relação à sensibilidade analítica pela hemi-nested RT-PCR (Figuras 7, 8 e 9), em que os primers foram utilizados em pares específicos para cada vírus padrão, observou-se uma sensibilidade de $10^{-1,7}$. Já pela reação de multiplex hemi-nested RT-PCR (Figura 22), a sensibilidade observada foi de $10^{-0,7}$ para WEEV e de $10^{-1,7}$ para CVS e EEEV, sendo que nesta última amostra, a intensidade de brilho observada foi baixa. Logo, foi observada uma diminuição na sensibilidade analítica da reação de multiplex hemi-nested RT-PCR em relação à hemi-nested RT-PCR, que provavelmente ocorreu por uma maior competição entre os primers e pelo maior consumo de reagentes, em especial o $\mathrm{Mg}^{2+}$, cuja interferência será discutida adiante.

Ainda em relação ao teste de limiar de detecção em amostra contendo os três vírus padrão, no resultado obtido pela reação de hemi-nested RT-PCR (Figuras 7, 8 e 9) foi possível verificar que, apesar de a amostra conter os três vírus, cada conjunto de primers selecionou especificamente o genoma a que era destinado. Além do resultado observado na eletroforese, realizou-se o sequenciamento genético das bandas obtidas, sendo que suas sequências foram, então, submetidas ao aplicativo BLAST/n, que por comparação com dados armazenados no GenBank, confirmou a correspondência da sequência obtida ao respectivo vírus pela comparação. Na reação de multiplex hemi-nested RT-PCR (Figura 22), por sua vez, foi possível a detecção simultânea dos três vírus. Apesar de não ter sido possível a 
realização do sequenciamento genético dessas bandas, observou-se na eletroforese a correspondência das bandas obtidas na amostra em relação às amostras de vírus padrão (Figura 22), indicando uma relevante especifidade analítica.

Comparando-se os resultados obtidos na primeira e na segunda amplificação do teste de limiar de detecção em amostras de vírus padrão CVS e WEEV, é possível observar que houve um aumento da sensibilidade analítica na segunda amplificação em relação à primeira amplificação. Esse aumento da sensibilidade também pode ser observado nos testes realizados com as amostras de campo. Na primeira amplificação das amostras positivas para raiva pela técnica de hemi-nested RT-PCR (Figuras 10 e 11), observou-se a banda esperada em 6 (33,3\%), sendo que na segunda amplificação (Figuras 12 e 13), em 17 (94,4\%). Um resultado semelhante foi observado quando as mesmas amostras foram submetidas à multiplex hemi-nested RT-PCR (Figuras 23 à 26). Com relação às amostras positivas para EEE, na primeira amplificação da reação de hemi-nested RT-PCR, 2 amostras (13,3\%) foram detectadas, e na segunda amplificação, em 15 amostras $(100 \%)$ foram observadas as bandas esperadas. A segunda amplificação, denominada de hemi-nested, é uma variação da reação de PCR, em que se utiliza um primer interno em conjunto com um dos primers da primeira amplificação, obtendo-se desta forma uma amplificação de uma região interna dos amplicons e consequentemente, uma maior sensibilidade analítica (SÁNCHEZ-SECO et al., 2001; FLORES, 2007).

Ao se aplicar a técnica de hemi-nested RT-PCR em amostras de campo positivas para raiva, utilizando o protocolo estabelecido, obteve-se um resultado satisfatório na segunda amplificação (Figuras 12 e 13). Todas as amostras apresentaram amplificação do fragmento esperado, com exceção apenas da amostra 6347/08, que não apresentou nenhum sinal tanto na primeira quanto na segunda amplificação. Esta amostra foi submetida novamente ao procedimento, desde a extração de RNA até a segunda amplificação para verificar se houve algum problema durante esse processo, porém o resultado obtido foi o mesmo. Ao se submeter as mesmas amostras à multiplex hemi-nested RT-PCR, além da amostra 6347/08, a amostra 6342/08 apresentou um resultado negativo. Apesar desse resultado, pelo cálculo do teste exato de Fisher, não houve diferença estatística na proporção de amostras detectadas como positiva pelas duas técnicas $(P=1,0000)$. 
Uma vez que se obteve uma nítida visualização da banda referente à amostra 6342/08 na reação de hemi-nested RT-PCR, uma possível explicação para seu resultado negativo pela multiplex hemi-nested RT-PCR poderia ser a degradação do RNA, uma vez que o mesmo RNA extraído foi utilizado para ambas reações, sendo submetido ao descongelamento por duas vezes. O RNA é particularmente sensível à degradação por RNAses, e sua manipulação deve ser realizada sempre em gelo. Além da manutenção do RNA em baixas temperaturas, sua integridade pode ser assegurada pelo uso de materiais livres de RNAses e de inibidores de RNAse comercialmente disponíveis (HOLLAND et al., 2003).

No caso de amostras que apresentam um resultado negativo, seria interessante o emprego de controles de amplificação interna, que consiste no uso de primers de uma sequência não alvo que seria amplificada simultaneamente com a sequência alvo. Desta forma, em uma PCR, o sinal do controle interno deveria ser produzido mesmo que não houvesse a presença do sinal da sequência alvo. A não observação do sinal do controle interno e da sequência alvo corresponderia a uma degradação do material genético ou uma inibição da reação, causada pelo mau funcionamento do termociclador, erro na preparação dos reagentes, baixa atividade da DNA polimerase ou presença de substâncias inibitórias na amostra (HOORFAR et al., 2004).

Com relação às amostras de campo positivas para EEE, quando as 15 amostras foram submetidas à multiplex hemi-nested RT-PCR, na primeira amplificação foram visualizadas as bandas esperadas em 4 amostras (26,6\%), enquanto que na primeira amplificação pela hemi-nested, observaram-se somente 2 $(13,3 \%)$. Portanto, aparentemente, com o protocolo estabelecido para a primeira amplificação da reação de multiplex, houve um aumento na sensibilidade analítica. Este fato provavelmente deve-se ao aumento da concentração dos primers cM3W e M2W, que foram utilizados para detecção de alfavírus.

Foi possível observar ainda, que quando foram submetidas ao protocolo da hemi-nested RT-PCR, na segunda amplificação, as 15 amostras apresentaram a banda esperada de 124pb. Nas figuras 15 e 16, observa-se que não houve a formação da banda inespecífica formada no controle positivo em testes realizados previamente. 
Por outro lado, pela reação de multiplex hemi-nested RT-PCR, na segunda amplificação, o que se observou foi uma diminuição na proporção de amostras positivas detectadas, uma vez que a visualização das bandas foi possível somente em 4 amostras (26,6\%), enquanto que pela hemi-nested RT-PCR, todas as amostras apresentaram a banda de $124 \mathrm{pb}$. Comparando-se o resultado de amostras positivas para EEE detectadas por essas duas reações pelo teste exato de Fisher, verificou-se que a proporção de amostras positivas detectadas pela hemi-nested RTPCR é estatisticamente maior do que a proporção de amostras positivas detectadas pela multiplex hemi-nested RT-PCR $(\mathrm{P}<0,0001)$.

A dificuldade do isolamento desses vírus, assim como a baixa frequência de diagnóstico de alfaviroses, tornam difícil a realização de estudos utilizando amostras de campo. Muitos estudos relacionados a esses vírus são realizados apenas com vírus padrão. Pfeffer et al. (1997) utilizaram vírus padrão inoculados em cultura de células Vero e BHK-21, desenvolvendo um hemi-nested RT-PCR para detecção de alfavírus. No estudo conduzido por Bronzoni et al. (2004) para o desenvolvimento de um multiplex nested RT-PCR, utilizaram-se amostras em suspensão a $20 \%$ de cérebros de camundongos inoculados com os vírus padrão. Sánchez-Seco et al. (2001), por sua vez, desenvolveram um nested RT-PCR utilizando vários allfavírus propagados em células Vero. Ao se trabalhar com vírus inoculados em células ou em camundongos, o título viral da amostra é consideravelmente alto, de forma que o resultado obtido no experimento pode não ter a reprodutibilidade esperada em amostras de campo.

O presente estudo, no entanto, foi realizado com pool de SNC de equídeos, sendo que a extração de RNA foi realizada diretamente do tecido original. A técnica de multiplex hemi-nested RT-PCR apresentou uma relevante sensibilidade e especificidade analítica em amostra de vírus padrão EEEV, mas houve uma baixa detecção ao se aplicar em amostras de campo, que provavelmente possuem um título viral menor. A amostra 4084/09, apesar de não titulada, provavelmente possui um título maior em relação às outras amostras, pois foi a única amostra em que foi possível realizar o IVC, bem como, a única que apresentou uma banda nitidamente visível na primeira amplificação tanto da hemi-nested RT-PCR, quanto da multiplex hemi-nested RT-PCR. 
Alguns parâmetros poderiam ter sido alterados para o aumento da sensibilidade da reação de multiplex hemi-nested RT-PCR em relação à detecção de EEEV. Um dos parâmetros seria a temperatura de anelamento da segunda amplificação. Ao se observar os resultados obtidos na segunda amplificação (Figuras 1, 2 e 3), verifica-se que a diminuição da temperatura de anelamento seria possível. No quadro 9, a menor temperatura para as amostras de vírus padrão CVS ficou estabelecida em $55,8^{\circ} \mathrm{C}$ devido ao critério de menor formação de banda inespecífica visualizada. Entretanto, na figura 1 observa-se que apesar dessa banda inespecífica ser favorecida pela diminuição da temperatura, sua visualização não interferiria na interpretação do resultado. Sendo assim, seria possível utilizar uma temperatura abaixo de $55,8^{\circ} \mathrm{C}$. Como já mencionado anteriormente, a diminuição da temperatura favorece $\mathrm{o}$ anelamento dos primers, o que poderia ajudar no anelamento dos primers direcionados ao genoma do EEEV.

Além disso, outros parâmetros poderiam ser alterados no protocolo estabelecido, como a concentração da enzima, do $\mathrm{Mg}^{2+}$, dNTP e do PCR Buffer, uma vez que a taxa de extensão das sequências alvo dos primers específicos dependem da atividade da enzima e da viabilidade de componentes (ELNIFRO et al., 2000). As DNA polimerases requerem cátions divalentes livres para atividade, sendo que esses cátions geralmente são o $\mathrm{Mg}^{2+}$. Os dNTPs e os primers também se ligam ao $\mathrm{Mg}^{2+}$, de forma que a concentração molar do cátion deve exceder a concentração molar de grupos fosfatos originados de dNTPs e primers (SAMBROOK; RUSSEL, 2001). Sendo assim, a concentração de $\mathrm{Mg}^{2+}$ pode ser um fator crítico em uma reação do tipo multiplex, pois há uma maior concentração de primers e, consequentemente, um maior consumo do reagente.

Outro fator que poderia ter aumentado a sensibilidade analítica dos testes seria a utilização de dois pares de primers na RT. Para a síntese de c-DNA, foi utilizado somente um primer senso (21G) para raiva e um primer antissenso (cM3W) para alfavírus. Talvez, a utilização dos pares de primers 21G-304 e cM3W-M2W na mesma reação de $\mathrm{RT}$, poderia ter aumentado a sensibilidade das técnicas, uma vez que tanto o primer 304 quanto o M2W poderiam formar um c-DNA em relação ao RNA antigenômico, que é utilizado como molde para formar a cópia do RNA viral. 
Em relação ao WEEV, apesar de não ter sido possível testar amostras de campo positivas para WEEV, os testes realizados conseguiram detectar as amostras de vírus padrão. Os resultados observados sugerem que a detecção em amostras de campo pela técnica de multiplex hemi-nested RT-PCR seria exequível, pois, em todos os protocolos testados foi possível uma nítida visualização das bandas, tanto na primeira como na segunda amplificação, semelhantemente aos resultados obtidos com as amostras positivas para raiva, a 7955/09 e o CVS.

Com relação à análise de custo com base nos reagentes utilizados nos protocolos estabelecidos nesse estudo, o valor de uma reação de hemi-nested RTPCR ficou em $R \$ 20,47$ (U\$12,33), enquanto que a reação de multiplex hemi-nested $R T-P C R$, em $R \$ 20,81$ (U\$12,53). O reagente que tem maior influência sobre o custo das reações é a enzima transcriptase reversa (Superscript ${ }^{\circledR}$ II, Invitrogen ${ }^{\circledR}$ ), cujo valor por reação fica em R $\$ 17,43$ (US\$ 10,50) (Apêndice B, Quadros 12 e 13, e Anexo B). Em uma reação do tipo multiplex, a quantidade de pares de primers será maior, sendo que o custo dos mesmos não representa um impacto no valor de uma reação. Com base nos protocolos estabelecidos, o custo de cada primer variou entre $R \$ 0,02$ à $R \$ 0,13$. Além disso, a diferença entre os valores das duas reações ficou em $\mathrm{R} \$ 0,34$ (US\$ 0,20), o que corrobora com a afirmação de que os valores dos primers não afetam de forma significativa o custo por reação.

Levando-se em consideração que a técnica de multiplex hemi-nested RT$P C R$ pode ser utilizada para a detecção de pelo menos dois agentes virais em uma mesma reação, e que a técnica de hemi-nested RT-PCR pode detectar somente um agente por reação, ao se utilizar a técnica de multiplex hemi-nested RT-PCR a economia seria no mínimo de, aproximadamente, 49,17\% em relação à hemi-nested RT-PCR.

Mahony et al. (2009) realizaram uma análise de custo mais complexa para verificar se o custo do teste de multiplex PCR para vírus respiratórios teria um valor superior ou inferior aos métodos de diagnóstico utilizados, sendo que foram empregadas quatro estratégias de diagnóstico para comparação: somente a IFD, a imunofluorescência direta seguida de isolamento em cultivo celular, somente a multiplex PCR ou a IFD com a multiplex PCR. Além disso, foram considerados na análise, os resultados verdadeiramente positivos e negativos, os falso positivos e 
negativos, prevalência da doença, sensibilidade e especificidade de cada técnica, e custos da hospitalização dos pacientes. Das quatro estratégias, a que apresentou o menor custo foi a estratégia em que se utilizou somente a multiplex PCR. Os dados do estudo sugeriram uma economia de US\$291,00 (R\$483,06) por caso investigado, o que acarretaria em uma economia significativa para o hospital.

$\mathrm{Na}$ rotina diagnóstica laboratorial da raiva em equinos, existem situações peculiares à espécie, como demonstrado por Peixoto et al. (2000), que detectou uma menor sensibilidade diagnóstica das técnicas de pesquisa de corpúsculo de Negri e IFD em amostras de equinos quando comparados com amostras da espécie bovina. Carrieri et al. (2006) também conduziu um estudo em relação ao diagnóstico de raiva em amostras de equinos, comparando a IFD e o IVC, utilizando cinco regiões diferentes do SNC: córtex, cerebelo, hipocampo, tronco encefálico e medula cervical. Nesse estudo, concluiu-se que ambos os testes apresentaram a mesma sensibilidade diagnóstica para tronco encefálico e medula cervical, sendo que essas duas regiões do SNC apresentaram uma sensibilidade maior em relação ao córtex, cerebelo e hipocampo.

Ao se observar os resultados apresentados do IVC das amostras positivas para raiva utilizadas nesse estudo, verifica-se que $5 / 18(27,8 \%)$ foram negativas no IVC (Quadro 2). Estes dados sugerem que a técnica de multiplex hemi-nested RTPCR poderia ser utilizada como uma ferramenta para auxiliar no diagnóstico da raiva, principalmente nos casos em que há envolvimento de vítimas humanas, que demandam maior rapidez na obtenção do resultado.

As EEE e WEE não são diagnosticadas com a mesma frequência em relação à raiva, porém estudos sugerem que há circulação do vírus no país. Pauvolid-Corrêa et al. (2010) reportaram a detecção de anticorpos neutralizantes para o EEEV e WEEV em equinos não vacinados em Nhecolândia no Sul do Pantanal, região Cento-Oeste do Brasil. Uma das amostras utilizadas no estudo, a 5032/08, era de um muar do proveniente Cuiabá, Estado do Mato Grosso, pertencente à mesma região do país. Silva et al. (2011) reportaram uma epidemia de EEE em equinos na região Nordeste do Brasil que ocorreu entre 2008 e 2009 nos Estados de Pernambuco, Paraíba e Ceará, e 13 animais foram diagnosticados positivos pela técnica de hemi-nested RT-PCR. Em 2011, foi reportado o caso do 
garoto de 14 anos que morreu de WEE no Uruguai (DELFRARO et al., 2011). Estes estudos demonstram a importância da vigilância para a encefalite equina do Leste e Oeste e reforçam a necessidade do desenvolvimento de técnicas para o diagnóstico diferencial para essas enfermidades, por se tratarem de doenças que podem acometer o ser humano.

Os equídeos são animais suscetíveis a vários vírus zoonóticos além do RABV, WEEV e EEEV, podendo-se destacar o VEEV, o vírus do Nilo Ocidental e o vírus de Saint Louis. Sendo assim, animais podem ser utilizados como indicadores da circulação viral em uma região, o que torna impressindível a realização de pesquisas para o desenvolvimento de técnicas diagnósticas, assim como a realizada para a técnica de multiplex hemi-nested RT-PCR.

Os resultados obtidos neste estudo sugerem a possibilidade da aplicação da técnica de multiplex hemi-nested RT-PCR para o diagnóstico de raiva, WEE e EEE, porém, para EEEV, a reação de hemi-nested apresentou um melhor desempenho, indicando que outras adequações seriam necessárias para a otimização da reação de multiplex hemi-nested RT-PCR. Em laboratórios de diagnóstico da raiva, notadamente os de referência nacional ou regional, o uso da técnica de multiplex hemi-nested RT-PCR tem sua importância, uma vez que permite um diagnóstico diferencial rápido, acurado e com custo assessível. 


\section{CONCLUSÃO}

- Com o protocolo estabelecido, a sensibilidade analítica da multiplex heminested RT-PCR foi semelhante à observada na hemi-nested RT-PCR. Ao se aplicar o protocolo de multiplex hemi-nested RT-PCR em amostras de vírus padrão, foi possível a detecção do RABV, WEEV e EEEV de forma acurada, sendo possível inclusive a detecção simultânea dos mesmos em uma amostra contendo os três vírus. Quando aplicado em amostras de campo positivas, foi possível a detecção de RABV e EEEV, porém, em amostras de EEEV, obtevese desempenho superior pela hemi-nested RT-PCR.

- O custo total dos reagentes de uma reação de hemi-nested RT-PCR e de uma reação de multiplex hemi-nested RT-PCR são semelhantes, porém, como em uma reação de multiplex hemi-nested RT-PCR é possível a detecção de pelo menos dois agentes, o custo sería, no mínimo, 49,17\% menor em relação ao custo de uma hemi-nested RT-PCR, que detecta somente um agente viral por reação. 


\section{REFERÊNCIAS}

ACHA, P. N.; SZYFRES, B. Zoonosis y enfermedades transmisibles comunes al hombre y a los animales. 3. ed. Washington, D. C.: Organización Panamericana de la Salud, 2003. v. 2, p. 425.

BERAN, G. W. (Ed.). Rabies and infections by Rabies-related viruses. In: BERAN, G. W. Handbook of zoonoses. 2. ed. Boca Ranton: CRC Press, 1994. Sec. B, p. 307357.

BERGALLO, M.; COSTA, C.; MARGIO, S.; SIDOTI, F.; TERLIZZI, M. E.;

CARVALHO, R. Development of a multiplex polymerase chain reaction for detection and typing of major human herpesviruses in cerebrospinal fluid. Canadian Journal of Microbiology, v. 53, p. 1117-1122, 2007.

BERQUÓ, E. S.; SOUZA, M. P.; GOETLIEB, S. L. D. Testes de hipóteses em tabelas de 2 x 2 e r x s. In: BERQUÓ, E. S.; SOUZA, M. P.; GOETLIEB, S. L. D.

Bioestatística. 2. ed. São Paulo: Editora Pedagógica e Universitária, 1981. p.281297.

BRANDÃO, P. E.; FREITAS, P. H. B.; JEREZ, J. A.; CARNIELI JR., P.; CARRIERI, M. L.; KOTAIT, I. Identification of eastern equine encephalitis virus (Togaviridae: Alphavirus) in the central nervous system of horses in São Paulo State, southern Brazil by nested-RT-PCR and DNA sequencing. Reviews and Research/ Sociedade Brasileira de Virologia, v. 10, p. 89, 2005. Supplement, 1.

BRITO, M. G.; CHAMONE, T. L.; SILVA, F. J.; WADA, M. Y.; MIRANDA, A. B.; CASTILHO, J. G.; CARRIERI, M. L.; KOTAIT, I.; LEMOS, F. L. Antemortem diagnosis of human rabies in a veterinarian infected when handling a herbivore in Minas Gerais, Brazil. Revista do Instituto de Medicina Tropical de São Paulo, v. 53, n. 1, p. 39-44, 2011.

BRONZONI, R. V. M.; BALEOTTI, F. G.; NOGUEIRA, R. M. R.; NUNES, M.; FIGUEIREDO, L.T. M. Duplex reverse transcription-PCR followed by nested PCR assays for detection and identification of Brazilian Alphaviruses and Flaviviruses. Journal of Clinical Microbiology, v. 43, n. 2, p. 696-702, 2005.

Segue diretrizes para apresentação de dissertações e teses na Faculdade de Medicina Veterinária e Zootecnia da Universidade de São Paulo. 
BRONZONI, R. V. M.; MORELI, M. L.; CRUZ, A. C. R.; FIGUEIREDO, L. T. M. Multiplex nested PCR for Brazilian Alphavirus diagnosis. Royal Society of Tropical Medicina and Hygiene, v. 98, p. 456-461, 2004.

BROWNIE, J.; SHAWCROSS, S.; THEAKER, J.; WHITCOMBE, D.; FERRIE, R.; NEWTON, C.; LITTLE, S. The elimination of primer-dimer accumulation in PCR. Nucleic Acids Research, v. 25, p. 3235-3241, 1997.

BRUNO LOBO, G. G.; BRUNO LOBO, M.; TRAVASSOS, J.; PINHEIRO, F.; PAZIN, I. P. Estudos sobre arbovirus III. Isolamento de um vírus sorologicamente relacionado ao subgrupo Western-Sindbis de um caso de encefalomielite eqüina ocorrido no Rio de Janeiro. Anais de Microbiologia, v.9, p. 183-195, 1961.

CALISHER, C. H. Medically Important Arboviruses of the United States and Canadá. Clinical Microbiology Reviews, v. 7, p. 89-116, 1994.

CALISHER, C. H.; MONATH, T. P.; MITCHELL, C. J.; SABATTINI, M. S.; CROPP, C. B.; KERCHNER, J.; HUNT, A. R.; LAZUICK J. S. Arbovirus investigations in Argentina, 1977-1980. III. Identification and characterization of viruses isolated, including new subtypes of western and Venezuelan equine encephalitis viruses and four new bunyaviruses (Las Maloyas, Resistencia, Barranqueras, and Antequera). American Journal of Tropical Medicine and Hygiene, v. 34, p. 956-965, 1985.

CALLEGARI-JACQUES, S. M. Testes não-paramétricos. In: CALLEGARI-JACQUES, S. M. Bioestatística: princípios e aplicações. Porto Alegre: Artmed, 2003. p.165184.

CARINI, A. Sur une grande epizootic de rage. Annales d I' Institut Pasteur, v. 25, p. 843-846, 1911.

CARNEIRO, V. A encefalomielite infecciosa dos eqüídeos do Brasil. Arquivos do Instituto Biológico, v. 8, p. 115-134, 1937.

CARNIELI JUNIOR, P.; FAHL, W. O.; CASTILHO, J. G.; OLIVEIRA, R. N.; MACEDO, C. I.; DURYMANOVA, E.; JORGE, R. S. P.; MORATO, R. G.; SPÍNDOLA, R. O.; MACHADO, L. M.; ÚNGAR DE SÁ, J. E.; CARRIERI, M. L.; KOTAIT,I.

Characterization of Rabies virus isolated from canids and identification of the main wild canid host in Northeastern Brazil. Virus Research, v. 131, p. 33-46, 2008.

CARRIERI, M. L.; PEIXOTO, Z. M. P.; PACIENCIA, M. L. B.; KOTAIT, I.; GERMANO, P. M. L. Laboratory diagnosis of equine rabies and its implications for 
human postexposure prophylaxis. Journal of Virological Methods, v. 138, p. 1-9, 2006.

CARSTENS, E. B. Ratification vote on taxonomic proposals to the International Committee on Taxonomy of Viruses (2009). Archives of Virology, v. 155, p. 133146, 2010.

CASTILHO, J. G.; IAMAMOTO, K.; LIMA, J. Y. O.; SCHEFFER, K. C.; CARNIELI JR., P.; OLIVEIRA, R. N. de; MACEDO, C. I.; ACHKAR, S. M.; CARRIERI, M. L.; KOTAIT, I. Padronização e aplicação da técnica de isolamento do vírus da raiva em células de neuroblastoma de camundongo (N2A). Boletim Epidemiológico Paulista, v. 4, n. 47, 2007. Disponível em: <http://www.cve.saude.sp.gov.br/agencia/bepa47_raiva.htm> Acesso em: 5 dez. 2007.

CASTILHO, J. G.; CARNIELI JUNIOR, P.; DURYMANOVA, E. A.; FAHL. W. O.; OLIVIERA, R. N.; MACEDO, C. I.; TRAVASSOS DA ROSA, E. S.; MANTILLA, A.; CARRIERI, M. L.; KOTAIT, I. Human rabies transmitted by vampire bats: Antigenic and genetic characterization of rabies virus isolates from the Amazon region (Brazil and Ecuador). Virus Research, v. 153, p. 100-105, 2010.

CAUSEY, O. R.; SHOPE, R. E.; SUTMOLLER, P.; LAEMMERT, H. Epizootic Eastern Equine Encephalitis in the Bragança Region of Para, Brazil. Revista do Serviço Especial de Saúde Pública, v. 12, n. 1, p. 40-45, 1962.

CHA, R. S.; THILLY, W. G. Specificity, efficiency, and fidelity of PCR. Genome Research, v. 3, p. S18-S29, 1993.

CHAMBERLAIN, J. S.; GIBBS, R. A.; RANIER, J. E.; NGUYEN, P. N.; CASKEY, C. $T$. Deletion screening of the Duchenne muscular dystrophy locus via multiplex DNA amplification. Nucleic Acids Research, v. 16, n. 23, p.11141-11156.

CORNISH-BOWDEN, A. Nomenclature for incompletely specified bases in nucleic acid sequences: recommendations 1984. Nucleic Acids Research, v. 13, p. 30213030, 1985.

COYLE, P. V.; DESAI, A.; WYATT, D.; McCAUGHEY, C.; O’NEILL, H. J. A comparison of virus isolation, indirect immunofluorescence and nested multiplex polymerase chain reaction for the diagnosis of primary and recurrent herpes simplex type 1 and type 2 infections. Journal of Virological Methods, v. 83, p. 75-82, 1999. 
DEAN, D. J.; ABELSETH, M. K.; ATANASIU, P. The fluorescent antibody test. In: MESLIN, F.-X.; KAPLAN, M. M.; KOPROWSKI, H. (Ed.). Laboratory techniques in rabies. 4. ed.Geneva: World Health Organization, 1996. p. 88-95.

DELFRARO, A.; BURGUEÑO, A.; MOREL, N.; GONZÁLES, G.; GARCÍA, A.; MORELLI, J.; PÉREZ, W.; CHIPARELLI, H.; ARBIZA, J. Fatal human case of Western Equine Encephalitis, Uruguay. Emerging Infectious Disease, v. 17, n. 15, p. 952-954, 2011. Disponível em: <http://www.cdc.gov/eid/content/17/5/pdfs/952.pdf> Acesso em: 31 maio 2011.

ELNIFRO, E. M.; ASHSHI, A. M.; COOPER, R. J.; KLAPPER, P. E. Multiplex PCR: optimization and application in diagnostic virology. Clinical Microbiology Reviews, v. 13, n. 4 , p. 559-570, 2000.

FAUQUET, C. M.; MAYO, M. A.; MANILOFF, J.; DESSELBERGER, U.; BALL, L. A. The negative sense single stranded RNA viruses. In: FAUQUET, C. M.; MAYO, M. A.; MANILOFF, J.; DESSELBERGER, U.; BALL, L. A. (Ed.). Virus taxonomy: classification and nomenclature of viruses. 1. ed. San Diego; London: Elsevier Academic Press. 2005a. Pt. 2, p.609-738. (Eighth Report of the International Committee on the Taxonomy of Viruses).

FAUQUET, C. M.; MAYO, M. A.; MANILOFF, J.; DESSELBERGER, U.; BALL, L. A. The positive sense single stranded RNA viruses. In: FAUQUET, C. M.; MAYO, M. A.; MANILOFF, J.; DESSELBERGER, U.; BALL, L. A. (Ed.). Virus taxonomy: classification and nomenclature of viruses. 1. ed. San Diego; London: Elsevier Academic Press. 2005b. Pt. 2, p.739-1128. (Eighth Report of the International Committee on the Taxonomy of Viruses).

FERNÁNDEZ, Z.; RICHARTZ, R.; TRAVASSOS DA ROSA, A.; SOCCOL, V. T. Identificação do vírus causador de encefalomielite eqüina, Paraná, Brasil. Revista de Saúde Pública, v. 34, n. 3, p. 232-235, 2000.

FIGUEIREDO, L. T. M. Emergent arboviruses in Brazil. Revista da Sociedade Brasileira de Medicina Tropical, v. 40, n. 2, p. 224-229, 2007.

FLORES, E. F. Togaviridae. In.: FLORES, E. F. (Ed.). Virologia Veterinária. Santa Maria: Editora da UFSM, 2007. p. 593-612.

GOLDWASSER, R. A.; KISSLING, R. E. Fluorescent antibody staining of street and fixed rabies vaccine antigens. Proceedings of the Society for Experimental Biology and Medicine, v. 98, p. 219-223, 1958. 
GRIFFIN, D. E. Alphaviruses. In: FIELDS, B. N.; KNIPE, D. M.; HOWLEY, P. M.

Virology. 5. ed. Philadelphia: Lippincott Williams \& Wilkins, 2007. p. 1024-1069.

HABEL, K. Habel test for potency. In: MESLIN, F.-X.; KAPLAN, M. M.; KOPROWSKI, $\mathrm{H}$. (Ed.). Laboratory techniques in rabies. 4. ed. Geneva: World Health Organization, 1996. p.369-373.

HALL, T. A. Bioedit: a user-friedly biological sequence alignment editor and analysis program for Windows 95/98/NT. Nucleic Acids Symposium Series, v. 41, n. 2, p. 95-98, 1999.

HANLON, C. A.; NIEZGODA, M.; RUPPRECHT, C. E. Rabies in terrestrial animals. In: JACKSON, A. C.; WUNNER, W. H. Rabies. 2. ed. San Diego: Academic Press, 2007. p. 201-258.

HARVALA, H.; BREMNER, J.; KEALEY, S.; WELLER, B.; MCLELLAN, S.; LLOYD, G.; STAPLES, E.; FAGGIAN, F.; SOLOMON, T. Case report: Eastern Equine Encephalitis virus imported to UK. Journal of Medical Virology, v. 81, p. 305-308, 2009.

HAUPT, H.; REHAAG, H. Raiva epizoótica nos rebanhos de Santa Catarina, transmitida por morcegos. Boletim da Sociedade Brasileira de Medicina Veterinária, v. 2, p.17-47, 1925.

HENEGARIU, O.; HEEREMA, N. A.; DLOUHY, S. R.; VANCE, G. H.; VOGT, P. H. Multiplex PCR: critical parameters and step-by-step protocol. BioTechniques, v. 23, p. 504-511, 1997.

HOLLAND, N. T.; SMITH, M. T.; ESKENAZI, B.; BASTAKI, M. Biological sample collection and processing for molecular epidemiological studies. Mutation Research, v. 543, p. $217-234,2003$.

HOORFAR, J.; MALORNY, B.; ABDULMAWJOOD, A.; COOK, N.; WAGNER, M.; $\mathrm{FACH}, \mathrm{P}$. Practical considerations in design of internal amplification controls for diagnostic PCR assays. Journal of Clinical Microbiology, v.42, n. 5, p. 1863-1868, 2004.

HOWITT, B. F. Recovery of the virus equine encephalomyelitis from the brain of a child. Science, v. 88, p. 455, 1938. 
ICTV. INTERNATIONAL COMMITTEE ON TAXONOMY OF VIRUSES. Virus Taxonomy List 2009. Disponível em:

$<$ http://www.ictvonline.org/virusTaxonomy. asp?version=2009>. Acesso em: 08 set. 2010.

IVERSSON, L. B.; ROSA, A. P. A. T.; ROSA, J. T. Estudos sorológicos para pesquisa de anticorpos de arbovírus em população humana da região do Vale do Ribeira. II - Inquérito em pacientes do hospital regional de Pariquera-açú, 1980.

Revista de Saúde Pública, v. 15, p. 587-602, 1981.

IVERSSON, L. B.; ROSA, A. P. A. T; ROSA, J. T; COSTA, C. S. Estudos sorológicos para pesquisa de anticorpos de arbovírus em população da região do Vale do Ribeira.III - Inquérito em cohabitantes com casos de encefalite por Flavivírus Rocio. Revista de Saúde Pública, v. 59, p. 37-41, 1982.

JACKSON, A. C. Rabies. Neurologic Clinics, v. 26, 717-726, 2008.

JORDAN, I.; LIPKIN, W.I. Borna disease virus. Reviews in Medical Virology, v. 11, p. 37-57, 2001.

KINNEY, R. M.; JOHNSON, B. J. B.; WELCH, J. B.; TSUCHIYA, K. R.; TRENT, D. $W$. The full-length nucleotide sequences of the virulent TRD strain of Venezuelan equine encephalitis virus and its attenuated vaccine derivative, strain TC-83.

Virology, v. 170, p. 19-30, 1989.

KOPROWSKI, H.; The mouse inoculation test. In: MESLIN, F.-X., KAPLAN, M. M.; KOPROWSKI, H. (Ed.). Laboratory techniques in rabies. 4 ed.Geneva: World Health Organization, 1996. p. 80-87.

KOTAIT, I.; BRANDÃO, P. E.; CARRIERI, M. L. Vigilância epidemiológica das encefalites eqüinas. Boletim Epidemiológico Paulista, ano. 3, n. 29, p. 14-18, 2006. Disponível em: <http://www.cve.saude.sp.gov.br/agencia/bepa29_encefa.htm> Acesso em: 15 jul. 2011.

KOTAIT, I.; PEIXOTO, Z. M.; COIMBRA, T. L. M.; CUNHA, E. M. S.; QUEIROZ, L. H.; MACRUZ, R.; NAGAMORI, A. H. Isolamento e identificação do vírus da encefalomielite eqüina, tipo leste, em equinos do Estado de São Paulo, Brasil. Arquivos do Instituto Biológico, v. 59, p. 37-41, 1992. 
KUZMIN, I. V.; MAYER, A. E.; NIEZGODA, M.; MARKOTTER, W.; AGWANDA, B.; BREIMAN, R. F.; RUPPRECHT, C. Shimoni bat virus, a new representative of the Lyssavirus genus. Virus Research, v. 149, p. 197-210, 2010.

MAHONY, J. B.; BLACKHOUSE, G.; BABWAH, J.; SMIEJA, M.; BURACOND, S.; CHONG, S.; CICCOTELI, W.; O'SHEA, T.; ALNAKHLI, D.; GRIFFITHS-TURNER, M.; GOEREE, R. Cost analysis of multiplex PCR testing for diagnosing respiratory virus infections. Journal of Clinical Microbiology, v. 47, n. 9, p. 2812-2817, 2009.

MANTHEY, J. A. mFold, delta $\mathrm{G}$, and melting temperature: what does it mean? Integrated DNA Technologies. 2005. Disponível em:

$<$ http://cdn.idtdna.com/Support/Technical/TechnicalBulletinPDF/mFold_Delta_G_and _melting_temperature_explained.pdf> Acesso em: 10 maio 2010.

MARKOULATOS, P.; GEORGOPOULOU, A.; KOTSOVASSILIS, C.; KARABOGIAKARAPHILLIDES, P.; SPYROU, N. Detection and Typing of HSV-1, HSV-2, and VZV by a Multiplex Polymerase Chain Reaction. Journal of Clinical Laboratory Analysis, v. 14, p. 214-219, 2000.

MEYER, K. F.; HARING, C. M.; HOWITT,B. The etiology of epizootic encephalomyelitis of horses in San Joachin Valley, 1930. Science, v. 74, 227-228, 1931.

MESLIN, F.-X.; KAPLAN, M. M. An overview of laboratory techniques in the diagnosis and prevention of rabies and in rabies research. In: MESLIN, F.-X.; KAPLAN, M. M.; KOPROWISK, H. (Ed.). Laboratory techniques in rabies. 4. ed. Geneva: World Health Organization, 1996. p. 9-27.

NADIN-DAVIS, S. A. Molecular epidemiology. In: JACKSON, A. C.; WUNNER, W. H. Rabies. 2. ed. London:Elsevier, 2007.

NADIN-DAVIS, S. A.; FEHLNER-GARDINER, C. Lyssaviruses:current trends. Advances in Virus Research, v.71, p. 207-250, 2008.

NADIN-DAVIS, S. A.; HUANG, W.; WANDELER, A. I. The design of strain-specific polymerase chain reactions for discrimination of the racoon rabies virus strain from indigenous rabies viruses of Ontario. Journal of Vorological Methods, v. 57, p. 114, 1996. 
NIETFELD, J. C.; RAKICH, P. M.; TYLER, D. E.; BAUER, R. W. Rabies-like inclusions in dogs. Journal of Veterinary Diagnostic Investigations, v.1, p. 333338, 1989.

NILSSON, M. R.; SUGAY, W. Ocorrência de encefalomielite eqüina em Itaporanga, Estado de São Paulo. Arquivos do Instituto Biológico, v. 29, p. 63-68, 1962.

OIE. ORGANIZACIÓN MUNDIAL DE SANIDAD ANIMAL. Equine Encephalomyelitis (Eastern and Western). In: OIE. Manual of Standards: diagnostic tests and vaccines. 2004. Disponível em:

<http://www.oie.int/fr/normes/mmanual/A_00081.htm> Acesso em: 5 dez. 2010

OLIVEIRA, R. N.; IAMAMOTO, K.; SILVA, M. L. C. R.; ACHKAR, S. M.; MACEDO, C. I.; CASTILHO, J. G.; DURYMANOVA, E.; LOBO, R. S. V.; BRANDÃO, P. E.;

CARRIERI, M. L.; KOTAIT, I. East equine ecephalitis diagnosis in horse's central nervous system samples between 2006 and 2009, in Brazil. Journal of the Brazilian Sociedty for Virology, v. 14, p. 181-182, 2009. Supplement 1. Trabalho apresentado no XX National Meeting of Virology, 2009, Brasília, D. F.

ORCIARI, L. A.; NIEZGODA, M.; HANLON, C. A.; SHADDOCK, J. H.; SANDERLIN, J. H. YAGER, P. A. RUPPRECHT, C. E. Rapid clearence of SAG-2 rabies virus from dogs after oral vaccination. Vaccine, v. 19, n. 31, p. 4511-4518, 2001.

PAUVOLID-CORRÊA, A.; TAVARES, F. N.; COSTA, ELIANE, V.; BURLANDY, F. M.; MURTA, M.; PELLEGRIN, A. O.; NOGUEIRA, M. F.; SILVA, E. E. Serologic evidence of the recent circulation of Saint Louis encephalitis virus and high prevalence of equine encephalitis viruses in horces in the Nhecolândia sub-region in South Pantanal, Central-West Brazil. Memórias do Instituto Oswaldo Cruz, v. 105, n. 6, p. 829-833, 2010.

PEIXOTO, Z. M. P.; CUNHA, E. M. S; SACRAMENTO, D. R. V.; SOUZA, C. A. M.; SILVA, L. H. Q.; GERMANO, P. L.; KROEFF, S. S.; KOTAIT, I. Rabies laboratory diagnosis: peculiar features of samples from equine origin. Brazilian Journal of Microbiology, v. 31, p. 72-75, 2000.

PFEFFER, M.; PROEBSTER, B.; KINNEY, R. M.; KAADEN, O. R. Genus-specific detection of alphaviruses by semi-nested reverse transcription-polymerase chain reaction. American Journal of Tropical Medicine and Hygiene , v. 57, p. 709-718, 1997. 
READ, S. J.; JEFFERY, K. J. M.; BANGHAM, C. R. M. Aseptic meningitis and encephalitis: the role of PCR in the diagnostic laboratory. Journal of Clinical Microbiology, v. 35, p. 691-696, 1997.

READ, S. J.; KURTZ, J. B. Laboratory diagnosis of commom viral infections of the central nervous system by using a single multiplex PCR screening assay. Journal of Clinical Microbiology, v. 37, p. 1352-1355, 1999.

REISEN, W. K.; MONATH, T. P. Western equine encephalomyelitis. In: MONATH, T.P. (Ed.). The arboviruses: epidemiology and ecology. Boca Raton: CRC Press, 1989. v. 5, p. 89-137.

ROMANO-LIEBER, N. S.; IVERSSON, L. B. Inquérito soroepidemiológico para pesquisa de infecções por arbovírus em moradores de reserva ecológica. Revista de Saúde Pública, v. 34, n. 3, p. 236-242, 2000.

RUPPRECHT, C. E.; HANLON, C. A.; HEMACHUDHA, T. Rabies re-examined. The Lancet, v. 2, p. 327-343, 2002.

SANCHÉZ-SECO, M. P.; ROSARIO, D.; QUIROZ, E.; GUZMÁN, G.; TENORIO, A. A generic nested-RT-PCR followed by sequencing for detection and identification of members of alphavirus genus. Journal of Virological Methods, v. 95, p. 153-161, 2001.

SAMBROOK, J.; RUSSEL, D. W. Molecular cloning: a laboratory manual. 3. ed. New York: Cold Spring Harbor Laboratory Press, 2001. v. 2, 1473 p.

SATO, G.; ITOU, T.; SHOJI, Y.; MIURA, Y.; MIKAMI, T.; ITO. M.; KURANE, I.; SAMARA, S. I.; CARVALHO, A. A. B.; NOCITI, D. P.; ITO, F. H.; SAKAI, T. Genetic and phylogenetic analysis of glycoprotein of rabies virus isolated from several species in Brazil. The Journal of Veterinary Medical Science, v. 66, n. 07, p. 747753, 2004.

SATO, G.; TANABE, H.; SHOJI, Y.; ITOU, T.; ITO, F. H.; SATO, T.; SAKAI, T. Rapid discrimination of rabies viruses isolated from various host species in Brazil by multiplex reverse transcription polymerase chain reaction. Journal of Clinical Virology, v. 33, p. 267-273, 2005.

SCHENELL, M. J.; MC GETTIGAN, J. P.; WIRBLICH, C.; PAPANERI, A. The cell biology of rabies virus:using stealth to reach the brain. Nature, v. 8, p. 51-61, 2010. 
SCOTT, T. W.; WEAVER, S. C. Eastern equine encephalomyelitis virus: epidemiology and evolution of mosquito transmission. Advances in Virus Research, v. 37, p. 277-328, 1989.

SILVA, M. L. C. R.; GALIZA, G. J. N.; DANTAS, A. F. M.; OLIVEIRA, R. N.; IAMAMOTO, K.; ACHKAR, S. M.; RIET-CORREA, F. Outbreaks of Eastern equine encephalitis in northeastern Brazil. Journal of Veterinary Diagnostic Investigaion, v. 23, n. 3, p. 570-575, 2011.

TAYLOR, L. H.; LATHAM, S. M.; WOOLHOUSE, M. E. J. Risk factors for human disease emergence. Philosophical Transactions of the Royal Society B:

Biological Sciences, v. 356, n.1411, p. 983-989, 2001.

TENORIO, A.; ECHEVARRIA, J. E.; CASAS, I.; ECHEVARRIA, J. M.; TABARES, E. Detection and typing of human herpesviruses by multiplex polymerase chain reaction. Jounal of Virological Methods, v. 44, p. 261-269, 1993.

TORDO, N.; POCH, O.; ERMINE, A.; KEITH. G.; ROUGEON, F. Walking along the rabies genome: is the large $G-L$ intergenic region a remnant gene? Proceedings of the National Academy of Sciences of the United States of America, v. 83, p. 3914-3918, 1986.

VASCONCELOS, P. F. C.; ROSA, A. P. A. T.; PINHEIRO, F. P.; SHOPE, R. E.; ROSA, J. F. S. T.; RODRIGUES, S. G.; DÉGALLIER, N.; ROSA, E. S. T. Arboviruses pathogenic for man in Brazil. In: ROSA, A. P. T.; VASCONCELOS, P. F. C.; ROSA, J. F. S. T. (Ed.) An overview of arbovirology in Brazil and neighbouring countries, Instituto Evandro Chagas, 1998. p. 72-99.

VODKIN, M. H.; McLAUGHLIN, G. L.; DAY, J. F.; SHOPE, R. E.; NOVAK, R. J. A rapid diagnostic assay for eastern equine encephalomyelitis viral RNA. American Journal of Tropical Medicine and Hygiene, v. 49, n. 6, p. 772-776.

WATERS, J. R. An epidemic of western encephalomyelitis in humans - Manitoba, 1975. Canadian Journal of Public Health, v. 67, p. 28-32, 1976. Supplement 1.

WEAVER, S. C.; POWERS, A. M.; BRAULT, A. C.; BARRETT, A. D. Molecular epidemiological studies of veterinary arboviral encephalitides. The Veterinary Journal, v. 157, 123-138, 1999.

WEBSTER, L. T.; DAWSON; J. R. Early diagnosis of rabies by mouse inoculation test. Measurement of humoral immunity to rabies by mouse protection test. 
Proceedings of the Society for Experimental Biology and Medicine, v. 32, p.570573, 1935.

WEBSTER, W. A.; CASEY, G. A. Virus isolation in neuroblastoma cell culture. In: MESLIN, F.-X.; KAPLAN, M. M.; KOPROWSKI, H. (Ed.). Laboratory techniques in rabies. 4. ed.Geneva: World Health Organization, 1996. p. 96-104.

WHO. WORLD HEALTH ORGANIZATION. Expert Consultation on Rabies: first report. Geneva: World Health Organization Press, 2005. p. 121. Disponível em: <http://www.who.int/rabies/trs931_\%2006_05.pdf> Acesso em: 20 out. 2010

WHO. WORLD HEALTH ORGANIZATION. The control of neglected zoonotic diseases : a route to poverty alleviation. Geneva: World Health Organization Press, 2006. p. 54. Disponível em: < http://www.who.int/zoonoses/Report_Sept06.pdf>Acesso em: 01 nov. 2010

WHO. WORLD HEALTH ORGANIZATION. First WHO report on neglected tropical diseases 2010: working to overcome the global impact of neglected tropical diseases. Geneva: World Health Organization Press, 2010. p. 186. Disponível em: $<$ http://www.who.int/neglected_diseases/2010report/NTD_2010report_web.pdf> Acesso em: 24 out. 2010.

WILD, T. F. Henipaviruses: a new family of emerging Paramyxoviruses. Pathologie Biologie, v. 57, p. 188-196, 2009.

WILKINSON, L. History. In: JAKCSON, A. C.; WUNNER, W. H. Rabies, 2002. San Diego: Academic Press, 2002. p. 1-22.

WUNNER, W. H. Rabies virus. In: JACKSON, A. C.; WUNNER, W. H. Rabies. 2. ed. Amsterdam: Elsevier Academic Press, 2007. p. 23-68. 


\section{ANEXO A - PROTOCOLO PARA EXTRAÇÃO DE RNA}

Insumos: TRIzol ${ }^{\circledR}\left(\right.$ Invitrogen $\left.^{\circledR}\right)$, clorofórmio $\left(\right.$ Merck $\left.^{\circledR}\right)$, isopropanol $\left(\right.$ Merck $\left.^{\circledR}\right)$, etanol $75 \%\left(\right.$ Merck $\left.^{\circledR}\right)$, água ultrapura livre de DNAse/RNAse (Invitrogen ${ }^{\circledR}$ ).

1. Utilizar $300 \mu \mathrm{L}$ de suspensão a $20 \%$ (peso/volume) ou $0,5 \mathrm{~g}$ de tecido cortado em pequenos fragmentos com bisturi estéril e descartável.

2. Colocar a amostra em tubos de $1,5 \mathrm{~mL}$, acrescentando $1 \mathrm{~mL}$ de TRIzol ${ }^{\circledR}$.

3. Agitar vigorasamente por aproximadamente 20 segundos e deixar à temperatura ambiente por 05 minutos.

4. Acrescentar $200 \mu \mathrm{L}$ de clorofórmio.

5. Agitar vigorasamente.

6. Centrifugar por 15 minutos a $12000 \mathrm{~g}$ na temperatura de $4^{\circ} \mathrm{C}$.

7. Após esta centrifugação passar a fase aquosa para outro tubo de $1,5 \mathrm{~mL}$.

8. Para realizar a precipitação do RNA, acrescentar isopropanol no mesmo volume da fase aquosa coletada anteriormente.

9. Agitar vigorasamente e deixar a temperatura ambiente por 10 minutos.

10. Centrifugar por 10 minutos a $12000 \mathrm{~g}$ na temperatura de $4^{\circ} \mathrm{C}$.

11. Após a centrifugação, verter o tubo para descartar o sobrenadante.

12. Após a remoção do sobrenadante, acrescentar $1 \mathrm{~mL}$ de etanol a $75 \%$.

13. Agitar e centrifugar por 5 minutos a $12000 \mathrm{~g}$ na temperatua de $4^{\circ} \mathrm{C}$.

14. Após a centrifugação, verter o tubo para descartar o etanol e secar 0 conteúdo em temperatura ambiente por aproximadamente 1 hora.

15. Após a secagem, ressuspender o RNA final em $25 \mu \mathrm{L}$ de água ultrapura livre de DNAse/RNAse (Invitrogen ${ }^{\circledR}$ ) e deixar em banho seco por 10 minutos à $56^{\circ} \mathrm{C}$.

16. Centrifugar rapidamente (spin) e guardar os tubos em freezer à temperatura de $-20^{\circ} \mathrm{C}$ ou $-80^{\circ} \mathrm{C}$ até o momento do uso. 
ANEXO B - CÓPIA DO ORÇAMENTO DAS ENZIMAS SUPERSCRIPT ${ }^{\circledR} \|$ E TAQ DNA POLIMERASE

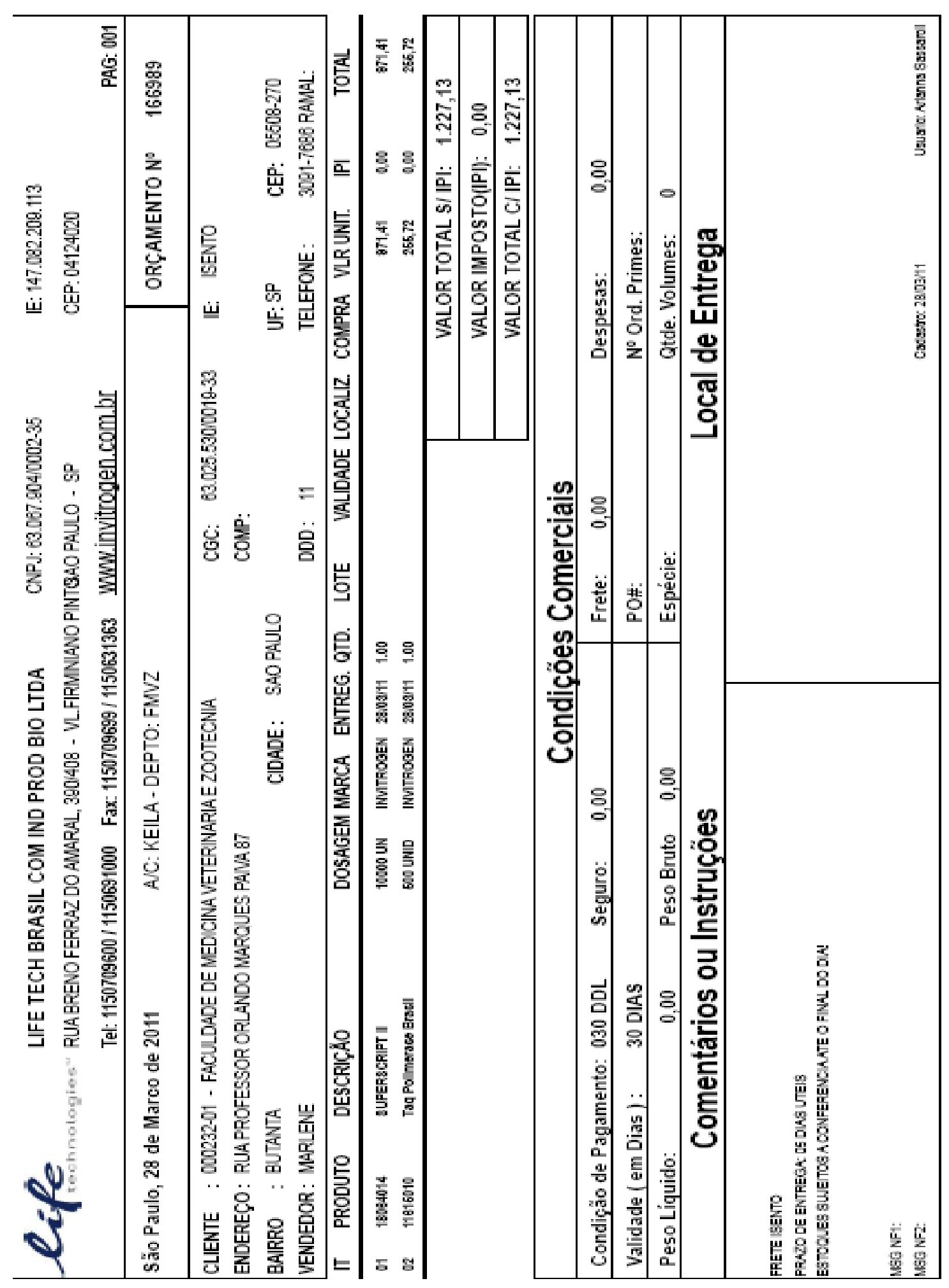




\section{APÊNDICE A - PRIMERS TESTADOS PREVIAMENTE}

Nos quadros 10 e 11, estão descritos os primers previamente testados na reação de hemi-nested RT-PCR para detecção de RABV e EEEV, respectivamente.

\begin{tabular}{|c|c|c|c|c|c|}
\hline Primer & Sentido & Sequência (5'-3') & Região* & Gene & Referências \\
\hline $21 G$ & senso & ATGTAACACCTCTACAATG & $55-73$ & $\mathrm{~N}$ & $\begin{array}{l}\text { Carnieli et al. (2008), } \\
\text { Castilho et al. (2010), } \\
\text { Brito et al. (2011) }\end{array}$ \\
\hline 304 & antissenso & TTGACGAAGATCTTGCTCAT & $1514-1533$ & $\mathrm{~N}$ & Orciari et al. (2001) \\
\hline 504 & senso & $\begin{array}{c}\text { TATACTCGAATCATGATGAATGGAGGTC } \\
\text { GACT }\end{array}$ & $1286-1317$ & $\mathrm{~N}$ & Orciari et al. (2001) \\
\hline $\begin{array}{c}\mathrm{GA} \\
3222-40\end{array}$ & senso & CGCTGCATTTTRTCARAGT & $3221-3229$ & G & Sato et al. (2004) \\
\hline $\begin{array}{c}\text { GB } \\
4119-39\end{array}$ & antissenso & GGAGGGCACCATTTGGTMTC & $4116-4135$ & $G$ & Sato et al. (2004) \\
\hline $\begin{array}{c}\text { GS } \\
3994\end{array}$ & senso & CGGMTTTGTGGATGAAAGRGGC & $3995-4016$ & $G$ & Sato et al. (2004) \\
\hline
\end{tabular}

* De acordo com o genoma do vírus PV (TORDO et al., 1986).

Códigos de sequências: $M=A / C ; R=A / G$ (CORNISH-BOWDEN, 1985).

Quadro 10 - Primers previamente testados para detecção do RABV, segundo sentido, sequência, região de anelamento, gene e referências

\begin{tabular}{|c|c|c|c|c|c|}
\hline Primer & Sentido & Sequência (5' $\left.{ }^{\prime} \mathbf{3}^{\prime}\right)$ & Região* $^{*}$ & Gene & Referências \\
\hline cM3W & antissenso & ACATRAANKGNGTNGTRTCRAANCCDAYCC & $568-597$ & NSP1 & Pfeffer et al. (1997) \\
\hline M2W & senso & YAGAGCDTTTCGCAYSTRGCHW & $164-186$ & NSP1 & Pfeffer et al. (1997) \\
\hline M2W2 & antissenso & TGYCCNVTGMDNWSYVCNGARGAYCC & $288-313$ & NSP1 & Pfeffer et al. (1997) \\
\hline nEEEV & senso & CCACGGTACCGTTGCC & $474-489$ & NSP1 & $\begin{array}{c}\text { Bronzoni et al. } \\
(2004)\end{array}$ \\
\hline nWEEV & senso & GGCGGCAGACCTGCTGGAA & $390-409$ & NSP1 & $\begin{array}{c}\text { Bronzoni et al. } \\
(2004)\end{array}$ \\
\hline
\end{tabular}

${ }^{*}$ De acordo com o genoma do vírus da encefalite equina Venezuelana (KINNEY et al., 1989).

Códigos de sequências: $R=A / G ; Y=C / T ; K=G / T ; S=C / G ; W=A / T ; M=A / C ; H=A / C / T ; D=$ $\mathrm{A} / \mathrm{G} / \mathrm{T} ; \mathrm{V}=\mathrm{A} / \mathrm{C} / \mathrm{G} ; \mathrm{N}=\mathrm{A} / \mathrm{C} / \mathrm{T} / \mathrm{G}$ (CORNISH-BOWDEN, 1985).

Quadro 11 - Primers previamente testados para detecção do EEEV, segundo sentido, sequência, região de anelamento, gene e referências 


\section{APÊNDICE B - CÁLCULO DO CUSTO DE UMA REAÇÃO DE HEMI-NESTED RT- PCR E DE UMA REAÇÃO DE MULTIPLEX HEMI-NESTED RT-PCR}

\begin{tabular}{|c|c|c|c|c|c|c|}
\hline Etapa & Reagente & Apresentação & $\begin{array}{c}\text { Diluição } \\
(\mu \mathrm{L})\end{array}$ & $\begin{array}{c}\text { Valor do } \\
\text { reagente ( } R \$)\end{array}$ & $\begin{array}{c}\text { Volume }(\mu \mathrm{L}) \text { ou } \\
\text { Unidade }(\mathrm{U}) / \text { reação }\end{array}$ & \begin{tabular}{|c} 
Valor por reação de Hemi- \\
Nested RT-PCR (R\$) \\
\end{tabular} \\
\hline RT & \begin{tabular}{|l} 
Superscript $^{\circledR}$ II \\
dNTP set \\
Primer $21 \mathrm{G}$ \\
Água Ultrapure \\
\end{tabular} & $\begin{array}{l}10000 \mathrm{U} \\
100 \mathrm{mM} / 250 \mu \mathrm{L} \\
100 \mathrm{mM} / 350 \mu \mathrm{L} \\
500 \mathrm{~mL}\end{array}$ & $\begin{array}{c}\text { NA } \\
2.500 \\
3500 \\
500.000\end{array}$ & $\begin{array}{c}871,41 \\
760,00 \\
39,90 \\
114,70 \\
\end{array}$ & $\begin{array}{c}200 \\
2 \\
2 \\
2 \\
\end{array}$ & $\begin{array}{l}17,43 \\
0,61 \\
0,02 \\
0,00\end{array}$ \\
\hline $\begin{array}{c}\text { Primeira } \\
\text { Amplificação }\end{array}$ & $\begin{array}{l}\text { Taq Polimerase Brasil } \\
\text { dNTP set } \\
\text { Primer } 21 \mathrm{G} \\
\text { Primer } 304 \\
\text { Água destilada }\end{array}$ & $\begin{array}{l}500 \mathrm{U} \\
100 \mathrm{mM} / 250 \mu \mathrm{L} \\
100 \mu \mathrm{M} / 352 \mu \mathrm{L} \\
100 \mu \mathrm{M} / 444 \mu \mathrm{L} \\
500 \mathrm{~mL}\end{array}$ & $\begin{array}{c}\text { NA } \\
20.000 \\
3520 \\
4440 \\
500.000\end{array}$ & $\begin{array}{c}255,72 \\
760,00 \\
39,90 \\
42,00 \\
114,70\end{array}$ & $\begin{array}{c}2,5 \\
8 \\
2,5 \\
2,5 \\
24,5\end{array}$ & $\begin{array}{l}1,28 \\
0,30 \\
0,03 \\
0,02 \\
0,01\end{array}$ \\
\hline $\begin{array}{c}\text { Segunda } \\
\text { Amplificação }\end{array}$ & $\begin{array}{l}\text { Taq Polimerase Brasil } \\
\text { dNTP set } \\
\text { Primer } 304 \\
\text { Primer } 504 \\
\text { Água destilada }\end{array}$ & $\begin{array}{l}500 \mathrm{U} \\
100 \mathrm{mM} / 250 \mu \mathrm{L} \\
100 \mu \mathrm{M} / 444 \mu \mathrm{L} \\
100 \mu \mathrm{M} / 334 \mu \mathrm{L} \\
500 \mathrm{~mL}\end{array}$ & $\begin{array}{c}\text { NA } \\
20.000 \\
4440 \\
3340 \\
500.000\end{array}$ & $\begin{array}{c}255,72 \\
760,00 \\
42,00 \\
67,20 \\
114,70\end{array}$ & $\begin{array}{c}5,0 \\
16,0 \\
5,0 \\
5,0 \\
49,0\end{array}$ & $\begin{array}{l}2.56 \\
0,61 \\
0,05 \\
0,10 \\
0,01\end{array}$ \\
\hline Total (R\$) & & & & & & 20,47 \\
\hline
\end{tabular}

Quadro 12 - Cálculo do custo de uma reação de hemi-nested RT-PCR, com base nos reagentes utilizados

\begin{tabular}{|c|c|c|c|c|c|c|}
\hline Etapa & Reagente & Apresentação & $\begin{array}{l}\text { Diluição } \\
(\mu \mathrm{L})\end{array}$ & $\begin{array}{c}\text { Valor do } \\
\text { reagente }(R \$)\end{array}$ & $\begin{array}{c}\text { Volume }(\mu L) \text { ou } \\
\text { Unidade(U)/reação }\end{array}$ & $\begin{array}{c}\text { Valor por reação de } \\
\text { Multiplex Hemi-Nested } \mathrm{RT} \\
\text { PCR }(\mathrm{R} \$)\end{array}$ \\
\hline RT & $\begin{array}{l}\text { Superscript }^{\circledR} \text { II } \\
\text { dNTP set } \\
\text { Primer } 21 \mathrm{G} \\
\text { Primer cM3W }\end{array}$ & $\begin{array}{l}10000 \mathrm{U} \\
100 \mathrm{mM} / 250 \mu \mathrm{L} \\
100 \mathrm{mM} / 350 \mu \mathrm{L} \\
100 \mathrm{mM} / 352 \mu \mathrm{L}\end{array}$ & $\begin{array}{c}N A \\
2.500 \\
3500 \\
3520\end{array}$ & $\begin{array}{c}871,41 \\
793,73 \\
39,90 \\
63,00\end{array}$ & $\begin{array}{r}200 \\
2,0 \\
2,0 \\
2,0\end{array}$ & $\begin{array}{l}17,43 \\
0,63 \\
0,02 \\
0,04\end{array}$ \\
\hline $\begin{array}{c}\text { Primeira } \\
\text { Amplificação }\end{array}$ & $\begin{array}{l}\text { Taq Polimerase Brasil } \\
\text { dNTP set } \\
\text { Primer } 21 \mathrm{G} \\
\text { Primer } 304 \\
\text { Primer cM3W } \\
\text { Primer M2W } \\
\text { Água destilada }\end{array}$ & $\begin{array}{l}500 \mathrm{U} \\
100 \mathrm{mM} / 250 \mu \mathrm{L} \\
100 \mu \mathrm{M} / 352 \mu \mathrm{L} \\
100 \mu \mathrm{M} / 444 \mu \mathrm{L} \\
100 \mathrm{mM} / 352 \mu \mathrm{L} \\
100 \mathrm{mM} / 446 \mu \mathrm{L} \\
500 \mathrm{~mL}\end{array}$ & $\begin{array}{c}\text { NA } \\
20.000 \\
3520 \\
4440 \\
3520 \\
4460 \\
500.000\end{array}$ & $\begin{array}{c}255,72 \\
793,73 \\
39,90 \\
42,00 \\
63,00 \\
48,30 \\
114,70 \\
\end{array}$ & $\begin{array}{l}2,5 \\
8,0 \\
1,5 \\
1,5 \\
3,5 \\
3,5 \\
24,5\end{array}$ & $\begin{array}{l}1,28 \\
0,32 \\
0,02 \\
0,01 \\
0,06 \\
0,04 \\
0,01\end{array}$ \\
\hline $\begin{array}{c}\text { Segunda } \\
\text { Amplificação }\end{array}$ & $\begin{array}{l}\text { Taq Polimerase Brasil } \\
\text { dNTP set } \\
\text { Primer } 304 \\
\text { Primer } 504 \\
\text { Primer cM3W } \\
\text { Primer nEEE } \\
\text { Primer nWEE } \\
\text { Água destilada }\end{array}$ & $\begin{array}{l}500 \mathrm{U} \\
100 \mathrm{mM} / 250 \mu \mathrm{L} \\
100 \mu \mathrm{M} / 444 \mu \mathrm{L} \\
100 \mu \mathrm{M} / 334 \mu \mathrm{L} \\
100 \mu \mathrm{M} / 352 \mu \mathrm{L} \\
100 \mu \mathrm{M} / 350 \mu \mathrm{L} \\
100 \mu \mathrm{M} / 358 \mu \mathrm{L} \\
500 \mathrm{~mL}\end{array}$ & $\begin{array}{c}\text { NA } \\
20.000 \\
4440 \\
3340 \\
3520 \\
3500 \\
3580 \\
500.000\end{array}$ & $\begin{array}{c}255,72 \\
760,00 \\
42,00 \\
67,20 \\
63,00 \\
33,60 \\
39,90 \\
114,70\end{array}$ & $\begin{array}{c}5,0 \\
16,0 \\
3,0 \\
3,0 \\
7,0 \\
7,0 \\
5,0 \\
49,0\end{array}$ & $\begin{array}{l}2.56 \\
0,61 \\
0,03 \\
0,06 \\
0,13 \\
0,07 \\
0,06 \\
0,01\end{array}$ \\
\hline Total (R\$) & & & & & & 20,81 \\
\hline
\end{tabular}

Quadro 13 - Cálculo do custo de uma reação de multiplex hemi-nested RT-PCR, com base nos reagentes utilizados 